\title{
Nutritional targets to enhance pulmonary rehabilitation efficacy in COPD
}

Citation for published version (APA):

van de Bool, C. (2017). Nutritional targets to enhance pulmonary rehabilitation efficacy in COPD. [Doctoral Thesis, Maastricht University]. Datawyse / Universitaire Pers Maastricht.

https://doi.org/10.26481/dis.20170517cvdb

Document status and date:

Published: 01/01/2017

DOI:

10.26481/dis.20170517cvdb

Document Version:

Publisher's PDF, also known as Version of record

Document license:

Unspecified

\section{Please check the document version of this publication:}

- A submitted manuscript is the version of the article upon submission and before peer-review. There can be important differences between the submitted version and the official published version of record.

People interested in the research are advised to contact the author for the final version of the publication, or visit the DOI to the publisher's website.

- The final author version and the galley proof are versions of the publication after peer review.

- The final published version features the final layout of the paper including the volume, issue and page numbers.

Link to publication

\footnotetext{
General rights rights.

- You may freely distribute the URL identifying the publication in the public portal. please follow below link for the End User Agreement:

www.umlib.nl/taverne-license

Take down policy

If you believe that this document breaches copyright please contact us at:

repository@maastrichtuniversity.nl

providing details and we will investigate your claim.
}

Copyright and moral rights for the publications made accessible in the public portal are retained by the authors and/or other copyright owners and it is a condition of accessing publications that users recognise and abide by the legal requirements associated with these

- Users may download and print one copy of any publication from the public portal for the purpose of private study or research.

- You may not further distribute the material or use it for any profit-making activity or commercial gain

If the publication is distributed under the terms of Article $25 \mathrm{fa}$ of the Dutch Copyright Act, indicated by the "Taverne" license above, 
Nutritional targets to enhance pulmonary rehabilitation efficacy in COPD

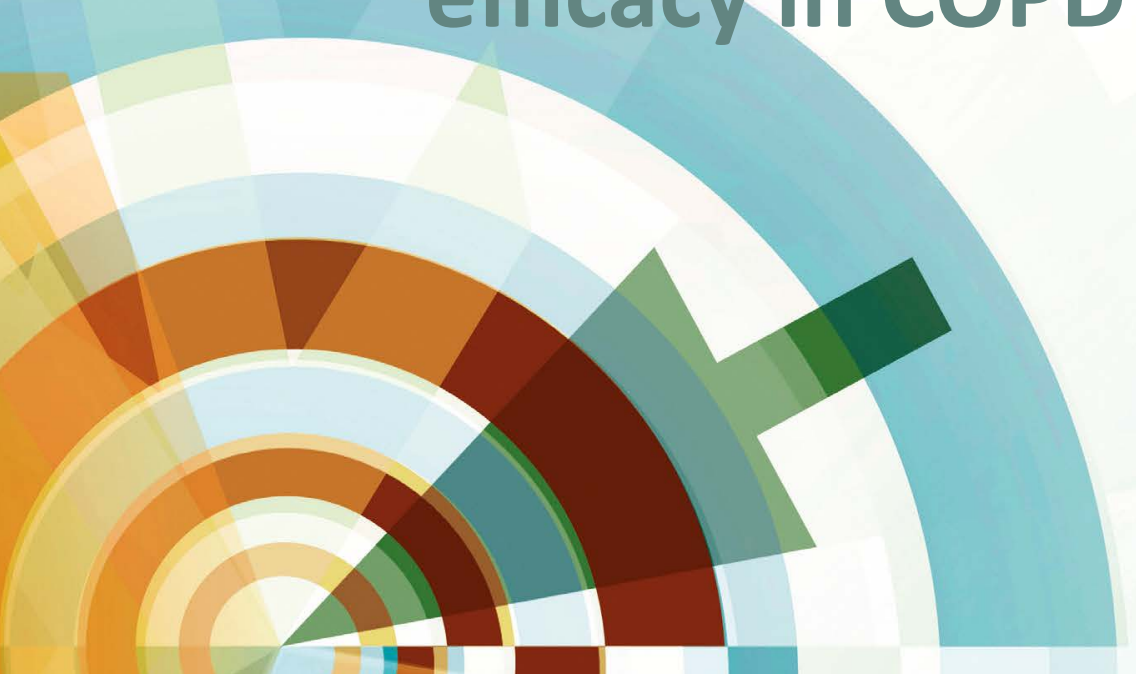




\section{Q}

Copyright Coby van de Bool, Maastricht, 2017

Cover design | Marie-José Verstappen

Print Datawyse | Universitaire Pers Maastricht

ISBN 9789461596963

The research described in this thesis was performed at the Department of Respiratory Medicine, NUTRIM School of Nutrition and Translational Research in Metabolism, Maastricht University Medical Center+, Maastricht, the Netherlands; and at CIRO+ Horn, the Netherlands.

The research was financially supported by the Lung Foundation Netherlands (grant 3.4.09.003) and by Nutricia Research. 


\title{
Nutritional targets to enhance pulmonary rehabilitation efficacy in COPD
}

\author{
PROEFSCHRIFT \\ ter verkrijging van de graad van doctor \\ aan de Universiteit Maastricht, \\ op gezag van de Rector Magnificus, Prof. dr. Rianne M. Letschert, \\ volgens het besluit van het College van Decanen, \\ in het openbaar te verdedigen \\ op woensdag 17 mei 2017, om 10.00 uur \\ door
}

Coby van de Bool 


\section{Promotores}

Prof. dr. ir. A.M.W.J. Schols

Prof. dr E.F.M. Wouters

\section{Beoordelingscommissie}

Prof. dr. ir. R.P. Mensink (voorzitter)

Prof. dr. A. Bast

Prof. dr. ir. C.P.G.M. de Groot (Wageningen University \& Research)

Prof. dr. Y.F. Heijdra (Radboud University)

Prof. dr. J.P. Kooman 


\section{Table of contents}

Chapter 1 General introduction

Chapter 2 Antagonistic implications of sarcopenia and abdominal obesity on physical performance in COPD

Chapter 3 Muscle quality is more impaired in sarcopenic patients with COPD

Chapter 4 Quality of dietary intake in relation to body composition in patients with chronic obstructive pulmonary disease eligible for pulmonary rehabilitation

Chapter 5 Nutritional targets to enhance exercise performance in COPD

Chapter 6 A randomised clinical trial investigating the efficacy of targeted nutrition as adjunct to exercise training in COPD

Chapter 7 General discussion

Samenvatting 125

Valorisation

Dankwoord 133

Curriculum vitae

List of publications 

Chapter

1

General introduction 



\section{CHRONIC OBSTRUCTIVE PULMONARY DISEASE}

Chronic obstructive pulmonary disease (COPD) is defined as a common, preventable and treatable disease, characterized by persistent airflow limitation that is usually progressive and associated with an enhanced chronic inflammatory response in the airways and the lung to noxious particles or gases (1). The primary cause for development of COPD is cigarette smoking but other identified risk factors include genetics and occupational exposure to dusts and chemical agents (2). Worldwide COPD is a leading cause of morbidity and mortality, resulting in a substantial and increasing economic and social burden (3). The airflow limitation is caused by small airways disease (chronic bronchitis) and/or alveolar destruction (emphysema) and is commonly used as measure of COPD severity. However, the degree of airflow limitation poorly correlates with actual disease burden (1).

\section{SYSTEMIC MANIFESTATIONS AND COMORBIDITIES IN COPD}

The COPD patient's health status is not only affected by pulmonary impairment, but also by extra-pulmonary manifestations and comorbidities. The most prevalent comorbidities are skeletal muscle dysfunction, osteoporosis, cardiovascular disease, metabolic syndrome, lung cancer, and psychological disorders (4), as they often contribute to symptoms (breathlessness, fatigue, reduced physical activity), exacerbations, hospital admissions and mortality. Skeletal muscle dysfunction in COPD likely results from disuse, systemic corticosteroid therapy, inflammation and oxidative stress and may have a direct impact on exercise capacity, fatigue and activity levels. Cardiovascular disease, largely due to atherosclerosis following inflammation, is the most frequent and important disease coexisting with COPD and includes heart failure, ischemic heart disease, atrial fibrillation and hypertension (5). Osteoporosis is a major, but often underdiagnosed comorbidity in COPD (6), which is characterized by a decreased bone mineral density and results in an increased bone fragility and consequently an increased fracture risk. Many comorbidities are related to specific phenotypes within COPD. Moreover, the presence of multiple chronic morbidities (multimorbidity) is common in patients with COPD and different comorbidity clusters can be identified. As such, recent unbiased statistical approaches demonstrated that muscle wasting and osteoporosis were highly prevalent in underweight patients, whereas they were almost absent in obesity (7). In contrast, atherosclerosis, dyslipidaemia, hyperglycaemia, and hypertension are more common in obese patients than in underweight patients. These identified clusters support the concept that body composition is able to discriminate between pulmonary phenotypes (8). 


\section{BODY COMPOSITION}

Body composition refers to the amount and distribution of tissue in the human body and can range from a two compartment (fat or fat-free mass) to a three compartment (fat, lean or bone mass) or four compartment model (fat, protein, mineral, or water). Research in COPD has mainly focused on the loss of body weight and fat-free mass, as these are associated with unfavourable effects on physical functioning and survival (9, 10). Furthermore, low fat-free mass is associated with a higher prevalence of low bone mineral density (osteoporosis) (11), suggesting overlapping determinants between these comorbidities.

It is now generally accepted that BMI poorly reflects body composition in COPD as a low fat-free mass can occur independently of body mass index (BMI). Indeed, BMI is unable to distinguish between lean and cachectic patients in underweight patients, and low muscle mass is often masked in normal to overweight patients (12). Traditionally, a fatfree mass index (FFMI) below sex-adjusted 10th-percentile values for healthy subjects $\left(<17 \mathrm{~kg} / \mathrm{m}^{2}\right.$ for males and $<15 \mathrm{~kg} / \mathrm{m}^{2}$ for females) was used to diagnose generalized wasting of muscle mass (cachexia) in Caucasian COPD patients (13). However, these cutoffs could lead to an underestimation of the prevalence of low muscle mass with increasing body weight when not adjusted for BMI. Also, from a functional perspective one could argue that (in particular in overweight subjects), whole body fat-free mass may not represent someone's physical functioning and advocate for appendicular fatfree mass as a more appropriate marker for muscle mass. Dual Energy X-ray Absorptiometry (DEXA) is a radiological technique able to measure total body composition. Originally DEXA has been developed for measurement of bone mass density as screening of osteoporosis and is therefore widely clinically available, but it also allows for assessment of fat mass (FM) and fat-free mass (FFM) at regional levels in addition to whole body level. Assessment of the appendicular (extremity) skeletal muscle mass of arms and legs (ASMI) traditionally originates from identification of age-related low muscle mass in elderly populations, a syndrome described as sarcopenia (14). Its application is relatively new in COPD, but might in theory be highly relevant even independent of generalized wasting commonly referred to as cachexia as the proportion of older COPD patients will increase rapidly and there are various indications that COPD is a disease of accelerated aging (15). Furthermore, appendicular skeletal muscle mass effectively determines muscle strength (16) and could be hypothesized as a stronger predictor than whole body fat free mass, as the latter also includes a large part of watercontaining organs and non-muscle tissue. Limited data on the prevalence of sarcopenia in COPD is yet available from a European population, or from patients eligible for pulmonary rehabilitation characterized by impaired physical functioning. Additionally, in current obesogenic society, low muscle mass may frequently coexist with abdominal adiposity, also in normal weight stable COPD patients. Indeed, several studies reported 
an elevated abdominal (visceral) fat mass in COPD patients, independent of their BMI (17-19). There is increasing evidence that adipose tissue significantly contributes to the systemic inflammatory load in COPD (20).

So far no data are available regarding the prevalence of and functional consequences of co-existent sarcopenia and abdominal obesity in COPD eligible for pulmonary rehabilitation. Therefore, the aim of chapter 2 was to provide a comprehensive profile of the sarcopenic phenotype with or without abdominal obesity in a representative group of Dutch COPD patients screened for PR, by: 1) exploring its prevalence across all BMI categories; 2) investigating its functional implications; and 3) determining the predictive value of ASMI over BMI and FFMI for physical functioning.

\section{STRUCTURAL AND METABOLIC ABNORMALITIES IN THE SKELETAL MUSCLE}

Next to low muscle mass, intrinsic alterations in peripheral skeletal muscles of COPD patients have been extensively described (21). It is yet well established that loss of quadriceps muscle mass is generally characterized by predominant atrophy of the fast twitch type IIx fibres (22). Furthermore COPD muscle is characterized by loss of oxidative capacity reflected by a shift from oxidative type I to glycolytic II muscle fibres and decreased capacity of oxidative enzymes. This is not only shown in advanced COPD (23), but also in patients with mild-to-moderate COPD (24). Moreover, intrinsic abnormalities in peripheral muscle seem more aggravated in emphysematous patients who are also more susceptible to weight loss (25-27).

We hypothesized that these alterations not only culminate in reduced muscle endurance, but could also drive or accelerate muscle wasting as muscles will become less energy efficient and the remaining type $\|$ fibres are more sensitive to atrophying disease-related triggers (28-30). The aim of the study in chapter 3 was therefore to explore if quadriceps muscle fibres-type characteristics are different between sarcopenic and non-sarcopenic patients with COPD.

\section{LIFESTYLE AS A TRIGGER FOR MUSCLE DYSFUNCTION}

The cause of abnormalities in body composition and structural changes within muscle in COPD are probably multifactorial, not only involving disease specific factors (e.g. hypoxia, systemic inflammation, oxidative stress and drug therapy such as corticosteroids) but also lifestyle factors. Lifestyle factors that have been studied in COPD mainly concern smoking and physical activity, but dietary behaviour and specific nutrient deficiencies may also be implicated. Dyspnoea, fatigue, anxiety and depression are common symptoms of COPD that contribute to poor appetite and altered dietary intake (31). Further- 
more, dietary intake could be unhealthy coherent with unhealthy lifestyle factors as smoking and low physical activity. These factors are associated with a low socioeconomic status, which on its turn is associated with development and progression of COPD (32).

So far, dietary intake analysis primarily focused on energy and protein balance in relation to weight loss and muscle wasting $(33,34)$. A low dietary intake not balancing elevated energy requirements can lead to weight loss in COPD (35), while overeating can contribute to the development of abdominal obesity (36). Surprisingly, limited studies have investigated micronutrient intake in relation to abnormalities in body composition in COPD. Vitamin D for instance plays a role in multiple COPD-related disease mechanisms, including muscle dysfunction and osteoporosis. Vitamin D insufficiency or deficiency occurs very frequently in COPD patients, as measured by low levels of serum or plasma levels of 25-hydroxyvitamin D $(37,38)$. Furthermore, large population-based studies demonstrated associations between a low dietary intake of anti-oxidant vitamins (vitamin $A, C, E$, ) and impaired pulmonary function (39-41). Oxidative stress has regularly been reported to be involved in muscle dysfunction in patients with severe $\operatorname{COPD}(26,42,43)$ and is also suggested to modulate signalling pathways of muscle loss and atrophy (44). Therefore, the aim of chapter 4 to investigate the quality of macroand micronutrient intake in relation to body composition profiles in COPD patients referred for pulmonary rehabilitation.

\section{MODULATION OF MUSCLE DYSFUNCTION: EXERCISE}

The past decade treatment of muscle dysfunction has been subject of intensive research to alleviate progressive disability and improve survival in patients with COPD. Exercise training is known to be effective in improving muscle function as well as exercise tolerance in patients with advanced COPD (45). Considered to be the cornerstone of pulmonary rehabilitation, the optimal training program combines resistance training for improving muscle mass and strength and endurance training for exercise endurance capacity, bearing in mind the muscle pathology in COPD. Nonetheless, exercise training is not only a stimulus for skeletal muscle, but will also increase energy requirements that may not always be compensated for by a spontaneous increase in dietary intake $(33,46)$ and consequently could induce weight loss in susceptible patients.

\section{MODULATION OF MUSCLE DYSFUNCTION: EXERCISE AND NUTRITION}

The latest Cochrane review by Ferreira et al. (47) reports moderate-quality evidence that nutritional supplementation promotes weight gain among patients with COPD, 
especially if undernourished. Current literature provides a strong rationale to broaden the scope of nutritional rehabilitation from pulmonary cachexia and end stage disease to muscle atrophy and less advanced disease, to improve vitality and compress morbidity of COPD. For instance, the INTERCOM trial compared an interdisciplinary communitybased COPD management program including individualized education, exercise training and nutritional intervention (the latter only for muscle wasted patients) vs. usual care in COPD patients with less advanced disease (43). A prescheduled post-hoc analysis of the muscle-wasted subgroup furthermore showed a prolonged positive response on FFM, respiratory and lower limb muscle function compared with usual care, while the latter showed a progressive decline in 6MWD (44). However, in the INTERCOM trial the specific contribution of nutritional intervention in muscle wasted patients could not be disentangled and the potential of nutritional strategies to enhance efficacy of exercise training is not yet well established. From this perspective, attention was not only focused on energy balance, but primarily on muscle mass and composition. The main objective of the current thesis was the randomized placebo-controlled multi-centre NUTRAIN-trial, for which we first performed a review of available literature (chapter 5).

In chapter 6 the randomized placebo-controlled multi-centre NUTRAIN-trial is described, in which we aimed to determine the efficacy of specific nutritional supplementation targeting muscle derangements as adjunct to exercise training in muscle wasted COPD patients. The nutritional supplement provided high quality protein (48), enriched with leucine, to support muscle build-up (49). It further contained a specific n-3 rich fatty acid composition to improve physical performance by targeting muscle metabolism (50). The supplement was also rich in vitamin D, to counteract highly prevalent vitamin D deficiency in COPD patients (37).

Overall the aim of the current thesis was to investigate nutritional targets to enhance pulmonary rehabilitation efficacy in COPD. The results of the thesis will be discussed and be placed in a broader context in chapter 7 . 


\section{REFERENCES}

1. Vestbo J, Hurd SS, Agusti AG, Jones PW, Vogelmeier C, Anzueto A, Barnes PJ, Fabbri LM, Martinez FJ, Nishimura M, Stockley RA, Sin DD, Rodriguez-Roisin R. Global strategy for the diagnosis, management, and prevention of chronic obstructive pulmonary disease: Gold executive summary. Am J Respir Crit Care Med 2013;187:347-365.

2. Salvi SS, Barnes PJ. Chronic obstructive pulmonary disease in non-smokers. Lancet 2009;374:733-743.

3. Mathers CD, Loncar D. Projections of global mortality and burden of disease from 2002 to 2030. PLoS medicine 2006;3:e442.

4. Patel AR, Hurst JR. Extrapulmonary comorbidities in chronic obstructive pulmonary disease: State of the art. Expert Rev Respir Med 2011;5:647-662.

5. Soriano JB, Visick GT, Muellerova H, Payvandi N, Hansell AL. Patterns of comorbidities in newly diagnosed copd and asthma in primary care. Chest 2005;128:2099-2107.

6. Madsen H, Brixen K, Hallas J. Screening, prevention and treatment of osteoporosis in patients with chronic obstructive pulmonary disease - a population-based database study. Clin Respir J 2010;4:22-29.

7. Vanfleteren LE, Spruit MA, Groenen M, Gaffron S, van Empel VP, Bruijnzeel PL, Rutten EP, Op 't Roodt J, Wouters EF, Franssen FM. Clusters of comorbidities based on validated objective measurements and systemic inflammation in patients with chronic obstructive pulmonary disease. Am J Respir Crit Care Med 2013;187:728-735.

8. Schols AM, Ferreira IM, Franssen FM, Gosker HR, Janssens W, Muscaritoli M, Pison C, Rutten-van Molken M, Slinde F, Steiner MC, Tkacova R, Singh SJ. Nutritional assessment and therapy in copd: A european respiratory society statement. Eur Respir J 2014.

9. Schols AM, Broekhuizen R, Weling-Scheepers CA, Wouters EF. Body composition and mortality in chronic obstructive pulmonary disease. Am J Clin Nutr 2005;82:53-59.

10. Schols AM, Mostert R, Soeters PB, Wouters EF. Body composition and exercise performance in patients with chronic obstructive pulmonary disease. Thorax 1991;46:695-699.

11. Bolton CE, lonescu AA, Shiels KM, Pettit RJ, Edwards PH, Stone MD, Nixon LS, Evans WD, Griffiths TL, Shale DJ. Associated loss of fat-free mass and bone mineral density in chronic obstructive pulmonary disease. Am J Respir Crit Care Med 2004;170:1286-1293.

12. Schols AM, Soeters PB, Dingemans AM, Mostert R, Frantzen PJ, Wouters EF. Prevalence and characteristics of nutritional depletion in patients with stable copd eligible for pulmonary rehabilitation. Am Rev Respir Dis 1993;147:1151-1156.

13. Vestbo J, Prescott E, Almdal T, Dahl M, Nordestgaard BG, Andersen T, Sorensen TI, Lange P. Body mass, fat-free body mass, and prognosis in patients with chronic obstructive pulmonary disease from a random population sample: Findings from the copenhagen city heart study. Am J Respir Crit Care Med 2006;173:79-83.

14. Cruz-Jentoft AJ, Baeyens JP, Bauer JM, Boirie Y, Cederholm T, Landi F, Martin FC, Michel JP, Rolland Y, Schneider SM, Topinkova E, Vandewoude M, Zamboni M. Sarcopenia: European consensus on definition and diagnosis. Age and Ageing 2010;39:412-423.

15. Houben JM, Mercken EM, Ketelslegers HB, Bast A, Wouters EF, Hageman GJ, Schols AM. Telomere shortening in chronic obstructive pulmonary disease. Respir Med 2009;103:230-236.

16. Engelen MP, Schols AM, Does JD, Wouters EF. Skeletal muscle weakness is associated with wasting of extremity fat-free mass but not with airflow obstruction in patients with chronic obstructive pulmonary disease. Am J Clin Nutr 2000;71:733-738.

17. Furutate R, Ishii T, Wakabayashi R, Motegi T, Yamada K, Gemma A, Kida K. Excessive visceral fat accumulation in advanced chronic obstructive pulmonary disease. Int J Chron Obstruct Pulmon Dis 2011;6:423430.

18. van den Borst B, Gosker HR, Koster A, Yu B, Kritchevsky SB, Liu Y, Meibohm B, Rice TB, Shlipak M, Yende S, Harris TB, Schols AM, Health A, Body Composition S. The influence of abdominal visceral fat on in- 
flammatory pathways and mortality risk in obstructive lung disease. The American journal of clinical nutrition 2012;96:516-526.

19. Vanfleteren LE, van Meerendonk AM, Franssen FM, Wouters EF, Mottaghy FM, van Kroonenburgh MJ, Bucerius J. A possible link between increased metabolic activity of fat tissue and aortic wall inflammation in subjects with copd. A retrospective 18f-fdg-pet/ct pilot study. Respiratory medicine 2014;108:883890.

20. van den Borst B, Gosker HR, Wesseling G, de Jager W, Hellwig VA, Snepvangers FJ, Schols AM. Low-grade adipose tissue inflammation in patients with mild-to-moderate chronic obstructive pulmonary disease. Am J Clin Nutr 2011;94:1504-1512.

21. Mathur S, Brooks D, Carvalho CR. Structural alterations of skeletal muscle in copd. Frontiers in physiology 2014;5:104.

22. Gosker HR, Engelen MP, van Mameren H, van Dijk PJ, van der Vusse GJ, Wouters EF, Schols AM. Muscle fiber type iix atrophy is involved in the loss of fat-free mass in chronic obstructive pulmonary disease. Am J Clin Nutr 2002;76:113-119.

23. Gosker HR, Zeegers MP, Wouters EF, Schols AM. Muscle fibre type shifting in the vastus lateralis of patients with copd is associated with disease severity: A systematic review and meta-analysis. Thorax 2007;62:944-949.

24. van den Borst B, Slot IG, Hellwig VA, Vosse BA, Kelders MC, Barreiro E, Schols AM, Gosker HR. Loss of quadriceps muscle oxidative phenotype and decreased endurance in patients with mild-to-moderate copd. J Appl Physiol (1985) 2013;114:1319-1328.

25. Gosker HR, van Mameren H, van Dijk PJ, Engelen MP, van der Vusse GJ, Wouters EF, Schols AM. Skeletal muscle fibre-type shifting and metabolic profile in patients with chronic obstructive pulmonary disease. Eur Respir J 2002;19:617-625.

26. Rabinovich RA, Bastos R, Ardite E, Llinas L, Orozco-Levi M, Gea J, Vilaro J, Barbera JA, Rodriguez-Roisin R, Fernandez-Checa JC, Roca J. Mitochondrial dysfunction in copd patients with low body mass index. Eur Respir J 2007;29:643-650.

27. Remels AH, Gosker HR, Schrauwen P, Hommelberg PP, Sliwinski P, Polkey M, Galdiz J, Wouters EF, Langen RC, Schols AM. Tnf-alpha impairs regulation of muscle oxidative phenotype: Implications for cachexia? FASEB J 2010;24:5052-5062.

28. Wang Y, Pessin JE. Mechanisms for fiber-type specificity of skeletal muscle atrophy. Curr Opin Clin Nutr Metab Care 2013;16:243-250.

29. Schakman O, Kalista S, Barbe C, Loumaye A, Thissen JP. Glucocorticoid-induced skeletal muscle atrophy. The international journal of biochemistry \& cell biology 2013;45:2163-2172.

30. de Theije CC, Langen RC, Lamers WH, Gosker HR, Schols AM, Kohler SE. Differential sensitivity of oxidative and glycolytic muscles to hypoxia-induced muscle atrophy. J Appl Physiol (1985) 2015;118:200-211.

31. Gronberg AM, Slinde F, Engstrom CP, Hulthen L, Larsson S. Dietary problems in patients with severe chronic obstructive pulmonary disease. J Hum Nutr Diet 2005;18:445-452.

32. Prescott E, Lange P, Vestbo J. Socioeconomic status, lung function and admission to hospital for copd: Results from the copenhagen city heart study. Eur Respir J 1999;13:1109-1114.

33. Goris AH, Vermeeren MA, Wouters EF, Schols AM, Westerterp KR. Energy balance in depleted ambulatory patients with chronic obstructive pulmonary disease: The effect of physical activity and oral nutritional supplementation. Br J Nutr 2003;89:725-731.

34. Schols AM, Wouters EF. Nutritional abnormalities and supplementation in chronic obstructive pulmonary disease. Clin Chest Med 2000;21:753-762.

35. Schols AM, Soeters PB, Mostert R, Saris WH, Wouters EF. Energy balance in chronic obstructive pulmonary disease. Am Rev Respir Dis 1991;143:1248-1252.

36. Bray GA, Paeratakul S, Popkin BM. Dietary fat and obesity: A review of animal, clinical and epidemiological studies. Physiol Behav 2004;83:549-555.

37. Janssens W, Bouillon R, Claes B, Carremans C, Lehouck A, Buysschaert I, Coolen J, Mathieu C, Decramer $M$, Lambrechts $D$. Vitamin d deficiency is highly prevalent in copd and correlates with variants in the vitamin d-binding gene. Thorax 2010;65:215-220. 


\section{Chapter 1}

38. Ceglia L. Vitamin d and its role in skeletal muscle. Curr Opin Clin Nutr Metab Care 2009;12:628-633.

39. Hu G, Cassano PA. Antioxidant nutrients and pulmonary function: The third national health and nutrition examination survey (nhanes iii). Am J Epidemiol 2000;151:975-981.

40. Varraso R, Fung TT, Barr RG, Hu FB, Willett W, Camargo CA, Jr. Prospective study of dietary patterns and chronic obstructive pulmonary disease among us women. Am J Clin Nutr 2007;86:488-495.

41. Varraso R, Fung TT, Hu FB, Willett W, Camargo CA. Prospective study of dietary patterns and chronic obstructive pulmonary disease among us men. Thorax 2007;62:786-791.

42. Koechlin C, Couillard A, Simar D, Cristol JP, Bellet H, Hayot M, Prefaut C. Does oxidative stress alter quadriceps endurance in chronic obstructive pulmonary disease? Am J Respir Crit Care Med 2004;169:1022-1027.

43. Barreiro E, Peinado VI, Galdiz JB, Ferrer E, Marin-Corral J, Sanchez F, Gea J, Barbera JA. Cigarette smokeinduced oxidative stress: A role in chronic obstructive pulmonary disease skeletal muscle dysfunction. Am J Respir Crit Care Med 2010;182:477-488.

44. Powers SK, Kavazis AN, McClung JM. Oxidative stress and disuse muscle atrophy. J Appl Physiol (1985) 2007;102:2389-2397.

45. Lacasse Y, Martin S, Lasserson TJ, Goldstein RS. Meta-analysis of respiratory rehabilitation in chronic obstructive pulmonary disease. A cochrane systematic review. Eura Medicophys 2007;43:475-485.

46. Slinde F, Ellegard L, Gronberg AM, Larsson S, Rossander-Hulthen L. Total energy expenditure in underweight patients with severe chronic obstructive pulmonary disease living at home. Clin Nutr 2003;22:159-165.

47. Ferreira IM, Brooks D, White J, Goldstein R. Nutritional supplementation for stable chronic obstructive pulmonary disease. Cochrane Database Syst Rev 2012;12:CD000998.

48. Jonker R, Deutz NE, Erbland ML, Anderson PJ, Engelen MP. Hydrolyzed casein and whey protein meals comparably stimulate net whole-body protein synthesis in copd patients with nutritional depletion without an additional effect of leucine co-ingestion. Clin Nutr 2014;33:211-220.

49. Drummond MJ, Rasmussen BB. Leucine-enriched nutrients and the regulation of mammalian target of rapamycin signalling and human skeletal muscle protein synthesis. Curr Opin Clin Nutr Metab Care 2008;11:222-226.

50. van de Bool C, Steiner MC, Schols AM. Nutritional targets to enhance exercise performance in chronic obstructive pulmonary disease. Curr Opin Clin Nutr Metab Care 2012;15:553-560. 


\section{Chapter}

\section{Antagonistic implications of sarcopenia and abdominal obesity on physical performance in COPD}




\section{ABSTRACT}

Background: Decreased physical performance due to loss of muscle mass (i.e. sarcopenia) is prevalent in ageing and appears more pronounced in chronic disease. A comprehensive profile of the sarcopenic phenotype in COPD is not yet available.

Aim: To characterize prevalence, functional implications and predictive value of sarcopenia with or without abdominal obesity in Dutch COPD patients eligible for pulmonary rehabilitation.

Methods: 505 COPD patients (aged 37-87y; 57\% male) underwent assessment of lung function, body composition and physical functioning, before entering pulmonary rehabilitation. Sarcopenia was assessed by appendicular skeletal muscle index (ASMI) and abdominal obesity by android/gynoid\%fat (A/G\%FM) using dual energy X-ray absorptiometry (DEXA).

Results: $86.5 \%$ of patients were sarcopenic and showed lower physical functioning, while coexistent abdominal obesity (78.0\%) resulted in higher physical functioning. Implications on endurance were less pronounced in women. The predictive value for physical functioning was higher for the '3-compartment'-model (ASMI, BMC and A/G $\% \mathrm{FM}$ ) than the '2-compartment'-model (FFMI and FMI) or '1-compartment'-model (BMI).

Conclusion: In patients eligible for pulmonary rehabilitation sarcopenia is highly prevalent in all BMI-categories and associated with impaired strength, and in men also with decreased endurance. Abdominal obesity seems to have protective effects on physical functioning. ASMI is a better predictor for physical functioning than FFMI. 


\section{INTRODUCTION}

Chronic obstructive pulmonary disease (COPD) is a major public health problem, which is projected to rank third worldwide in terms of mortality in 2020 (1). Evidence is accumulating that disease burden in COPD is largely determined by extra-pulmonary impairment including skeletal muscle dysfunction, osteoporosis and cardiovascular disease (2). Nutritional status is an important determinant of these extra-pulmonary effects.

Today, it is generally accepted that body mass index (BMI) is limited to indicate differences in nutritional status. Indeed, we and others have previously shown hidden obesity in normal weight patients with COPD due to proportionally low muscle mass (3-5). To characterize low muscle mass in COPD, traditionally a fat-free mass index (FFMI) below age- and gender-adjusted 10th percentile values for healthy subjects is commonly used, corresponding to a FFMl<17 kg/m for males and $<15 \mathrm{~kg} / \mathrm{m}^{2}$ for females in normal to underweight Caucasian COPD patients (6). This criterion was mainly developed to diagnose patients with or at risk for cachexia, a syndrome that causes generalized wasting of muscle mass (7).

It is expected that in the current obesogenic society the proportion of COPD patients with sarcopenic obesity will increase. Recently, FFMI percentiles were proposed that also adjust for BMI (8), but Dual Energy X-ray Absorptiometry (DEXA) nowadays also allows additional assessment of fat mass and fat-free mass at regional level besides assessment of bone mineral density.

An appendicular skeletal muscle mass index (ASMI) of $\geq 2$ standard deviations below the mean of healthy persons between 20-30 years of age of the same ethnic group is nowadays commonly used to define sarcopenia in elderly (9). In the general well-functioning aged population, sarcopenia according to this definition is prevalent in $\pm 15 \%$ (10), but only sparse data is available in COPD. In a non-institutionalized civilian population of South Korea, sarcopenia was found in $32.8 \%$ of male and $12.2 \%$ of female COPD patients (11). However, no data are yet available from a European population, as well as from patients eligible for pulmonary rehabilitation which are characterized by impaired physical functioning. Moreover, we recently demonstrated a high prevalence of abdominal obesity in patients eligible for pulmonary rehabilitation (12), but so far no data are available regarding the relative contribution of sarcopenia and abdominal obesity to impaired physical functioning in COPD.

The aim of the current study was to provide a comprehensive profile of the sarcopenic (low ASMI) with or without abdominal obesity (high A/G \%FM) phenotype in a representative group of Dutch COPD patients screened for pulmonary rehabilitation, by 1) exploring it's prevalence across all BMI categories; 2 ) investigating its functional implications; and 3) determining the predictive value of ASMI over BMI and FFMI for physical functioning. Because it is suggested that the relationship between body composition 
and functional capacity differs between males and females (13), we also explored putative gender differences. We hypothesize that functional consequences of low muscle mass can better be predicted by ASM than whole body FFM as the latter also includes a large part of water-containing organs and non-muscle tissue.

\section{SUBJECTS AND METHODS}

\section{Subjects}

The COPD patients were recruited from $\mathrm{ClRO}+$, centre of expertise for organ failure in Horn, the Netherlands, between 2010 and 2011 (14). Diagnosis of COPD was confirmed according to the Global Initiative for Chronic Obstructive Lung Disease (GOLD) guidelines (1), after referral for pulmonary rehabilitation by chest physicians from several hospitals in the Southeast of the Netherlands. Patients were clinically stable and those without DEXA measurements were excluded. In total, 505 patients were included in the analyses. This retrospective study uses de-identified and pre-existing data for analyses and is institutional review board exempted.

\section{Measurements}

Measurements were performed at $\mathrm{CIRO}+$ before entering pulmonary rehabilitation, as part of a 3-day baseline assessment (14). Gender and age were recorded from demographics.

\section{Lung function}

In accordance with the latest GOLD guidelines (1), standardized equipment (Masterlab ${ }^{\circledR}$, Jaeger, Germany) was used to assess post-bronchodilator forced expiratory volume in 1 second $\left(F E V_{1}\right)$ and forced vital capacity (FVC). Diffusion capacity of carbon monoxide (DLCO) was assessed by single-breath method. All obtained values were expressed as percentages of the predicted value, by comparison with age and gender-specific reference values (15).

\section{Body composition}

Total body height was measured to the nearest $0.5 \mathrm{~cm}$ with a wall-mounted stadiometer and total body weight to the nearest $0.1 \mathrm{~kg}$ using a weighing scale. BMI was calculated as weight/height ${ }^{2}\left(\mathrm{~kg} / \mathrm{m}^{2}\right)$ and categorized according to the recent ERS statement on Nutritional assessment and therapy in COPD (6): BMI<20 kg/m² (underweight); BMI $20-25 \mathrm{~kg} / \mathrm{m}^{2}$ (normal weight), BMI $25-30 \mathrm{~kg} / \mathrm{m}^{2}$ (overweight) and BMI>30 kg/m² (obese). 
Body composition was measured by DEXA (Lunar Prodigy system, GE Healthcare, Madison, USA). Fat-free mass index (FFMI) was calculated by dividing FFM (lean mass + bone mineral content $(\mathrm{BMC})$ ) by height ${ }^{2}$ and fat mass by subtracting FFM from total weight. Low FFMI was defined as a FFMI $<17 \mathrm{~kg} / \mathrm{m}^{2}$ for men and $<15 \mathrm{~kg} / \mathrm{m}^{2}$ for women (6). The ratio of the percentage fat mass (FM) in the android region (waist) to the percentage FM in the gynoid region (hip) was used as a measure for abdominal fat mass. Sarcopenia was defined according to cut-offs for ASMI $\left(<7.23 \mathrm{~kg} / \mathrm{m}^{2}\right.$ for men; $<5.67 \mathrm{~kg} / \mathrm{m}^{2}$ for women) (9). The ratio android/gynoid \%fat mass (A/G\%FM) $>1.0$ for men and $>0.8$ for women was applied to diagnose abdominal obesity (16). Osteopenia was defined as a $T$ score between -1 and -2.5, osteoporosis as a T-score $\leq-2.5$ (17).

\section{Physical functioning}

A supervised symptom-limited cardiopulmonary incremental cycle test (CPET) was conducted on an electronically braked cycle ergometer (Carefusion, Houten, the Netherlands) to determine peak workload. Additionally, a constant work rate cycling endurance test (CWRT) was performed at $75 \%$ of the peak workload to determine cycle endurance time (CET). The best of two 6MWD's was selected for analyses. Peak quadriceps muscle strength was assessed during volitional isokinetic contractions (angular velocity of $90^{\circ}$ per second) on a Biodex (Biodex System 4 Pro, Biodex Medical Systems, Inc., New York, USA).

\section{CRP measurement}

Plasma levels of C-reactive protein (CRP) were assessed by high-sensitivity particleenhanced immunoassay (COBAS Mira ${ }^{\circledR}$, Radiometer, Copenhagen) and were used as a marker for systemic inflammation.

\section{Statistical analysis}

All statistical analyses were performed using the Statistical Package for Social Sciences version 20.0 (SPSS, Inc., Chicago, IL, USA). Two-sided P-values <0.05 were considered statistically significant. The Shapiro-Wilk test was used to assess data for normal distribution. Continuous variables were presented as median \pm interquartile range and were compared between two groups by the Student's t-test for independent samples (parametric data) or Mann-Whitney test (nonparametric data), and compared between more than two groups by one-way ANOVA (parametric data) or Kruskal-Wallis test (nonparametric data). Discrete variables were presented as percentages and compared by the chisquared test. Multivariate backward linear regression analyses were performed to determine the predictive values of body composition models to physical functioning outcomes. 


\section{RESULTS}

\section{Subject characteristics}

In general, the median age of the 505 COPD patients was 64 years, $57 \%$ were male and the majority was former smoker (71.2\%), 26.2\% current smoker, while $2.6 \%$ never smoked. COPD severity ranged from mild to very severe (GOLD I/II/III/IV: 7.9/40.8/39.8/ $11.5 \%$ ). Men were slightly older than women (66 vs 60 y, $P<0.001$ ).

\section{Prevalence of body composition phenotypes}

In general, the majority of patients (37.8\%) had normal body weight, followed by $28.7 \%$ overweight, $18.8 \%$ obese and $14.7 \%$ underweight. Applying the ASMI cut-offs revealed sarcopenia in $83.0 \%$ of men and $91.2 \%$ of women, resulting in a total of $86.5 \%$. Almost $34 \%$ had a low FFMI. Further classification revealed abdominal obesity in the majority of the patients $(80.6 \%)$, as well as $78.0 \%$ in the sarcopenic patients.

Figure 1 shows that a highly prevalent sarcopenic phenotype across all BMI-categories: $100 \%$ in underweight, $96.9 \%$ in normal weight, $87.6 \%$ in overweight and $53.7 \%$ in obese patients. These proportions were comparable for both sexes, except in those overweight $(82.0 \%$ in men vs. $96.4 \%$ in women, $\mathrm{P}<0.05)$. In contrast, the prevalence of a low FFMI rapidly reduced from $83.8 \%$ in underweight patients, to $48.2 \%$ in normal weight patients, $13.8 \%$ in overweight patients and none of the obese patients (table 1 ). Coexistence of abdominal obesity and sarcopenia across BMI-categories was comparable between sarcopenic men and women: $33.8 \%$ in underweight, $78.4 \%$ in normal weight, $94.5 \%$ in overweight and $100 \%$ in obese. Additionally, $97.1 \%$ of non-sarcopenic patients were abdominal obese.

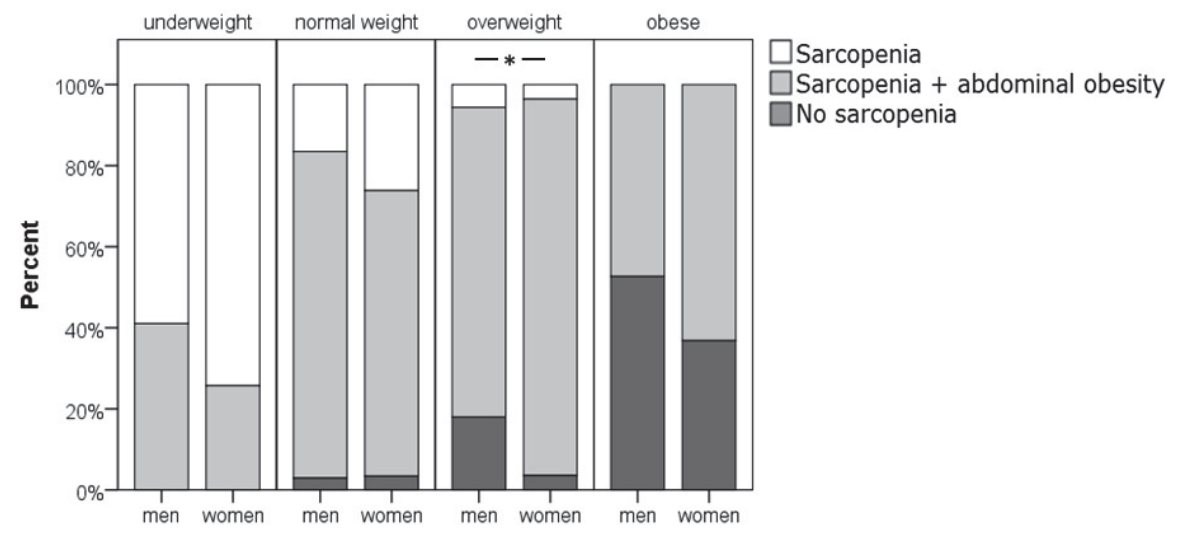

Figure 1. Prevalence of sarcopenia, in presence and absence of abdominal obesity, across BMI categories.

* Significant at $\mathrm{P}<0.05$. 
Table 1. Comparison of prevalence's of low FFMI and low ASMI (sarcopenia) across BMI categories.

\begin{tabular}{|c|c|c|c|c|c|c|}
\hline & \multicolumn{2}{|c|}{ Low FFMI } & \multicolumn{2}{|c|}{ Normal FFMI } & \multicolumn{2}{|l|}{ Total } \\
\hline \multicolumn{7}{|l|}{ Underweight } \\
\hline Non-sarcopenic & 0 & $(0.0 \%)$ & 0 & $(0.0 \%)$ & 0 & $(0.0 \%)$ \\
\hline Sarcopenic & 62 & $(83.8 \%)$ & 12 & $(16.2 \%)$ & 74 & $(100.0 \%)$ \\
\hline Total & 62 & $(83.8 \%)$ & 12 & $(16.2 \%)$ & 74 & $(100.0 \%)$ \\
\hline \multicolumn{7}{|l|}{ Normal weight } \\
\hline Non-sarcopenic & 0 & $(0.0 \%)$ & 6 & (3.1\%) & 6 & (3.1\%) \\
\hline Sarcopenic & 92 & $(48.2 \%)$ & 93 & $(48.7 \%)$ & 185 & (96.9\%) \\
\hline Total & 92 & $(48.2 \%)$ & 99 & (51.8\%) & 191 & $(100.0 \%)$ \\
\hline \multicolumn{7}{|l|}{ Overweight } \\
\hline Non-sarcopenic & 0 & $(0.0 \%)$ & 18 & $(12.4 \%)$ & 18 & $(12.4 \%)$ \\
\hline Sarcopenic & 20 & $(13.8 \%)$ & 107 & $(73.8 \%)$ & 127 & $(87.6 \%)$ \\
\hline Total & 20 & $(13.8 \%)$ & 125 & (86.2\%) & 145 & $(100.0 \%)$ \\
\hline \multicolumn{7}{|l|}{ Obese } \\
\hline Non-sarcopenic & 0 & $(0.0 \%)$ & 44 & $(46.3 \%)$ & 44 & $(46.3 \%)$ \\
\hline Sarcopenic & 0 & $(0.0 \%)$ & 51 & $(53.7 \%)$ & 51 & (53.7\%) \\
\hline Total & 0 & $(0.0 \%)$ & 95 & $(100.0 \%)$ & 95 & $(100.0 \%)$ \\
\hline \multicolumn{7}{|l|}{ Total } \\
\hline Non-sarcopenic & 0 & $(0.0 \%)$ & 68 & $(13.5 \%)$ & 68 & $(13.5 \%)$ \\
\hline Sarcopenic & 174 & (34.5\%) & 263 & (52.1\%) & 437 & $(86.5 \%)$ \\
\hline Total & 174 & $(34.5 \%)$ & 331 & $(65.5 \%)$ & 505 & $(100.0 \%)$ \\
\hline
\end{tabular}

Results presented as count (percentage)

In general, sarcopenic patients without abdominal obesity were younger and had lower diffusion capacity and CRP levels than sarcopenic patients with abdominal obesity (table 2). Patients with this combined phenotype showed more impaired lung function than non-sarcopenic patients. Per definition, additional differences in body composition were found across body composition phenotypes regarding BMI, FFMI, FMI, fat percentage and android FM. Prevalence of osteoporosis was highest in the sarcopenic patients without abdominal obesity. 
Table 2. Subjects characteristics per body composition phenotype

\begin{tabular}{|c|c|c|c|c|}
\hline & $\begin{array}{l}\text { A. Sarcopenia } \\
(n=96)\end{array}$ & $\begin{array}{l}\text { B. Sarcopenia }+ \\
\text { abdominal obesity } \\
(n=341)\end{array}$ & $\begin{array}{l}\text { C. "No sarcopenia" } \\
(n=68)\end{array}$ & $\begin{array}{l}\text { Significant } \\
\text { difference } \\
\text { between group }\end{array}$ \\
\hline \multicolumn{5}{|l|}{ General characteristics } \\
\hline Male, \% & 46.9 & 56.9 & 72.1 & $A B-C$ \\
\hline Age, years & $60.5(54.0-67.0)$ & $65.0(58.0-70.0)$ & $63.0(58.0-68.8)$ & $A-B$ \\
\hline $\mathrm{FEV}_{1}, \%$ predicted & $43.0(32.3-58.8)$ & $47.0(35.5-62.5)$ & $63.5(51.3-72.0)$ & $A B-C$ \\
\hline FVC, \%predicted & $99.0(85.3-110.5)$ & $98.0(84.0-113.5)$ & $103.0(89.0-123.5)$ & NS \\
\hline $\mathrm{FEV}_{1} / \mathrm{FVC}$ & $37.0(28.9-47.2)$ & $39.5(30.3-49.2)$ & $47.9(41.1-58.7)$ & $A-B C, B-C$ \\
\hline DLCO, \%predicted & $45.0(37.0-54.0)$ & $53.0(43.0-63.0)$ & $67.5(56.5-77.5)$ & $A-B C, B-C$ \\
\hline $\mathrm{VO}_{2}$ peak, L & $0.9(0.7-1.1)$ & $1.1(0.9-1.2)$ & $1.5(1.3-1.7)$ & $A-B C, B-C$ \\
\hline $\mathrm{VO}_{2}$ peak, \%predicted & 45.9 (27.8-71.9) & $38.3(28.3-53.0)$ & $40.8(34.6-52.6)$ & $A-B$ \\
\hline $\mathrm{CRP}, \mathrm{mg} / \mathrm{L}$ & $2.1(0.5-8.8)$ & $3.4(1.4-8.5)$ & $3.6(1.9-9.2)$ & $A-B C$ \\
\hline \multicolumn{5}{|l|}{ Body composition } \\
\hline Height, cm & $167.0(160.1-172.9)$ & $168.2(162.5-174.0)$ & $172.3(169.0-177.4)$ & $A B-C$ \\
\hline $\mathrm{BMI}, \mathrm{kg} / \mathrm{m}^{2}$ & $20.0(18.2-22.1)$ & $25.0(22.6-28.3)$ & $31.9(28.7-34.8)$ & $A-B C, B-C$ \\
\hline FFM, kg & $43.2(37.6-51.5)$ & $47.9(40.8-54.6)$ & $62.7(54.3-67.1)$ & $A-B C, B-C$ \\
\hline FFMI, $\mathrm{kg} / \mathrm{m}^{2}$ & $15.2(14.5-17.0)$ & $16.7(15.4-18.2)$ & $20.6(19.5-22.0)$ & $A-B C, B-C$ \\
\hline Low FFMI, \% & 60.4 & 34.0 & 0 & $A-B C, B-C$ \\
\hline ASM, kg & $16.9(14.4-20.4)$ & $18.5(15.7-22.0)$ & $26.1(22.1-27.8)$ & $A-B C, B-C$ \\
\hline ASMI, kg/m² & $5.0(4.5-5.9)$ & $5.5(4.8-6.4)$ & $7.5(6.6-7.9)$ & $A-B C, B-C$ \\
\hline $\mathrm{FM}, \mathrm{kg}$ & $12.7(5.7-17.5)$ & $23.3(17.7-30.2)$ & $34.0(26.3-39.1)$ & $A-B C, B-C$ \\
\hline $\mathrm{FMI}, \mathrm{kg} / \mathrm{m}^{2}$ & $4.2(2.1-6.1)$ & $8.2(6.2-10.9)$ & $11.1(8.5-13.4)$ & $A-B C, B-C$ \\
\hline Fat percentage, $\%$ & $21.0(12.0-28.9)$ & $33.1(27.2-39.0)$ & $34.3(29.4-39.0)$ & $A-B C$ \\
\hline Android FM, kg & $0.9(0.4-1.3)$ & $2.4(1.8-3.3)$ & $3.7(2.9-4.4)$ & $A-B C, B-C$ \\
\hline A/G \%FM & $0.75(0.6-0.9)$ & $1.2(1.0-1.3)$ & $1.3(1.2-1.4)$ & $A-B C, B-C$ \\
\hline Abdominal obese, \% & 0 & 100 & 97.1 & $A-B C, B-C$ \\
\hline Osteopenia, \% & 32.3 & 55.1 & 48.5 & $A-B C$ \\
\hline Osteoporosis, \% & 50 & 28.2 & 13.2 & $A-B C, B-C$ \\
\hline
\end{tabular}

Results presented as median (IQR) or percentages. NS: not significant.

\section{Functional implications}

Sarcopenic patients without abdominal obesity performed less during the different tests than non-sarcopenic patients, reflected by lower muscle strength and peak workload, as well as a shorter CET and 6MWD in men (figure 2). In case of concomitant abdominal obesity, sarcopenic patients achieved higher muscle strength. Moreover, sarcopenic men with abdominal obesity achieved higher peak workload and longer CET. Nonetheless, physical functioning was still significantly lower compared to non-sarcopenic patients, including muscle strength, peak workload, CET and 6MWD (CET and 6MWD only in men). 

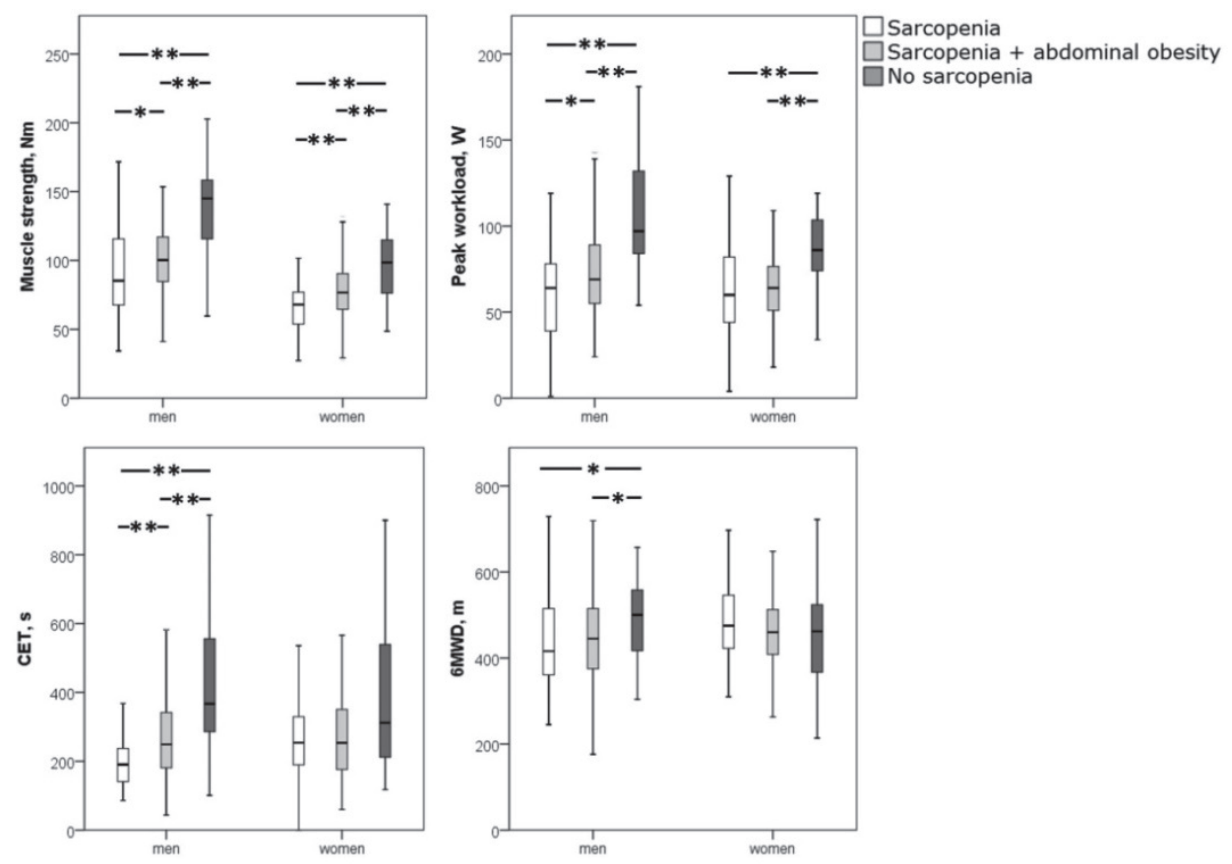

Figure 2. Functional implications of sarcopenia in presence or absence of abdominal obesity. ${ }^{*}$ Significant at $\mathrm{P}<0.05$; ** Significant at $\mathrm{P}<0.01$.

To assess the ASM quality between body composition phenotypes, functional measures were also compared expressed per kilogram ASM (table 3). Both in men and women, muscle strength expressed per kilogram ASM was lower in those sarcopenic without abdominal obesity compared to those sarcopenic and abdominal obese. In men only, muscle strength was highest in the non sarcopenic patients compared to both sarcopenic patients with or without abdominal obesity. Furthermore also in men, peak workload and $\mathrm{VO}_{2}$ peak per kg ASM was lower in both sarcopenic groups compared to the non-sarcopenic group, while the CET expressed per kg ASM was lowest in the sarcopenic group without abdominal obesity compared to the other two groups. 
Table 3. Qualitative implications of sarcopenia (with or without abdominal obesity).

\begin{tabular}{|c|c|c|c|c|}
\hline & $\begin{array}{l}\text { A. Sarcopenia } \\
(n=96)\end{array}$ & $\begin{array}{l}\text { B. Sarcopenia }+ \\
\text { abdominal obesity } \\
(n=341)\end{array}$ & $\begin{array}{l}\text { C. "No sarcopenia" } \\
(n=68)\end{array}$ & $\begin{array}{l}\text { Significant } \\
\text { difference } \\
\text { between } \\
\text { group }\end{array}$ \\
\hline \multicolumn{5}{|l|}{ Men } \\
\hline Muscle strength/ASM, Nm/kg & $4.2(3.4-5.4)$ & $4.7(4.0-5.45)$ & $5.2(4.3-6.0)$ & $A-B C, B-C$ \\
\hline Peak workload/ASM, W/kg & $3.2(2.3-3.8)$ & $3.2(2.6-4.1)$ & $3.6(3.2-4.6)$ & $A B-C$ \\
\hline $\mathrm{VO}_{2}$ peak/ASM, $\mathrm{mL} / \mathrm{kg}$ & $47.6(40.2-53.8)$ & $49.4(41.9-60.4)$ & $55.0(49.3-60.7)$ & $A B-C$ \\
\hline CET/ASM, s/kg & $9.9(7.2-12.1)$ & $11.5(8.4-16.1)$ & $13.5(10.6-20.8)$ & $A-B C$ \\
\hline \multicolumn{5}{|l|}{ Women } \\
\hline Muscle strength/ASM, Nm/kg & $4.5(3.9-5.1)$ & $5.0(4.4-5.7)$ & $4.7(3.7-5.7)$ & $A-B$ \\
\hline Peak workload/ASM, W/kg & $4.0(3.1-5.3)$ & $4.1(3.3-4.9)$ & $4.4(3.8-4.9)$ & NS \\
\hline $\mathrm{VO}_{2}$ peak/ASM, mL/kg & $60.3(51.7-70.7)$ & $65.7(56.7-73.8)$ & $73.1(57.2-74.9)$ & NS \\
\hline CET/ASM, s/kg & $17.8(12.4-23.2)$ & $16.4(11.9-23.2)$ & $14.1(10.1-27.2)$ & NS \\
\hline
\end{tabular}

Comparison of significant physical functioning measures expressed per kilogram ASM across body composition phenotypes. Results presented as median (IQR). NS: not significant.

\section{Predictive value}

Table 4 shows the results of the gender-specific backward regression analyses on the predictive value of 1-compartment (BMI), 2-compartment (FFMI+FMI) and 3compartment (ASMI+BMC+A/G\%FM) assessment of body composition, corrected for age and $\mathrm{FEV}_{1}$. BMI was a significant predictor for muscle strength, peak workload and 6MWD (6MWD only in women). The '1-compartment' model explained less than the '2compartment' model, which explained $30-31 \%$ of total muscle strength variability, with FFMI and FMI as positive predictors (FMI only in women). The predictive value increased even more to $47-51 \%$ in the 3 compartment model, in which ASMI, BMC and $\mathrm{A} / \mathrm{G} \% \mathrm{FM}$ retained positive predictors. At the level of peak workload, FFMI retained a positive predictor in the '2-compartment' model, explaining $41-48 \%$ of total variability, while 47-56\% was explained by the '3-compartment' model, with positive roles for ASMI and BMC (BMC only in men). Regarding CET, $2 \%$ of variability was explained by the '2compartment' model, with FFMI as positive predictor (only in men), whereas 4-7\% was explained by the model, including ASMI and BMC as positive predictors (ASMI only in men). Furthermore, the '2-compartment' model explained $16-27 \%$ of total variability in $6 \mathrm{MWD}$, in which FFMI retained a positive predictor in men and FMI a negative predictor in men and women. Explained variability decreased to $16-20 \%$ by the '3-compartment' model, comprising $A / G \% F M$ as a positive predictor in men, but a negative predictor for 6MWD in women. 
Table 4. Predictive value of body composition assessment models.

\begin{tabular}{|c|c|c|c|c|c|c|c|c|}
\hline & \multirow[b]{2}{*}{ Model } & \multirow[b]{2}{*}{ Predictors } & \multicolumn{3}{|l|}{ Men } & \multicolumn{3}{|l|}{ Women } \\
\hline & & & Adjusted $R^{2}$ & $\beta$ & $P$-value & Adjusted $R^{2}$ & $\beta$ & $P$-value \\
\hline \multirow{6}{*}{$\begin{array}{l}\text { Muscle } \\
\text { strength }\end{array}$} & 1 & $\mathrm{BMI}$ & 0.29 & 2.50 & 0.00 & 0.30 & 1.58 & 0.00 \\
\hline & 2 & FFMI & 0.32 & 6.28 & 0.00 & 0.31 & 3.41 & 0.00 \\
\hline & & FMI & & - & NS & & 0.97 & 0.03 \\
\hline & 3 & ASMI & 0.47 & 17.01 & 0.00 & 0.51 & 11.74 & 0.00 \\
\hline & & $\mathrm{BMC}$ & & 0.01 & 0.00 & & 0.02 & 0.00 \\
\hline & & $\mathrm{A} / \mathrm{G} \% \mathrm{FM}$ & & - & NS & & 16.68 & 0.00 \\
\hline \multirow{6}{*}{$\begin{array}{l}\text { Peak } \\
\text { workload }\end{array}$} & 1 & $\mathrm{BMI}$ & 0.47 & 0.96 & 0.00 & 0.40 & 0.56 & 0.02 \\
\hline & 2 & FFMI & 0.48 & 2.90 & 0.00 & 0.41 & 1.92 & 0.01 \\
\hline & & FMI & & - & ns & & - & ns \\
\hline & 3 & ASMI & 0.56 & 8.06 & 0.00 & 0.47 & 10.68 & 0.00 \\
\hline & & $\mathrm{BMC}$ & & 0.01 & 0.00 & & - & NS \\
\hline & & $\mathrm{A} / \mathrm{G} \% \mathrm{FM}$ & & - & NS & & - & NS \\
\hline \multirow[t]{6}{*}{ CET } & 1 & $\mathrm{BMI}$ & 0.02 & - & NS & 0.02 & - & NS \\
\hline & 2 & FFMI & 0.02 & 17.53 & 0.01 & 0.02 & - & NS \\
\hline & & FMI & & - & - & - & - & NS \\
\hline & 3 & ASMI & 0.07 & 42.31 & 0.03 & 0.04 & - & NS \\
\hline & & BMC & & 0.08 & 0.03 & & 0.10 & 0.02 \\
\hline & & $\mathrm{A} / \mathrm{G} \% \mathrm{FM}$ & & - & NS & & - & NS \\
\hline \multirow[t]{6}{*}{ 6MWD } & 1 & $\mathrm{BMI}$ & 0.14 & - & NS & 0.26 & -5.47 & 0.00 \\
\hline & 2 & FFMI & 0.16 & 7.19 & 0.04 & 0.27 & - & NS \\
\hline & & FMI & & -5.43 & 0.01 & & -7.62 & 0.00 \\
\hline & 3 & ASMI & 0.16 & - & NS & 0.20 & - & NS \\
\hline & & $\mathrm{BMC}$ & & - & NS & & - & NS \\
\hline & & $\mathrm{A} / \mathrm{G} \% \mathrm{FM}$ & & 64.52 & 0.01 & & -60.45 & 0.04 \\
\hline
\end{tabular}

Summary of backward multiple regression analysis, with muscle strength, peak workload, CET and 6MWD as dependent variables and body composition models (1 compartment: BMI, 2 compartment: FFMI and FMI or 3 compartment: ASMI, BMC and A/G \%FM) as predictors. All models are adjusted for age and FEV1. NS: not significant.

\section{DISCUSSION}

This is the first study presenting the prevalence of sarcopenia and abdominal obesity, to characterize its functional implications and predictive value for physical functioning in a representative group of Dutch COPD patients eligible for pulmonary rehabilitation.

To date, the prevalence of sarcopenia has only been explored in a non-institutionalized civilian population of South Korea (32.8\% of male and $12.2 \%$ of female COPD patients) (11). Clearly, the current proportions overshadow the prevalence in South Korea, but the latter was reported in a relatively healthy population, as individuals admitted to hospital or nursing homes were not included. The higher prevalence of sarcopenia in COPD than in healthy elderly (based on available literature (10)) reflects the suggested accelerated ageing in COPD, which is further supported by the reported shorter telomere length in 
COPD patients (18). Potential catabolic triggers for inducing the sarcopenic process in COPD include physical inactivity, oxidative stress, inflammation, use of glucocorticosteroids and hypoxia (19). As described in the recently published ERS statement on Nutritional assessment and therapy in COPD (6), abnormally low FFMI in normal to underweight COPD patients is based on well-established adverse effects of low FFMI on physical performance and survival and defined as a FFMI below age- and gender-specific 10th percentile values. Depending on the cut-off value, prevalence rates range from 15 to 35 $(3,20,21)$, but are low or absent in overweight and obese subjects. Although we did not use BMI-specific ASMI reference values as recently proposed by Prado et al. (22), a high prevalence of the sarcopenic phenotype persisted across all BMI categories, including $\mathbf{7 4 . 5 \%}$ of overweight and $53.7 \%$ of obese patients. The ASMI cut-offs for sarcopenia are therefore particularly useful to diagnose abnormal body composition in overweight and obese patients. This concept has also been observed in patients with non-small cell lung cancer, in which 59\% of the overweight patients were sarcopenic (23).

For the diagnosis of sarcopenia, the European Working Group on Sarcopenia in Older People (EWGSOP) recommends using the presence of low physical function (strength or performance) next to low ASMI (9). One study aimed to verify the association between ASMI and physical functioning in older COPD outpatients (24). However, they only assessed 6MWD as a measure for physical functioning and concluded that $\mathrm{FEV}_{1}$ was a stronger predictor of physical functioning in COPD patients than body composition. Another study demonstrated that skeletal muscle weakness in COPD patients was due to loss of ASM, but was not related to airflow obstruction (25). We explored the relation between low ASMI and a comprehensive set of functional outcome measures in the current population of COPD patients, as the relative influence of muscle mass versus impaired lung function on performance might differ between tests $(24,26,27)$. Indeed, we showed that sarcopenia (in general and expressed per kilogram ASM) is not only accompanied by impaired muscle strength, but also with impaired exercise performance, which was more pronounced for peak workload than for 6MWD. Although actual $\mathrm{VO}_{2}$ peak was lowest in sarcopenic patients, they showed the highest $\mathrm{VO}_{2}$ peak expressed as \%predicted. This is due to the lower predicted values for this group, which are based on weight-class. Non-sarcopenic patients were generally overweight to obese and overall showed better physical functioning, typically reflecting the 'obesity paradox' (stating that obesity is on one hand associated with better survival and some functional outcomes, but on the other hand also with increased risk of cardiovascular and metabolic diseases). Referring to the high prevalence of abdominal obesity in COPD patients (12) and moreover in sarcopenic patients (11), it was relevant to investigate if and in what direction coexistence of abdominal obesity further affected physical functioning in COPD patients. This group of sarcopenic patients with concomitant abdominal obesity generally displayed a higher physical functioning than sarcopenic patients without abdominal obesity. This finding corresponds to previous literature reporting that exercise 
capacity is preserved or even increased in obese COPD patients during cycling (nonweight bearing exercise) $(28,29)$, except when walking is used as testing modality (weight bearing exercise) (30). A potential explanation for this functional improvement in advanced COPD might be a lowering effect of obesity on resting and dynamic hyperinflation as established determinant of exercise impairment in $\operatorname{COPD}(29,31)$. Nonetheless, this condition of excessive body weight with a disproportional low muscle mass (i.e. sarcopenic obesity) may exert cumulative risks on metabolic and cardiovascular health, resulting in increased morbidity and mortality (32). Loss of muscle mass can result in decreased muscle oxidative capacity which is related to metabolic disorders including diabetes and metabolic syndrome in non-obese individuals (33). Decreased oxidative capacity may even be more pronounced in COPD due to a muscle fibre I to II shift. Indeed, a recent population study demonstrated an association between sarcopenia and metabolic syndrome in male COPD patients (11). Although conclusive data were not available in the present study, abdominal obesity was accompanied by higher CRPlevels, corresponding with recent data indicating that excessive abdominal fat mass contributes to the systemic inflammation in COPD, which in turn is an important risk factor for cardiovascular disease $(4,34)$. Albeit abdominal obesity seem to be protective in the present study, the effect on cardiovascular co-morbidity should be further evaluated in subsequent study in order to be able to point out the net effect of this phenotype.

In our COPD patients, a '3-compartment body composition'-model (including ASMI, $B M C$ and $A / G \% F M)$ had a higher predictive value for physical functioning than a '2compartment'-model (including FFMI and FMI) or '1-compartment'-model (BMI). Nonetheless, differences were found in the predictive values of the body composition variables when comparing physical functioning outcomes, but also when comparing men with women. ASMI positively contributed to muscle strength, peak workload and CET (CET only in men), whereas $A / G \% F M$ positively contributed to muscle strength and 6MWD in men, but negatively to 6MWD in women. The better prediction of ASMI for muscle strength and peak workload as compared to CET and 6MWD can be attributed to the direct interaction between muscle mass and weakness in this population, whereas muscle endurance is suggested to be affected by multiple additional factors related to COPD (35). Noticeable is the independent contribution of BMC to endurance in the regression model. Lower functional performance has been described in patients with osteoporosis, but a contribution of the bone mass to functional performance has never been shown so far.

Our analyses revealed more gender variations, as all reported physical functioning outcomes significantly differed across body composition phenotypes in men, but in women no differences could be detected in CET and 6MWD across body composition phenotypes. Moreover, the coexistence of abdominal obesity next to sarcopenia resulted in higher muscle strength, peak workload and CET in men, while this only applied for mus- 
cle strength in women. Therefore, especially sarcopenic men might be protected for physical functioning by the presence of abdominal obesity. However, the reason for the gender difference in the functional impact of abdominal obesity is unclear. Nonetheless, gender differences in the degree of muscle function impairment have also been found in cancer patients $(36,37)$. Its underlying mechanism may differ between men and women, suggesting that the degree of physical impairment is affected by sexual dimorphism (36).

Some shortcomings of the current study need to be considered. Because of the crosssectional nature of our data, we were not able to identify cause-effect relationships. Another limitation was the lack of data on (unintended) weight loss to assess the relative contribution of cachexia (unintentional weight loss $>5 \%$ in 6 months and low FFMI) to sarcopenia. Additionally, the current results cannot be generalised to the whole COPD population, because the studied patient sample consisted exclusively of patients referred for pulmonary rehabilitation. However, these patients pertain an interesting population because of their functional impairments.

Future research is necessary to further unravel the causes and effects of sarcopenia and abdominal obesity in COPD. Nonetheless, the current findings indicate that assessment of the 3-compartimental body composition (ASMI, A/G\%FM and BMC) might be favourable over distinction between FFMI and FMI, indicated by 1) the high persisting prevalence's of sarcopenia and abdominal obesity in all BMI categories; 2) it's discrimination for impaired muscle strength and endurance; 3) the higher predictive value of the 3compartment regression model compared to the 1 or 2 compartment models.

\section{CONCLUSION}

This paper shows that sarcopenia is highly prevalent across all BMI categories in patients eligible for pulmonary rehabilitation in the Netherlands. Moreover, we showed loss of muscle strength in sarcopenic patients and in men also impaired endurance. The coexistence of abdominal obesity might protect against impaired physical functioning in sarcopenic patients. The predictive value for physical functioning was higher for the '3compartment'-model (ASMI, BMC and A/G\%FM) than the '2-compartment'-model (FFMI and FMI) or '1-compartment'-model (BMI). The mechanisms underlying these observations remain to be elucidated. 


\section{REFERENCES}

1. Vestbo J, Hurd SS, Agusti AG, Jones PW, Vogelmeier C, Anzueto A, Barnes PJ, Fabbri LM, Martinez FJ, Nishimura M, Stockley RA, Sin DD, Rodriguez-Roisin R. Global strategy for the diagnosis, management, and prevention of chronic obstructive pulmonary disease: Gold executive summary. Am J Respir Crit Care Med 2013;187:347-365.

2. Patel AR, Hurst JR. Extrapulmonary comorbidities in chronic obstructive pulmonary disease: State of the art. Expert Rev Respir Med 2011;5:647-662.

3. Schols AM, Soeters PB, Dingemans AM, Mostert R, Frantzen PJ, Wouters EF. Prevalence and characteristics of nutritional depletion in patients with stable copd eligible for pulmonary rehabilitation. Am Rev Respir Dis 1993;147:1151-1156.

4. Rutten EP, Breyer MK, Spruit MA, Hofstra T, van Melick PP, Schols AM, Wouters EF. Abdominal fat mass contributes to the systemic inflammation in chronic obstructive pulmonary disease. Clin Nutr 2010;29:756-760.

5. Marquis K, Maltais F, Duguay V, Bezeau AM, LeBlanc P, Jobin J, Poirier P. The metabolic syndrome in patients with chronic obstructive pulmonary disease. J Cardiopulm Rehabil 2005;25:226-232; discussion 233-224.

6. Schols AM, Ferreira IM, Franssen FM, Gosker HR, Janssens W, Muscaritoli M, Pison C, Rutten-van Molken M, Slinde F, Steiner MC, Tkacova R, Singh SJ. Nutritional assessment and therapy in copd: A european respiratory society statement. Eur Respir J 2014.

7. Engelen MP, Schols AM, Lamers RJ, Wouters EF. Different patterns of chronic tissue wasting among patients with chronic obstructive pulmonary disease. Clin Nutr 1999;18:275-280.

8. Franssen FM, Rutten EP, Groenen MT, Vanfleteren LE, Wouters EF, Spruit MA. New reference values for body composition by bioelectrical impedance analysis in the general population: Results from the uk biobank. J Am Med Dir Assoc 2014.

9. Cruz-Jentoft AJ, Baeyens JP, Bauer JM, Boirie Y, Cederholm T, Landi F, Martin FC, Michel JP, Rolland Y, Schneider SM, Topinkova E, Vandewoude M, Zamboni M. Sarcopenia: European consensus on definition and diagnosis. Age and Ageing 2010;39:412-423.

10. Cherin P, Voronska E, Fraoucene N, de Jaeger C. Prevalence of sarcopenia among healthy ambulatory subjects: The sarcopenia begins from 45 years. Aging Clin Exp Res 2013.

11. Chung JH, Hwang HJ, Han CH, Son BS, Kim do H, Park MS. Association between sarcopenia and metabolic syndrome in chronic obstructive pulmonary disease: The korea national health and nutrition examination survey (knhanes) from 2008 to 2011. COPD 2015;12:82-89.

12. van de Bool C, Mattijssen-Verdonschot C, van Melick PP, Spruit MA, Franssen FM, Wouters EF, Schols AM, Rutten EP. Quality of dietary intake in relation to body composition in patients with chronic obstructive pulmonary disease eligible for pulmonary rehabilitation. Eur J Clin Nutr 2014;68:159-165.

13. Schols AM, Broekhuizen R, Weling-Scheepers CA, Wouters EF. Body composition and mortality in chronic obstructive pulmonary disease. Am J Clin Nutr 2005;82:53-59.

14. Spruit MA, Vanderhoven-Augustin I, Janssen PP, Wouters EF. Integration of pulmonary rehabilitation in copd. Lancet 2008;371:12-13.

15. Clausen JL, Coates AL, Quanjer PH. Measurement of lung volumes in humans: Review and recommendations from an ats/ers workshop. Eur Respir J 1997;10:1205-1206.

16. Bjorntorp P. Regional patterns of fat distribution. Ann Intern Med 1985;103:994-995.

17. Who scientific group on the prevention and management of osteoporosis. Prevention and management of osteoporosis; report of a who scientific group.; 2003.

18. Houben JM, Mercken EM, Ketelslegers HB, Bast A, Wouters EF, Hageman GJ, Schols AM. Telomere shortening in chronic obstructive pulmonary disease. Respir Med 2009;103:230-236.

19. Remels AH, Gosker HR, Langen RC, Schols AM. The mechanisms of cachexia underlying muscle dysfunction in copd. J Appl Physiol (1985) 2013;114:1253-1262. 
20. Vestbo J, Prescott E, Almdal T, Dahl M, Nordestgaard BG, Andersen T, Sorensen TI, Lange P. Body mass, fat-free body mass, and prognosis in patients with chronic obstructive pulmonary disease from a random population sample: Findings from the copenhagen city heart study. Am J Respir Crit Care Med 2006;173:79-83.

21. Vermeeren MA, Creutzberg EC, Schols AM, Postma DS, Pieters WR, Roldaan AC, Wouters EF. Prevalence of nutritional depletion in a large out-patient population of patients with copd. Respir Med 2006;100:1349-1355.

22. Prado CM, Siervo M, Mire E, Heymsfield SB, Stephan BC, Broyles S, Smith SR, Wells JC, Katzmarzyk PT. A population-based approach to define body-composition phenotypes. Am J Clin Nutr 2014;99:1369-1377.

23. Baracos VE, Reiman T, Mourtzakis M, Gioulbasanis I, Antoun S. Body composition in patients with nonsmall cell lung cancer: A contemporary view of cancer cachexia with the use of computed tomography image analysis. Am J Clin Nutr 2010;91:1133S-1137S.

24. Cesari M, Pedone C, Chiurco D, Cortese L, Conte ME, Scarlata S, Incalzi RA. Physical performance, sarcopenia and respiratory function in older patients with chronic obstructive pulmonary disease. Age Ageing 2012;41:237-241.

25. Engelen MP, Schols AM, Does JD, Wouters EF. Skeletal muscle weakness is associated with wasting of extremity fat-free mass but not with airflow obstruction in patients with chronic obstructive pulmonary disease. Am J Clin Nutr 2000;71:733-738.

26. Gosselink R, Troosters T, Decramer M. Peripheral muscle weakness contributes to exercise limitation in copd. Am J Respir Crit Care Med 1996;153:976-980.

27. Andrianopoulos V, Wagers SS, Groenen MT, Vanfleteren LE, Franssen FM, Smeenk FW, Vogiatzis I, Wouters EF, Spruit MA. Characteristics and determinants of endurance cycle ergometry and six-minute walk distance in patients with copd. BMC Pulm Med 2014;14:97.

28. Ora J, Laveneziana P, Ofir D, Deesomchok A, Webb KA, O'Donnell DE. Combined effects of obesity and chronic obstructive pulmonary disease on dyspnea and exercise tolerance. Am J Respir Crit Care Med 2009;180:964-971.

29. Ora J, Laveneziana P, Wadell K, Preston M, Webb KA, O'Donnell DE. Effect of obesity on respiratory mechanics during rest and exercise in copd. J Appl Physiol (1985) 2011;111:10-19.

30. Sava F, Laviolette L, Bernard S, Breton MJ, Bourbeau J, Maltais F. The impact of obesity on walking and cycling performance and response to pulmonary rehabilitation in copd. BMC Pulm Med 2010;10:55.

31. Laviolette L, Sava F, O'Donnell DE, Webb KA, Hamilton AL, Kesten S, Maltais F. Effect of obesity on constant workrate exercise in hyperinflated men with copd. BMC Pulm Med 2010;10:33.

32. Biolo G, Cederholm T, Muscaritoli M. Muscle contractile and metabolic dysfunction is a common feature of sarcopenia of aging and chronic diseases: From sarcopenic obesity to cachexia. Clin Nutr 2014.

33. Moon SS. Low skeletal muscle mass is associated with insulin resistance, diabetes, and metabolic syndrome in the korean population: The korea national health and nutrition examination survey (knhanes) 2009-2010. Endocrine journal 2014;61:61-70.

34. van den Borst B, Gosker HR, Koster A, Yu B, Kritchevsky SB, Liu Y, Meibohm B, Rice TB, Shlipak M, Yende $S$, Harris TB. The influence of abdominal visceral fat on inflammatory pathways and mortality risk in obstructive lung disease. Am J Clin Nutr 2012;96:516-526.

35. Malaguti C, Napolis LM, Villaca D, Neder JA, Nery LE, Dal Corso S. Relationship between peripheral muscle structure and function in patients with chronic obstructive pulmonary disease with different nutritional status. J Strength Cond Res 2011;25:1795-1803.

36. Stephens NA, Gray C, MacDonald AJ, Tan BH, Gallagher IJ, Skipworth RJ, Ross JA, Fearon KC, Greig CA. Sexual dimorphism modulates the impact of cancer cachexia on lower limb muscle mass and function. Clin Nutr 2012;31:499-505.

37. Palomares MR, Sayre JW, Shekar KC, Lillington LM, Chlebowski RT. Gender influence on weight-loss pattern and survival of nonsmall cell lung carcinoma patients. Cancer 1996;78:2119-2126. 


\section{Chapter}

\section{Muscle quality is more impaired in sarcopenic patients with COPD}

Coby van de Bool, Harry R. Gosker, Bram van den Borst, Celine M. Op den Kamp, Ilse G.M. Slot and Annemie M.W.J. Schols

Journal of the American Medical Directors Association. 2016 May 1;17(5):415-20 


\section{ABSTRACT}

Background: Quadriceps muscle fiber atrophy and a loss of oxidative type I muscle fibers and mitochondrial content often occur in COPD, which adversely affects exercise performance. Sarcopenia is an age-related syndrome characterized by wasting and weakness of muscle mass. We recently showed in a large cohort of patients that COPDrelated sarcopenia, in particular in male patients, was not only associated with impaired quadriceps muscle strength but also with decreased exercise performance endurance, which could imply involvement of altered muscle fiber type composition. Hence, we hypothesized that both the fiber atrophy and loss of oxidative muscle fibers are more pronounced in sarcopenic compared to non-sarcopenic COPD patients.

Objective: The objective of this study was to investigate quadriceps muscle fiber-type characteristics in relation to presence of sarcopenia in patients with COPD and in healthy age matched controls.

Design: For this retrospective cross-sectional study, body composition (assessed by Dual-energy X-ray Absorptiometry) and quadriceps muscle biopsy (fiber type distribution and sizes) data were collected from 45 COPD patients (aged 42-77 y) and 52 healthy controls (aged 50-77 y). Sarcopenia was based on assessment of appendicular skeletal muscle mass index (ASMI).

Results: Sarcopenia was found in 5.8\% of healthy controls and in $31.1 \%$ of patients with COPD $(p<0.01)$. The proportion of oxidative type I fibers and size of type IIx muscle fibers were decreased in COPD, and the sarcopenic sub-group showed a further decreased proportion as well as a lower size of type I fibers.

Conclusions: Type I muscle fiber proportion is lower in sarcopenic compared to nonsarcopenic COPD patients. Longitudinal studies may elucidate if the loss of muscle oxidative phenotype drives or accelerates the process of muscle wasting. 


\section{INTRODUCTION}

Muscle wasting is a major hallmark of patients with chronic obstructive pulmonary disease (COPD) besides impaired lung function and contributes to impaired exercise capacity (1), decreased health status (2), and increased mortality in $\operatorname{COPD}(3,4)$. Alongside the development and positioning of new radiographic measurements of body composition as integrated part of disease phenotyping, nutritional assessment has shifted from a body weight-centered to a body composition-centered approach. Recently, the ERS taskforce on Nutritional assessment and therapy in COPD (5) proposed Dual Energy X-ray Absorptiometry (DEXA) as the most appropriate method for body composition analysis in COPD, as it allows for screening of osteoporosis combined with assessment of fat mass (FM) and fat-free mass (FFM) at regional levels in addition to whole body level. Assessment of the appendicular skeletal muscle mass index (ASMI) traditionally originates from identification of age-related low muscle mass in elderly populations, a syndrome described as sarcopenia (6). Its application is relatively new in COPD, but might in theory be highly relevant as COPD is suggested as disease of accelerated ageing (7). Indeed, we recently identified sarcopenia in the majority of Dutch COPD patients eligible for pulmonary rehabilitation across all BMI categories (8). Moreover, in this large cohort of patients ( $n=505)$, we demonstrated that low ASMI was not only associated with impaired quadriceps muscle strength but, in particular in men, also with decreased cycle exercise endurance and walking distance. Whereas decreased muscle strength directly results from loss of peripheral skeletal muscle mass (9), this does not apply for the loss of endurance, which is rather associated with loss of oxidative phenotype (10). Consequently, it could be hypothesized that sarcopenia in COPD is characterized by intrinsic muscular alterations as well. In COPD, consistent intrinsic alterations in peripheral skeletal muscles have indeed been described (11). More specifically, quadriceps muscle in advanced COPD is characterized by predominant atrophy of type IIx fibers (12) as well as a loss of oxidative phenotype, i.e. a shift from oxidative type I to glycolytic II muscle fibers (13). Furthermore, van den Borst et al. (14) previously demonstrated that loss of quadriceps oxidative phenotype and decreased quadriceps endurance was already present in patients with mild-to-moderate COPD in the absence of muscle and fiber atrophy.

These alterations culminate in reduced muscle endurance, but in addition could also drive or accelerate muscle wasting since the loss of muscle oxidative phenotype may render muscle in COPD less energy efficient, and (the remaining) type II fibers are more sensitive to atrophying disease-related triggers (15-17). Moreover, intrinsic abnormalities in peripheral muscle seem more aggravated in emphysematous patients who are also more susceptible to weight loss (18-20). Additionally, Gouzi et al. (21) recently identified an atrophic cluster of COPD patients with reduced BMI, FFMI, type I fiber proportion and fiber CSA using an unsupervised clustering method. 
Although assessment of muscle fiber alterations is crucial for understanding the process of muscle wasting in COPD, data is lacking on differences in muscle fiber-type characteristics between sarcopenic and non-sarcopenic COPD patients. Therefore, the aim of this retrospective study was to compare quadriceps muscle fiber-type characteristics in relation to sarcopenia (6) in patients with COPD and in healthy controls. We hypothesize that muscle fiber atrophy and loss of oxidative muscle fibers is more pronounced in the sarcopenic COPD phenotype.

\section{SUBJECTS AND METHODS}

\section{Subjects}

The studied population consisted of 45 clinically stable COPD patients and 52 healthy controls. All patients were recruited from the outpatient clinic of the Maastricht University Medical Centre+ (Maastricht, The Netherlands) and via local newspapers advertisement. Exclusion criteria comprised use of long-term oxygen therapy or oral prednisolone, acute exacerbation with hospital admission in the previous 4-8 weeks or rehabilitation in the previous 6 months. Patients with known comorbidities as diabetes, recent cardiovascular event, inflammatory bowel disease, obstructive sleep apnoea, thyroid disease, and cancer were carefully excluded because of potential interference with study outcomes. Healthy controls were recruited via local newspaper advertisement. Absence of diseases was verified through history-taking by a physician and absence of airflow limitation was verified by pulmonary function tests. All subjects participated in one out of three cross-sectional studies of which data has been previously published $(12,14,22)$. Subjects were included in 1996-1997, July 2007-July 2010 and March 2009April 2010.

\section{Ethics}

Followed procedures were in accordance with the ethical standards of the responsible institutional or regional committee on human experimentation or in accordance with the Helsinki Declaration of 1975 as revised in 1983.

\section{Lung function measurement}

In accordance with the latest GOLD guidelines (23), standardized equipment (Masterlab ${ }^{\circledR}$, Jaeger, Germany) was used to assess post-bronchodilator forced expiratory volume in 1 second $\left(\mathrm{FEV}_{1}\right.$ ) and forced vital capacity (FVC). Diffusion capacity of carbon monoxide (DICO) was assessed by single-breath method. All obtained values were ex- 
pressed as percentages of the predicted value, by comparison with age and genderspecific reference values (24).

\section{Body composition and muscle phenotyping}

Total body height was measured to the nearest $0.5 \mathrm{~cm}$ with a wall-mounted stadiometer and total body weight to the nearest $0.1 \mathrm{~kg}$ using a weighing scale. BMI was calculated as weight/height ${ }^{2}\left(\mathrm{~kg} / \mathrm{m}^{2}\right)$. Body composition was measured by DEXA (Lunar Prodigy system, GE Healthcare, Madison, USA; Hologic Discovery, Hologic, Bedford, MA, USA). Fat-free mass index (FFMI) was calculated by dividing FFM (lean mass + bone mineral content (BMC)) by height ${ }^{2}$ and fat mass by subtracting FFM from body weight. Sarcopenia was defined according to cut-offs for ASMI $\left(<7.23 \mathrm{~kg} / \mathrm{m}^{2}\right.$ for men; $<5.67$ $\mathrm{kg} / \mathrm{m}^{2}$ for women) (6).

\section{Muscle fiber typing}

Quadriceps muscle biopsy analyses have previously been described in detail for the three individual studies $(12,14,22)$. In short, needle biopsies were obtained from the vastus lateralis under local anesthesia. Samples were frozen in melting isopentane (precooled in liquid nitrogen) and serial $5 \mu \mathrm{m}$ crysections were cut. A combination of myosin ATPase-activity staining and immunohistochemistry (antibodies against different myosin heavy chain isoforms) was applied to determine fiber type proportions and fiber crosssectional areas using imaging software. All samples were analyses within a year after collection.

\section{Statistical analysis}

The Statistical Package for Social Sciences version 20.0 (SPSS, Inc., Chicago, IL, USA) was used to perform statistical analyses. Normal distribution was assed using the ShapiroWilk test. Discrete variables were compared by the chi-squared test and presented as percentages. Continuous variables were presented as median \pm interquartile range (characteristics) or mean \pm standard error (muscle fiber composition) and were compared between two groups by the Student's t-test for independent samples (parametric data) or Mann-Whitney test (nonparametric data), and compared between more than two groups by one-way ANOVA (parametric data) or Kruskal-Wallis test (nonparametric data). Two-sided P-values $<0.05$ were considered statistically significant.

Due to a too small number of female subjects we could not perform separate analyses for males and females. Nonetheless, separate analyses could be performed for males, which are presented in the supplemental data. 


\section{RESULTS}

\section{Subject characteristics}

Both the COPD and healthy control groups consisted largely out of men $(64.6 \%$ and $67.9 \% ; P=0.723)$. The majority of COPD patients had moderate to severely impaired lung function, as $6.4 \%$ of patients were classified in GOLD stage I, 36.2\% in GOLD stage II, 48.9\% in GOLD stage III and $8.5 \%$ in GOLD stage IV.

Applying the gender-specific cut-offs for ASMI revealed presence of sarcopenia in 3 male healthy controls, 1 female COPD patient and 13 male COPD patients, resulting in a total of $5.8 \%$ of healthy controls, compared to $31.1 \%$ in patients with COPD $(P<0.01)$. In males, $8.6 \%$ of control subjects were sarcopenic, compared to $44.8 \%$ in COPD patients $(P<0.01)$. Healthy controls with sarcopenia were excluded in further analyses because of the low number of subjects.

Table 1. Subject characteristics.

\begin{tabular}{|c|c|c|c|}
\hline & $\begin{array}{l}\text { Non-sarcopenic } \\
\text { Control }(n=49)\end{array}$ & $\begin{array}{l}\text { Non-sarcopenic COPD } \\
(n=31)\end{array}$ & $\begin{array}{l}\text { Sarcopenic COPD } \\
(n=14)\end{array}$ \\
\hline \multicolumn{4}{|c|}{ General characteristics } \\
\hline Male, \% & 65.3 & 51.6 & $92.9^{\S}$ \\
\hline Age, years & $64.0(59.5-67.0)$ & $65.0(61.0-69.0)$ & $68.0(66.8-74.3) *$ \\
\hline $\mathrm{FEV}_{1}, \%$ predicted & $112.8(103.9-123.8)$ & $57.3(45.8-69.5) *$ & $42.1(33.0-49.3)^{* \S}$ \\
\hline FVC, \%predicted & $121.8(113.8-135.4)$ & $103.0(83.5-116.3)$ * & $86.4(76.1-117.5) *$ \\
\hline $\mathrm{FEV}_{1} / \mathrm{FVC}, \%$ & $92.5(86.6-98.7)$ & $59.3(48.2-67.7) *$ & $42.3(36.5-46.8) *^{\S}$ \\
\hline DICO, \%predicted & $104.2(90.2-120.3)$ & $55.4(40.0-67.8) *$ & $42.2(35.6-70.1) *$ \\
\hline GOLD I/II/III/IV, \% & & $10 / 50 / 36.7 / 3.3$ & $0 / 14.3 / 71.4 / 14.3^{\S}$ \\
\hline \multicolumn{4}{|l|}{ Body composition } \\
\hline Height, cm & $173.0(166.3-178.8)$ & $168.0(158.0-175.0)$ * & 171.9 (165.2-176.6) \\
\hline $\mathrm{BMI}, \mathrm{kg} / \mathrm{m}^{2}$ & $25.5(23.3-28.2)$ & $25.8(23.6-27.8)$ & $23.5(20.6-25.7)^{* \S}$ \\
\hline FFMI, $\mathrm{kg} / \mathrm{m}^{2}$ & $19.0(17.2-20.3)$ & $18.2(15.8-19.4)$ & $16.8(16.2-17.5)^{*^{\S}}$ \\
\hline ASMI, kg/m² & $8.2(6.9-8.7)$ & $7.3(6.3-7.9)$ * & $7.0(6.5-7.1) *$ \\
\hline $\mathrm{FMI}, \mathrm{kg} / \mathrm{m}^{2}$ & $6.0(4.8-8.3)$ & $7.2(5.8-10.0)$ & $6.3(3.5-7.7)^{\S}$ \\
\hline Fat percentage, \% & $25.1(19.1-30.6)$ & $28.7(24.1-37.0) *$ & $26.4(19.5-31.2)$ \\
\hline
\end{tabular}

Results presented as median (IQR). * Statistically different from non-sarcopenic controls; ${ }^{\S}$ Statistically different from non-sarcopenic COPD patients.

Table 1 shows the subject characteristics per metabolic phenotype. Sarcopenic COPD patients were of similar age as non-sarcopenic patients, but were slightly older compared to the non-sarcopenic healthy controls (68 vs. 64 y; $P<0.001$ ). Additionally, airflow limitation was more pronounced in sarcopenic compared to non-sarcopenic COPD patients (FEV $142.1 \%$ predicted vs. FEV $157.3 \%$ predicted). However, age and FEV 1 were no 
significant predictors for ASMI in a regression model, whereas subject group (control or COPD) significantly predicted ASMI $(P<0.01)$. Non-sarcopenic COPD patients had a higher fat percentage compared to non-sarcopenic controls. In line with a lower ASMI, sarcopenic COPD patients showed a lower BMI, FFMI and FMI than non-sarcopenic COPD patients. Similar results were found in males only (supplemental table 1).

\section{Quadriceps muscle fiber type composition}

Figure 1 shows the proportion of type I muscle fibers across groups. In comparison with non-sarcopenic controls, a significantly lower proportion of type I fibers was found in both sarcopenic (26.0 vs. 50.7\%, $P<0.001$ ) and non-sarcopenic COPD patients (38.7 vs. $50.7 \%, P<0.01)$. Furthermore, the proportion of type I fibers was significantly lower in sarcopenic COPD patients than non-sarcopenic patients $(P=0.048)$. Analyses in males showed similar results (supplemental figure 1 ).
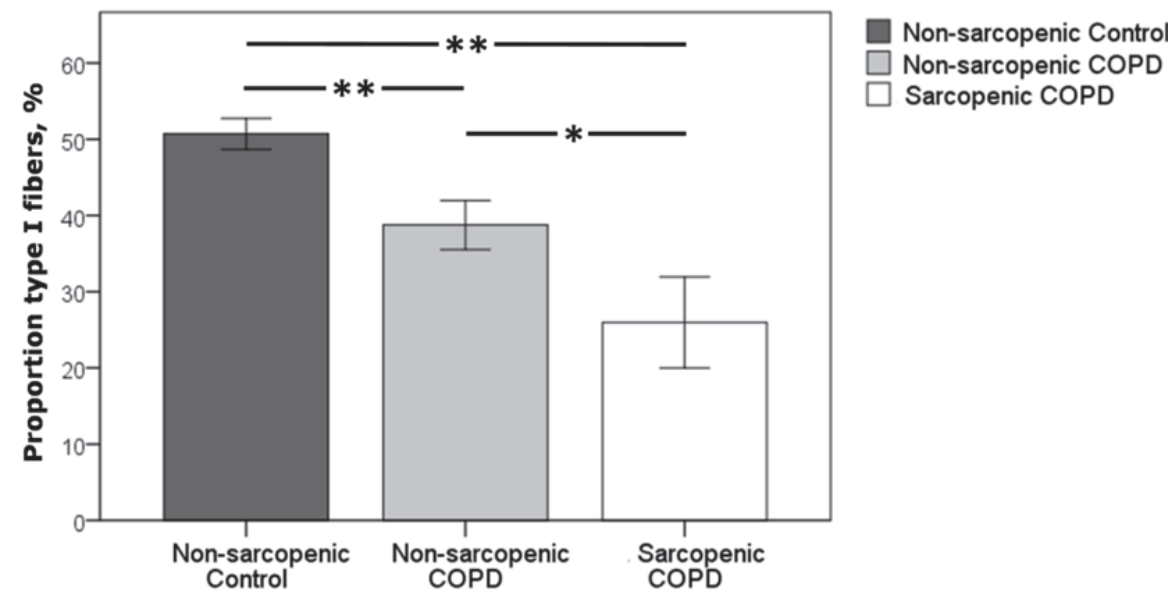

Figure 1. Comparison of muscle fiber composition across groups. * Significant at $P<0.05$; ** Significant at $P<0.01$.

The comparison of muscle fiber types CSA across groups is shown in figure 2. In general, COPD patients showed a significantly lower CSA of type IIx muscle fiber compared to non-sarcopenic controls (3464 vs. $4472 \mu \mathrm{m}^{2} ; P<0.05$ ), but no differences were found across sarcopenic phenotypes in COPD. Additionally, CSA of type I fibers were significantly lower in sarcopenic COPD patients compared to non-sarcopenic patients (5726 vs. $\left.7879 \mu^{2} ; P<0.05\right)$. No significant differences were found in CSA of type I/lla, Ila, Ila/IIx muscle fiber or mean CSA, although CSA of type Ila/IIx and mean CSA tended to be lower in sarcopenic patients. Comparisons in males showed an additional difference 
in CSA of type Ila/IIx fibers, which were significantly lower in sarcopenic patients than non-sarcopenic patients (4280 vs. $6411 \mu \mathrm{m}^{2} ; P<0.05$ ) (supplemental figure 2).
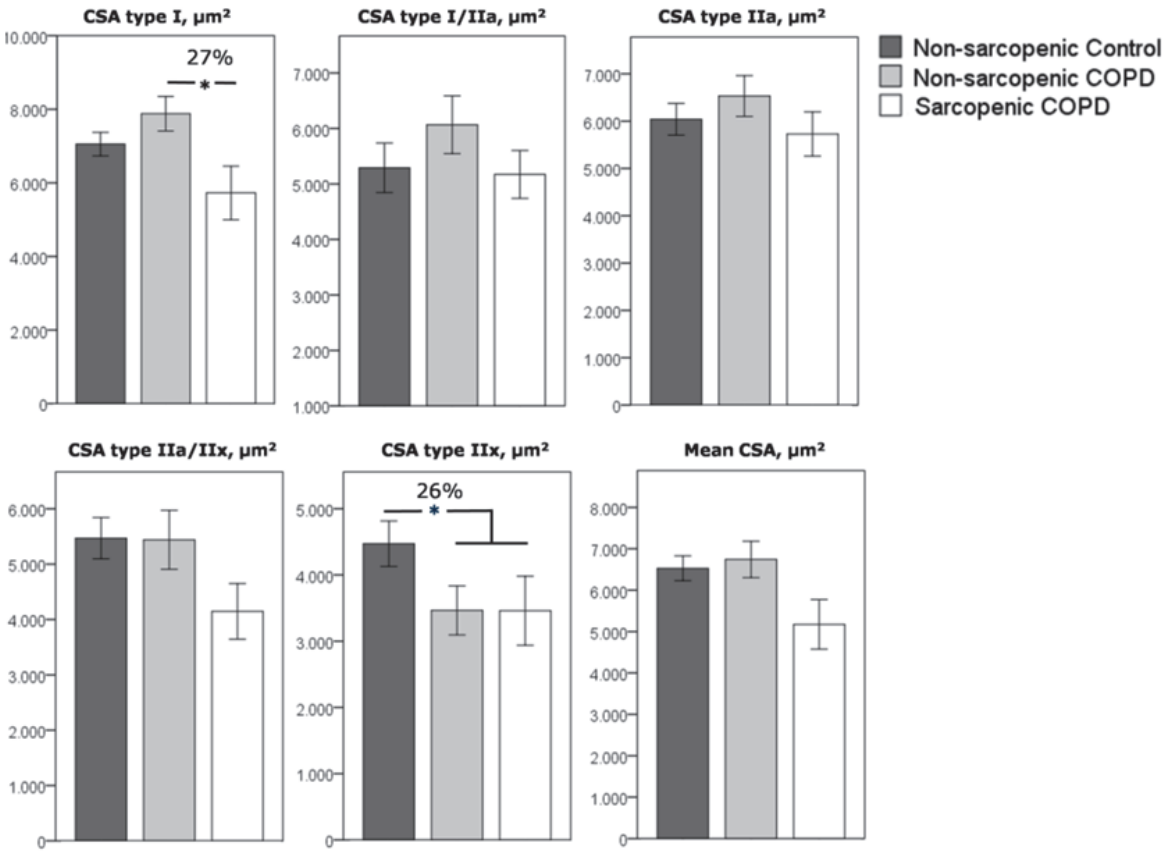

Figure 2. Comparison of muscle fiber cross-sectional area (CSA) across groups. * Significant at $P<0.05$.

\section{DISCUSSION}

This is the first study investigating quadriceps muscle fiber-type characteristics in relation to sarcopenia in patients with COPD and in healthy controls. Previous studies have already demonstrated a loss of muscle oxidative phenotype, including a muscle fiber type $I \rightarrow \|$ shift $(13,14)$, and selective atrophy of the type IIx fibers $(12)$ in patients with COPD. Added to the existing knowledge, the novelty of the current study is that it demonstrates a more pronounced decrease in oxidative type I fiber proportion in COPD patients with sarcopenia. Moreover, these sarcopenic patients are characterized by selective atrophy of the type I fibers, which seems independent of the more generalized type II atrophy in COPD as a whole.

Applying the ASMI cut-offs in our study population revealed sarcopenia in $31.1 \%$ of the COPD patients and $5.8 \%$ of the healthy control subjects. A comparable proportion of sarcopenic COPD patients was found in a South Korean non-institutionalized civilian population, in which $32.8 \%$ of male and $12.2 \%$ of female COPD patients were sarcopenic (25), as well as in a Brazilian COPD outpatient clinic, in which sarcopenia was ob- 
served in $39.6 \%$ of the patients (26). We recently reported a considerably higher proportion of sarcopenia in more advanced COPD patients eligible for a pulmonary rehabilitation program (8). This is not surprising as skeletal muscle weakness is an important determinant of impaired exercise performance as important indication for referral to pulmonary rehabilitation.

Regarding muscle fiber composition, we found a significant decrease in CSA of type IIx fibers in the patient group compared to the (non-sarcopenic) healthy control group, which is in line with previous reports $(12,27,28)$. Type Ilx muscle fiber atrophy was not related to sarcopenia, as it was present in both sarcopenic and non-sarcopenic patients. Nonetheless, CSA of type Ila/IIx fibers tended to be lower in sarcopenic patients than in non-sarcopenic patients reaching statistical significance in the male subgroup (supplemental data). Multiple disease-related triggers, occurring in isolation or combined, have been suggested to contribute to the atrophy of type II muscle fibers in COPD. Putative catabolic triggers include nutritional depletion, inflammation, oxidative stress and myostatin $(29,30)$. Nutritional depletion often occurs in COPD and is a likely contributor to atrophy of type II fibers based on collective findings of studies on anorexia nervosa, chronic heart failure, AIDS and chronic renal failure (12). Additionally, the majority of COPD patients, especially muscle wasted patients (31), exhibit chronic low-grade inflammation with elevated circulating concentrations of tumor necrosis factor- $\alpha$, mediating muscle atrophy via the inflammatory signaling pathway nuclear factor KB (32). Furthermore, muscle wasted COPD patients show elevated concentrations of myostatin (33) and systemic oxidative stress (34), which have also been shown to correlate negatively with muscle mass in COPD patients $(33,34)$.

In addition to muscle atrophy, peripheral muscle in COPD is characterized by a I-to-II fiber type shift, leading to an impaired oxidative phenotype (13). Long-term disuse has been described as catabolic trigger preferentially affecting type I muscle fibers (35). Indeed, our COPD patients displayed a decreased proportion of type I fibers in comparison with healthy controls. Moreover, this shift was even more pronounced in sarcopenic COPD patients, accompanied by a clear reduction in the CSA in the type I muscle fibers. In the literature, prolonged inactivity has indeed been described as an important driver for sarcopenia, as the sarcopenic process seems attenuated by higher levels of physical activity (36) and effects of inactivity result in accelerated loss of skeletal muscle and functional capacity (37).

Collectively, the present findings confirm our hypothesis of a more pronounced loss of oxidative phenotype in sarcopenic COPD and correspond with our previous finding of decreased muscle strength and endurance in sarcopenic COPD patients. In addition to reduced exercise capacity (38), loss of oxidative phenotype might potentially accelerate muscle wasting. First, a shift towards more type II fibers will lead to an increased reliance on glycolytic metabolism, contributing to metabolic inefficiency. Furthermore, 
type II fibers are more susceptible to atrophying disease-related triggers as inflammation-induced and oxidative stress-induced damage (15-17). Moreover, fiber shifting in the vastus lateralis of patients with COPD was recently identified as an independent predictor of mortality in patients with severe to very severe COPD (39).

Some limitations of the present study deserve discussion. Nowadays, the European Working Group on Sarcopenia in Older People (EWGSOP) recommends using the presence of low physical function (strength or performance) next to low ASMI (40). The current study design was retrospective, restraining the availability of a functional measure performed in each of the three study populations. Therefore, sarcopenia was diagnosed based on the presence of low ASMI only. None of the subgroups was confined to a single study population and since only standardized and routine measurements were studied, we are confident that this did not introduce selection bias. Furthermore, the study design was cross-sectional and although this was suitable to answer the current research question. Longitudinal studies monitoring how fiber type alterations develop as the muscle wasting process progresses are required to disentangle cause and consequence. Finally the unequal gender distribution between the subgroups does not rule out putative gender differences in the association between sarcopenia and loss of oxidative phenotype.

The current study supports exercise training programs for COPD patients that combine resistance and aerobic exercises as commonly applied in pulmonary rehabilitation, or combining endurance exercise with anabolics. Myostatin inhibitors for example are currently investigated as promising anabolic pharmacological agent for restoring muscle mass. However, some studies suggest that inhibition of myostatin might have detrimental effects on the oxidative capacity of muscle fibers (41-44) which could be combatted by a multimodal intervention approach.

In conclusion, this study shows evidence for a more pronouncedly decreased type I fiber proportion in sarcopenic COPD patients. These findings could reflect a cross-talk between muscle mass and oxidative phenotype regulation, which might accelerate the muscle wasting process in COPD. 


\section{REFERENCES}

1. Engelen MP, Schols AM, Baken WC, Wesseling GJ, Wouters EF. Nutritional depletion in relation to respiratory and peripheral skeletal muscle function in out-patients with copd. Eur Respir J 1994;7:1793-1797.

2. Mostert R, Goris A, Weling-Scheepers C, Wouters EF, Schols AM. Tissue depletion and health related quality of life in patients with chronic obstructive pulmonary disease. Respir Med 2000;94:859-867.

3. Schols AM, Broekhuizen R, Weling-Scheepers CA, Wouters EF. Body composition and mortality in chronic obstructive pulmonary disease. Am J Clin Nutr 2005;82:53-59.

4. Marquis K, Debigare R, Lacasse Y, LeBlanc P, Jobin J, Carrier G, Maltais F. Midthigh muscle cross-sectional area is a better predictor of mortality than body mass index in patients with chronic obstructive pulmonary disease. Am J Respir Crit Care Med 2002;166:809-813.

5. Schols AM, Ferreira IM, Franssen FM, Gosker HR, Janssens W, Muscaritoli M, Pison C, Rutten-van Molken M, Slinde F, Steiner MC, Tkacova R, Singh SJ. Nutritional assessment and therapy in copd: A european respiratory society statement. Eur Respir J 2014;44:1504-1520.

6. Newman AB, Kupelian V, Visser M, Simonsick E, Goodpaster B, Nevitt M, Kritchevsky SB, Tylavsky FA, Rubin SM, Harris TB, Health ABCSI. Sarcopenia: Alternative definitions and associations with lower extremity function. J Am Geriatr Soc 2003;51:1602-1609.

7. Mui TS, Man JM, McElhaney JE, Sandford AJ, Coxson HO, Birmingham CL, Li Y, Man SF, Sin DD. Telomere length and chronic obstructive pulmonary disease: Evidence of accelerated aging. J Am Geriatr Soc 2009; 57:2372-2374.

8. van de Bool C, Rutten EP, Franssen FM, Wouters EF, Schols AM. Antagonistic implications of sarcopenia and abdominal obesity on physical performance in copd. Eur Respir J 2015;46:336-345.

9. Bernard S, LeBlanc P, Whittom F, Carrier G, Jobin J, Belleau R, Maltais F. Peripheral muscle weakness in patients with chronic obstructive pulmonary disease. Am J Respir Crit Care Med 1998;158:629-634.

10. Allaire J, Maltais F, Doyon JF, Noel M, LeBlanc P, Carrier G, Simard C, Jobin J. Peripheral muscle endurance and the oxidative profile of the quadriceps in patients with copd. Thorax 2004;59:673-678.

11. Mathur S, Brooks D, Carvalho CR. Structural alterations of skeletal muscle in copd. Frontiers in physiology 2014;5:104.

12. Gosker HR, Engelen MP, van Mameren H, van Dijk PJ, van der Vusse GJ, Wouters EF, Schols AM. Muscle fiber type iix atrophy is involved in the loss of fat-free mass in chronic obstructive pulmonary disease. Am J Clin Nutr 2002;76:113-119.

13. Gosker HR, Zeegers MP, Wouters EF, Schols AM. Muscle fibre type shifting in the vastus lateralis of patients with copd is associated with disease severity: A systematic review and meta-analysis. Thorax 2007;62:944-949.

14. van den Borst B, Slot IG, Hellwig VA, Vosse BA, Kelders MC, Barreiro E, Schols AM, Gosker HR. Loss of quadriceps muscle oxidative phenotype and decreased endurance in patients with mild-to-moderate copd. J Appl Physiol (1985) 2013;114:1319-1328.

15. Wang Y, Pessin JE. Mechanisms for fiber-type specificity of skeletal muscle atrophy. Curr Opin Clin Nutr Metab Care 2013;16:243-250.

16. Schakman O, Kalista S, Barbe C, Loumaye A, Thissen JP. Glucocorticoid-induced skeletal muscle atrophy. The international journal of biochemistry \& cell biology 2013;45:2163-2172.

17. de Theije CC, Langen RC, Lamers WH, Gosker HR, Schols AM, Kohler SE. Differential sensitivity of oxidative and glycolytic muscles to hypoxia-induced muscle atrophy. J Appl Physiol (1985) 2015;118:200-211.

18. Gosker HR, van Mameren H, van Dijk PJ, Engelen MP, van der Vusse GJ, Wouters EF, Schols AM. Skeletal muscle fibre-type shifting and metabolic profile in patients with chronic obstructive pulmonary disease. Eur Respir J 2002;19:617-625.

19. Rabinovich RA, Bastos R, Ardite E, Llinas L, Orozco-Levi M, Gea J, Vilaro J, Barbera JA, Rodriguez-Roisin R, Fernandez-Checa JC, Roca J. Mitochondrial dysfunction in copd patients with low body mass index. Eur Respir J 2007;29:643-650. 


\section{Chapter 3}

20. Remels AH, Gosker HR, Schrauwen P, Hommelberg PP, Sliwinski P, Polkey M, Galdiz J, Wouters EF, Langen RC, Schols AM. Tnf-alpha impairs regulation of muscle oxidative phenotype: Implications for cachexia? FASEB J 2010;24:5052-5062.

21. Gouzi F, Abdellaoui A, Molinari N, Pinot E, Ayoub B, Laoudj-Chenivesse D, Cristol JP, Mercier J, Hayot M, Prefaut $C$. Fiber atrophy, oxidative stress, and oxidative fiber reduction are the attributes of different phenotypes in chronic obstructive pulmonary disease patients. J Appl Physiol (1985) 2013;115:17961805.

22. Op den Kamp CM, Langen RC, Snepvangers FJ, de Theije CC, Schellekens JM, Laugs F, Dingemans AM, Schols AM. Nuclear transcription factor kappa b activation and protein turnover adaptations in skeletal muscle of patients with progressive stages of lung cancer cachexia. Am J Clin Nutr 2013;98:738-748.

23. Vestbo J, Hurd SS, Agusti AG, Jones PW, Vogelmeier C, Anzueto A, Barnes PJ, Fabbri LM, Martinez FJ, Nishimura M, Stockley RA, Sin DD, Rodriguez-Roisin R. Global strategy for the diagnosis, management, and prevention of chronic obstructive pulmonary disease: Gold executive summary. Am J Respir Crit Care Med 2013;187:347-365.

24. Clausen JL, Coates AL, Quanjer PH. Measurement of lung volumes in humans: Review and recommendations from an ats/ers workshop. Eur Respir J 1997;10:1205-1206.

25. Chung JH, Hwang HJ, Han CH, Son BS, Kim do H, Park MS. Association between sarcopenia and metabolic syndrome in chronic obstructive pulmonary disease: The korea national health and nutrition examination survey (knhanes) from 2008 to 2011. COPD 2015;12:82-89.

26. Costa TM, Costa FM, Moreira CA, Rabelo LM, Boguszewski CL, Borba VZ. Sarcopenia in copd: Relationship with copd severity and prognosis. J Bras Pneumol 2015;41:415-421.

27. Fermoselle C, Rabinovich R, Ausin P, Puig-Vilanova E, Coronell C, Sanchez F, Roca J, Gea J, Barreiro E. Does oxidative stress modulate limb muscle atrophy in severe copd patients? Eur Respir J 2012;40:851862 .

28. Natanek SA, Riddoch-Contreras J, Marsh GS, Hopkinson NS, Man WD, Moxham J, Polkey MI, Kemp PR. Yin yang 1 expression and localisation in quadriceps muscle in copd. Arch Bronconeumol 2011;47:296302.

29. Remels AH, Gosker HR, Langen RC, Schols AM. The mechanisms of cachexia underlying muscle dysfunction in copd. J Appl Physiol (1985) 2013;114:1253-1262.

30. Langen RC, Gosker HR, Remels AH, Schols AM. Triggers and mechanisms of skeletal muscle wasting in chronic obstructive pulmonary disease. The international journal of biochemistry \& cell biology 2013;45:2245-2256.

31. Van Helvoort HA, Heijdra YF, Thijs HM, Vina J, Wanten GJ, Dekhuijzen PN. Exercise-induced systemic effects in muscle-wasted patients with copd. Med Sci Sports Exerc 2006;38:1543-1552.

32. Li H, Malhotra S, Kumar A. Nuclear factor-kappa b signaling in skeletal muscle atrophy. Journal of molecular medicine (Berlin, Germany) 2008;86:1113-1126.

33. Ju CR, Chen RC. Serum myostatin levels and skeletal muscle wasting in chronic obstructive pulmonary disease. Respir Med 2012;106:102-108.

34. van Helvoort HA, Heijdra YF, de Boer RC, Swinkels A, Thijs HM, Dekhuijzen PN. Six-minute walkinginduced systemic inflammation and oxidative stress in muscle-wasted copd patients. Chest 2007; 131:439-445.

35. Murton AJ, Greenhaff PL. Physiological control of muscle mass in humans during resistance exercise, disuse and rehabilitation. Curr Opin Clin Nutr Metab Care 2010;13:249-254.

36. Hughes VA, Roubenoff R, Wood M, Frontera WR, Evans WJ, Fiatarone Singh MA. Anthropometric assessment of 10-y changes in body composition in the elderly. Am J Clin Nutr 2004;80:475-482.

37. Evans WJ. Skeletal muscle loss: Cachexia, sarcopenia, and inactivity. Am J Clin Nutr 2010;91:1123S$1127 \mathrm{~S}$.

38. Maltais F, LeBlanc P, Whittom F, Simard C, Marquis K, Belanger M, Breton MJ, Jobin J. Oxidative enzyme activities of the vastus lateralis muscle and the functional status in patients with copd. Thorax 2000;55:848-853. 
39. Patel MS, Natanek SA, Stratakos G, Pascual S, Martinez-Llorens J, Disano L, Terzis G, Hopkinson NS, Gea J, Vogiatzis I, Maltais F, Polkey MI. Vastus lateralis fiber shift is an independent predictor of mortality in chronic obstructive pulmonary disease. Am J Respir Crit Care Med 2014;190:350-352.

40. Cruz-Jentoft AJ, Baeyens JP, Bauer JM, Boirie Y, Cederholm T, Landi F, Martin FC, Michel JP, Rolland Y, Schneider SM, Topinkova E, Vandewoude M, Zamboni M. Sarcopenia: European consensus on definition and diagnosis. Age and Ageing 2010;39:412-423.

41. Ploquin C, Chabi B, Fouret G, Vernus B, Feillet-Coudray C, Coudray C, Bonnieu A, Ramonatxo C. Lack of myostatin alters intermyofibrillar mitochondria activity, unbalances redox status, and impairs tolerance to chronic repetitive contractions in muscle. Am J Physiol Endocrinol Metab 2012;302:E1000-1008.

42. Hennebry A, Berry C, Siriett V, O'Callaghan P, Chau L, Watson T, Sharma M, Kambadur R. Myostatin regulates fiber-type composition of skeletal muscle by regulating mef2 and myod gene expression. Am J Physiol Cell Physiol 2009;296:C525-534.

43. Girgenrath S, Song K, Whittemore LA. Loss of myostatin expression alters fiber-type distribution and expression of myosin heavy chain isoforms in slow- and fast-type skeletal muscle. Muscle Nerve 2005;31:34-40.

44. Baan JA, Kocsis T, Keller-Pinter A, Muller G, Zador E, Dux L, Mendler L. The compact mutation of myostatin causes a glycolytic shift in the phenotype of fast skeletal muscles. J Histochem Cytochem 2013;61:889-900. 
Chapter 3

\section{SUPPLEMENTAL DATA}

Supplemental table 1. Male subject characteristics.

\begin{tabular}{|c|c|c|c|}
\hline & $\begin{array}{l}\text { Non-sarcopenic control } \\
(n=32)\end{array}$ & $\begin{array}{l}\text { Non-sarcopenic COPD } \\
(n=16)\end{array}$ & $\begin{array}{l}\text { Sarcopenic COPD } \\
(n=13)\end{array}$ \\
\hline \multicolumn{4}{|c|}{ General characteristics } \\
\hline Age, years & $64.0(61.3-67.0)$ & $67.2(64.3-73.3)$ & $69.0(66.5-74.5) *$ \\
\hline $\mathrm{FEV}_{1}, \%$ predicted & $111.4(103.5-120.7)$ & $47.9(41.4-69.4)^{*}$ & $40.5(32.0-49.5) *$ \\
\hline FVC, \%predicted & 120.7 (108.7-130.9) & $94.0(75.8-104.1)^{*}$ & $86.2(75.1-113.7)^{*}$ \\
\hline $\mathrm{FEV}_{1} / \mathrm{FVC}, \%$ & $91.8(87.1-98.8)$ & $61.7(48.9-66.9) *$ & $42.5(36.8-47.7) *^{\S}$ \\
\hline DICO, \%predicted & $112.7(95.4-137.2)$ & $56.0(51.3-71.0) *$ & $45.9(35.3-70.9) *$ \\
\hline GOLD I/II/III/IV, \% & & $6.7 / 40.0 / 46.7 / 6.7$ & 0/15.4/69.2/15.4 \\
\hline \multicolumn{4}{|l|}{ Body composition } \\
\hline Height, cm & $177.3(172.3-180.9)$ & 174.5 (169.6-176.7) & $173.8(167.3-.77 .3)$ \\
\hline $\mathrm{BMI}, \mathrm{kg} / \mathrm{m}^{2}$ & $25.7(23.4-27.9)$ & $25.4(23.6-26.5)$ & $24.0(21.3-25.7) *$ \\
\hline FFMI, $\mathrm{kg} / \mathrm{m}^{2}$ & $19.7(19.0-20.8)$ & $18.8(18.3-19.7)$ & $16.8(16.3-17.6)^{* \S}$ \\
\hline ASMI, kg/m² & $8.6(8.2-9.0)$ & $7.9(7.7-8.1)^{*}$ & $7.0(6.5-7.1) *^{\S}$ \\
\hline $\mathrm{FMI}, \mathrm{kg} / \mathrm{m}^{2}$ & $5.5(4.4-6.9)$ & $6.3(4.5-7.3)$ & $6.4(4.2-7.8)$ \\
\hline Fat percentage, $\%$ & $21.1(18.6-26.0)$ & $24.5(20.1-27.4)$ & $27.0(19.7-31.6)$ \\
\hline
\end{tabular}

Results presented as median (IQR). * Statistically different from non-sarcopenic controls; ${ }^{\S}$ statistically different from non-sarcopenic COPD patients.

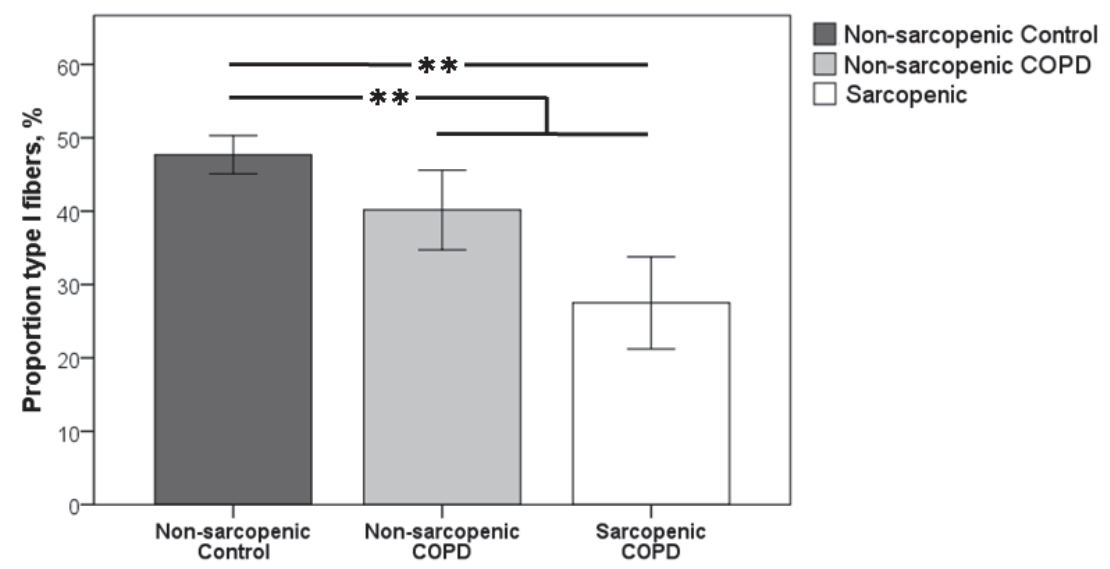

Supplemental figure 1. Comparison of muscle fiber composition across male groups. ${ }^{* *}$ Significant at $P<0.01$. 

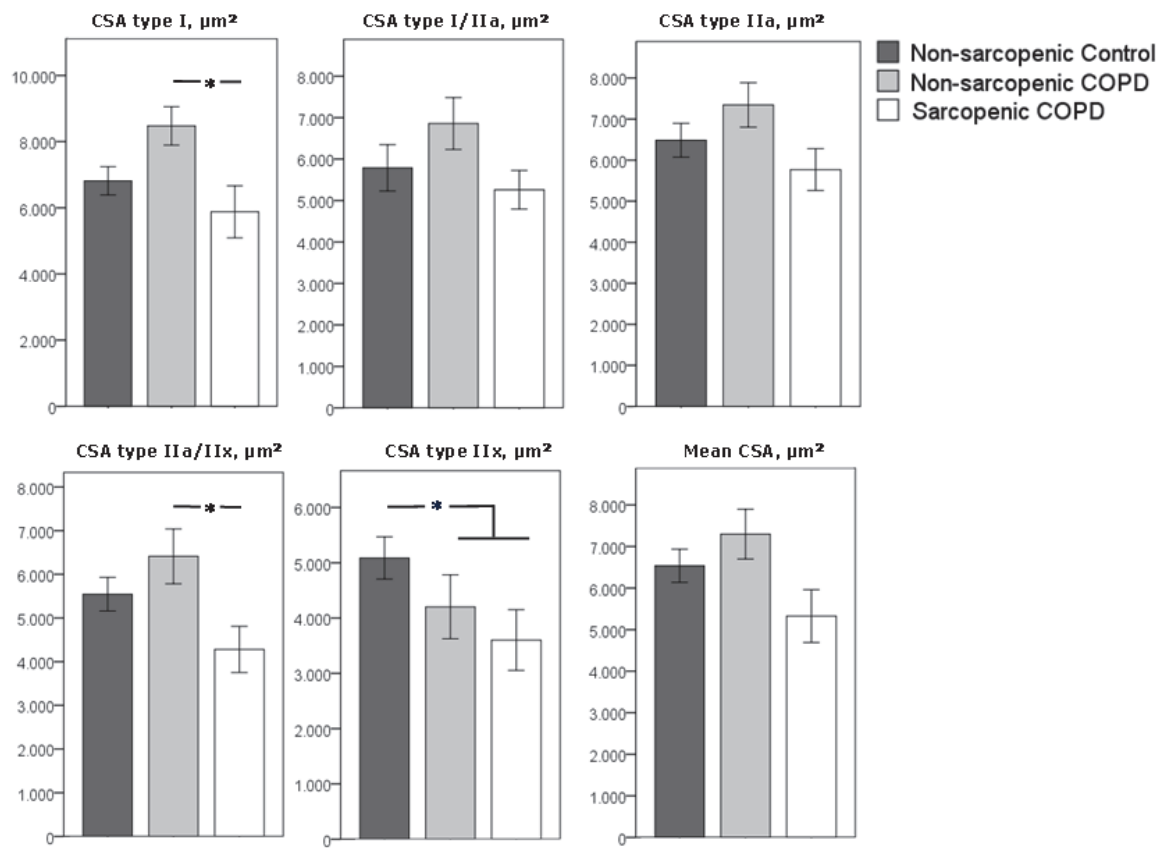

Supplemental figure 2. Comparison of muscle fiber CSA across male groups. ${ }^{*}$ Significant at $P<0.05$. 



\section{Chapter}

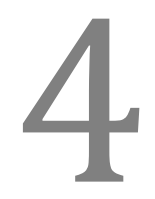

Quality of dietary intake in relation to body composition in patients with chronic obstructive pulmonary disease eligible for pulmonary rehabilitation

Coby van de Bool, Christel Mattijssen-Verdonschot, Paula P.M.J. van Melick, Martijn A. Spruit, Frits M.E. Franssen, Emiel F. M. Wouters, Annemie M.W.J. Schols, Erica P. A. Rutten 


\section{ABSTRACT}

Background/Objectives: A poor dietary quality may accelerate disturbances in body composition in COPD, but only limited studies have investigated dietary intake from this perspective. The objective of the current study was to investigate dietary intake in relation to low fat-free mass and abdominal obesity in COPD.

Subjects/Methods: Dietary intake was assessed by a cross-check dietary history method in 564 COPD patients referred for pulmonary rehabilitation. The Dutch Food Composition Database was used to calculate nutrient intake, which was compared with 2006 recommendations from the Dutch Health Council. Body composition was assessed by DEXA scan.

Results: In general, the reported intake of macronutrients represented a typical Western diet. With regard to micronutrients, vitamin $\mathrm{D}$ and calcium intake was below recommendations in the majority of patients (>75\%), while vitamin A, C and $E$ intake was below recommendations in over one third of patients. Patients with inadequate vitamin $\mathrm{D}$ intake more frequently reported low intake of protein $(P=0.02)$ and micronutrients $(P<0.001)$. Patients with a low fat free mass index more often had low intake of protein, while abdominal obese patients more often had low intake of protein and most micronutrients $(P<0.05)$. Patients with both low fat free mass index and abdominal obesity appeared most susceptible for a poor dietary quality.

Conclusions: Our data indicate that dietary quality is low in COPD patients referred for pulmonary rehabilitation and differs between patients with different body composition profiles. 


\section{INTRODUCTION}

Chronic obstructive pulmonary disease (COPD) is characterized by a usually progressive, persistent airflow limitation and an enhanced chronic inflammatory response in the airways (1). COPD is associated with progressive disability and declined health status, although this poorly correlates with severity of pulmonary impairment (2). There is increasing evidence in the literature that COPD should not be considered as a localised pulmonary disorder, but as a systemic disease. Well characterized systemic features are muscle atrophy and weakness and osteoporosis (3). Recently, a high prevalence of abdominal obesity was found in COPD (4) as well as an elevated abdominal visceral fat mass, independent of whole body fat mass, contributing to the increased cardiovascular risk in COPD patients (5).

Common symptoms of COPD that contribute to a poor appetite and altered dietary intake are dyspnoea, fatigue, anxiety and depression (6). So far, dietary intake analysis primarily focused on energy and protein balance in relation to weight loss and muscle wasting $(7,8)$. Dietary intake has recently also been related to COPD risk and progression. Studies have focused on individual nutrients $(9,10)$ or foods $(11)$, as well as on overall dietary patterns (12). Weight loss in COPD can occur due to low dietary intake not balancing elevated energy requirements (13) or due to anorexia (6) On the contrary, higher intake of dietary (saturated) fat is an important factor for the development of abdominal obesity (14).

Surprisingly limited studies have investigated dietary quality in more advanced disease. In a small group ( $n=17$ ) of Swedish elderly underweight $\left(B M I \leq 20 \mathrm{~kg} / \mathrm{m}^{2}\right)$ patients with established severe COPD, it was reported that energy and protein intake were in line with recommendations for healthy people (15). Intake of saturated fatty acids was higher than recommended, while intake of polyunsaturated fatty acids and vitamin D was below recommendations. Furthermore, a Spanish group of 275 moderate-to-severe COPD patients reported an adequate intake of macro- and micronutrients according to local recommendations, except for vitamin D (16). A recent study in 251 COPD patients in South Korea showed that patients with different states of disease severity differ in dietary intake, as total calorie intake was higher in patients with BODE stage 1 than in BODE stage 2, but this was not reflected in significant differences in nutrient intake (17).

The question arises whether diet represents another lifestyle factor, next to physical inactivity and smoking, which is associated with or may accelerate existing abnormalities in body composition. Therefore, the aim of the current study was to investigate the quality of macro- and micronutrient intake in relation to body composition profiles in COPD patients referred for pulmonary rehabilitation. 


\section{SUBJECTS AND METHODS}

\section{Subjects}

The study population was recruited from $\mathrm{ClRO}+$, centre of expertise for organ failure in Horn, the Netherlands, between 2006 and 2009 (18). Inclusion criteria concerned patients with COPD according to the Global Initiative for Chronic Obstructive Lung Disease (GOLD) guidelines (1), which were referred for a pulmonary rehabilitation program by chest physicians from several hospitals in the Southeast of the Netherlands. Patients without DEXA measurements were excluded. In total, 564 patients fulfilled the criteria. Because of the use of de-identified and pre-existing data, our retrospective study is institutional review board exempt.

\section{Measurements}

All measurements were performed at $\mathrm{CIRO}+$ before entering pulmonary rehabilitation, as part of a 3-day baseline assessment (18).

\section{Lung function}

For pulmonary function, post-bronchodilator forced expiratory volume in 1 second (FEV1) and forced vital capacity (FVC) were determined in accordance with the latest GOLD guidelines (1) with standardized equipment (Masterlab ${ }^{\circledR}$, Jaeger, Germany).

\section{Body composition}

Total body height was measured to the nearest $0.5 \mathrm{~cm}$ with a wall mounted stadiometer. Total body weight was assessed to the nearest $0.1 \mathrm{~kg}$ using a weighing scale and body mass index (BMI) was calculated as weight/height ${ }^{2}\left(\mathrm{~kg} / \mathrm{m}^{2}\right)$. Body composition was measured by dual-energy X-ray absorptiometry (Lunar Prodigy system, GE Healthcare, Madison, USA). Fat free mass index (FFMI) was calculated by dividing FFM by height ${ }^{2}$ and the ratio of the percentage fat mass (FM) in the android region (waist) to the percentage FM in the gynoid region (hip) was used as a measure for abdominal fat mass. Low FFMI was defined as a FFMI below $16 \mathrm{~kg} / \mathrm{m}^{2}$ for men and $15 \mathrm{~kg} / \mathrm{m}^{2}$ for women (19). Abdominal obesity was defined as android/gynoid \%fat mass above 1.0 for men and 0.8 for women (20). 


\section{Dietary intake}

Habitual dietary intake of the last month, including intake of oral nutritional supplements, was assessed by three trained dieticians using a validated cross-check dietary history method and calculated using the Dutch Food Composition Database. In this database, intake of alcohol is separately described, but not taken into account in the current analyses as there were no recommended daily intake (RDI) values.

Dietary intake was individually compared to gender- and age group-specific Dutch governmental recommendations in energy percentages (E\%) for macronutrients and in absolute terms for specific micronutrients (vitamin A, C, D, E and calcium). These exact RDI values were used as strict cut-off values to categorize dietary intake (e.g. above RDI, adequate or below RDI) (Table 1). Protein intake was also expressed per kilogram body weight (g/kg body weight) as recommendations are adjusted for body weight.

Table 1. Reference daily intake (RDI).

\begin{tabular}{|c|c|c|c|c|c|c|}
\hline & $31-50 y$ & $51-60 y$ & $61-70 y$ & $>70 y$ & Upper limit & Ref. \\
\hline \multicolumn{7}{|l|}{ Macronutrients } \\
\hline Protein, E\% & $10-25$ & $10-25$ & $10-25$ & $10-25$ & & $(21)$ \\
\hline Protein, g/kg BW & $\begin{array}{l}0.8 \text { (normal) } \\
1.5 \text { (low FFMI) }\end{array}$ & $\begin{array}{l}0.8 \text { (normal) } \\
1.5 \text { (low FFMI) }\end{array}$ & $\begin{array}{l}0.8 \text { (normal) } \\
1.5 \text { (low FFMI) }\end{array}$ & $\begin{array}{l}0.8 \text { (normal) } \\
1.5 \text { (low FFMI) }\end{array}$ & & (22) \\
\hline $\mathrm{CHO}, \mathrm{E} \%$ & $40-70$ & $40-70$ & $40-70$ & $40-70$ & & (23) \\
\hline Fat total, E\% & $20-40$ & $20-40$ & $20-40$ & $20-40$ & & (23) \\
\hline Saturated FA, E\% & a.l.a.p. & a.l.a.p. & a.l.a.p. & a.l.a.p. & 10 & (23) \\
\hline PUFA, E\% & & & & & 12 & (23) \\
\hline \multicolumn{7}{|l|}{ Micronutrients } \\
\hline Vitamin A, mcg & $\begin{array}{l}1000(\mathrm{M}) \\
800(\mathrm{~F})\end{array}$ & $\begin{array}{l}1000(\mathrm{M}) \\
800(\mathrm{~F})\end{array}$ & $\begin{array}{l}1000(\mathrm{M}) \\
800(\mathrm{~F})\end{array}$ & $\begin{array}{l}1000(\mathrm{M}) \\
800(\mathrm{~F})\end{array}$ & 3000 & (24) \\
\hline Vitamin C, mg & 70 & 70 & 70 & 70 & 2000 & \\
\hline Vitamin D, mcg & 2.5 & 5 & 7.5 & 12.5 & 100 & (25) \\
\hline Vitamin $\mathrm{E}, \mathrm{mg}$ & $\begin{array}{l}11.8(\mathrm{M}) \\
9.3(\mathrm{~F})\end{array}$ & $\begin{array}{l}10.7(M, 50-65 y) \\
8.7(F, 50-65 y)\end{array}$ & $\begin{array}{l}9.4(M,>65 y) \\
8.3(F,>65 y)\end{array}$ & $\begin{array}{l}9.4(\mathrm{M}) \\
8.3(\mathrm{~F})\end{array}$ & 300 & \\
\hline Calcium, mg & 1000 & 1100 & 1100 & 1200 & 2500 & (26) \\
\hline
\end{tabular}

Overview of the specific Dutch governmental RDI's used for comparison with individual dietary intake. Abbreviations: $\mathrm{BW}=$ body weight; $\mathrm{FFMI}=$ fat free mass; $\mathrm{CHO}=$ carbohydrate; $\mathrm{FA}=$ fatty acid; $\mathrm{PUFA}=$ poly unsaturated fatty acid; a.I.a.p. = as low as possible; $M=$ males; $F=$ females.

\section{Statistical analysis}

Patients were studied as a group and stratified by abnormal body composition: low FFMI, or abdominal obesity or both.

All statistical analyses were performed using the Statistical Package for Social Sciences version 20.0 (SPSS, Inc., Chicago, IL, USA). Two-sided P values <0.05 were considered 
statistically significant. All data were first assessed for normal distribution. FEV ${ }_{1}$, $\mathrm{FEV}_{1} / \mathrm{VC}$, protein intake (expressed in $\mathrm{g} / \mathrm{kg}$ body weight), calcium and vitamin $\mathrm{A}, \mathrm{C}, \mathrm{D}$ and $E$ were not normally distributed and thus log transformed for analyses. Continuous variables were presented as median \pm interquartile range and were compared by the Student's t test for independent samples and one way ANOVA. Discrete variables were presented as percentages and compared by the chi squared test.

Not all data were available for the total study group. Data for abdominal obesity classification were missing in 130 patients; lung function data were missing in two patients; and in the vitamin $\mathrm{C}$ data one extreme outlier was deleted.

\section{RESULTS}

\section{Subject characteristics}

In total, 564 patients ( $57 \%$ men) were included in the analyses. The group was characterized by moderate to severe airflow obstruction (Table 2). Male patients were of older age than female patients, had a comparable BMI, a higher FFMI and higher degree of airflow limitation. Despite a normal median BMI, almost a quarter of the patients had a low FFMI and more than three quarter was abdominal obese.

\section{Quality of dietary intake}

The current COPD sample had a median total energy intake of 2018 (1664 - 2498) kcal. Median macronutrient composition comprised 44.3 E\% carbohydrates, $37.1 \mathrm{E} \%$ fat, of which 13.5 E\% saturated fat, and 15.0 E\% protein, representing a typical Western diet. Apart from a higher total energy and vitamin D intake and a lower vitamin $C$ in men, dietary intake was not significantly different between men and women (Table 2).

Figure 1 categorizes the macro- and micronutrient intake according to age-dependent governmental recommendations for healthy subjects. Compared to the RDI (expressed in energy percentages), only $2 \%$ of the patients had a low dietary protein intake. Nevertheless, this proportion increased to $30 \%$ of all patients when protein intake was expressed per kg body weight. Carbohydrate intake was lower than recommended in $26 \%$ of patients, while dietary fat intake was too high in almost one third of the patients. Especially saturated fat was frequently consumed too much (89\% of patients). Almost all patients showed an adequate consumption of poly-unsaturated fatty acids (PUFA). On the level of micronutrients, intake of vitamin $D$ often appeared to be lower than recommended (78\% of patients), followed by too low calcium intake ( $72 \%$ of patients). In line, absolute intake was below RDI for vitamin A (34\% of women vs. $48 \%$ of men; $P=$ 
0.001), for vitamin C (35\% of patients) and for vitamin E (33\% of patients). Therefore, further analyses were performed for men and women together.

Table 2. Characteristics and dietary intake of the patient group, stratified by gender.

\begin{tabular}{|c|c|c|c|}
\hline & Women $(n=245)$ & Men $(n=319)$ & P-value \\
\hline \multicolumn{4}{|l|}{ Characteristics } \\
\hline Age, years & $62.0(56.0-69.0)$ & $67.0(60.0-73.0)$ & $<0.001$ \\
\hline Length, cm & $160.0(155.0$ - 165.0) & $172.0(168.0$ - 177.0) & $<0.001$ \\
\hline Weight, kg & 63.6 (53.9 - 71.5) & $73.7(64.8$ - 83.1) & $<0.001$ \\
\hline $\mathrm{BMI}, \mathrm{kg} / \mathrm{m}^{2}$ & $25.0(21.2-28.3)$ & $25.0(21.9-27.9)$ & 0.714 \\
\hline FFM, kg & $40.2(37.2-43.3)$ & $54.1(49.2-58.6)$ & $<0.001$ \\
\hline $\mathrm{FFMI}, \mathrm{kg} / \mathrm{m}^{2}$ & $15.5(14.7-16.8)$ & $18.2(16.8-19.5)$ & $<0.001$ \\
\hline Low FFMI, \% & 33.5 & 14.7 & $<0.001$ \\
\hline Abdominal obese, $\%$ & 74.5 & 80.0 & 0.171 \\
\hline $\mathrm{FEV}_{1}, \%$ of predicted & $51.0(33.5-65.5)$ & $43.0(32.0-62.0)$ & 0.017 \\
\hline FVC, $\%$ of predicted & $101.0(84.0$ - 118.0) & $95.0(80.0$ - 111.0) & 0.016 \\
\hline $\mathrm{FEV}_{1} / \mathrm{NC}, \%$ & $39.0(32.0-51.0)$ & $35.0(28.0-45.0)$ & $<0.001$ \\
\hline \multicolumn{4}{|l|}{ Dietary intake } \\
\hline Total energy, kcal & $1852(1545-2271)$ & $2118(1769-2586)$ & $<0.001$ \\
\hline Protein, E\% & $15(13-17)$ & $15(13-17)$ & 0.858 \\
\hline Protein, g/kg BW & $1.1(0.9-1.4)$ & $1.0(0.9-1.4)$ & 0.220 \\
\hline $\mathrm{CHO}, \mathrm{E} \%$ & $45(40-50)$ & $44(39-49)$ & 0.173 \\
\hline Fat total, E\% & $37(34-41)$ & $37(33-41)$ & 0.714 \\
\hline Saturated FA, E\% & $14(12-17)$ & $13(12-16)$ & 0.241 \\
\hline PUFA, E\% & $7(6-8)$ & $7(6-9)$ & 0.072 \\
\hline Vitamin A, mcg & $934(718-1248)$ & 1025 (797 - 1269) & 0.069 \\
\hline Vitamin C, mg & $93(58-139)$ & $82(56-117)$ & 0.028 \\
\hline Vitamin D, mcg & $4(3-6)$ & $5(4-7)$ & $<0.001$ \\
\hline Vitamin E, mg & $12(8-18)$ & $12(9-17)$ & 0.347 \\
\hline Calcium, mg & $923(689-1205)$ & $857(667-1158)$ & 0.500 \\
\hline
\end{tabular}

Results are presented as median (interquartile range) unless otherwise indicated and were compared by the Student's t test for independent samples. Results of statistical analysis showed that men differed from women in age, length, weight, FFM, FFMI and airflow limitation and dietary intake of vitamin C and D. Abbreviations: $\mathrm{BMI}=$ body mass index; FFM = fat free mass; FFMI = FFM-index; $F E V_{1}=$ forced expiratory volume in one second; FVC = forced vital capacity; $\mathrm{BW}=$ body weight; $\mathrm{CHO}=$ carbohydrate; $\mathrm{FA}=$ fatty acid; $\mathrm{PUFA}=$ poly unsaturated fatty acid. 


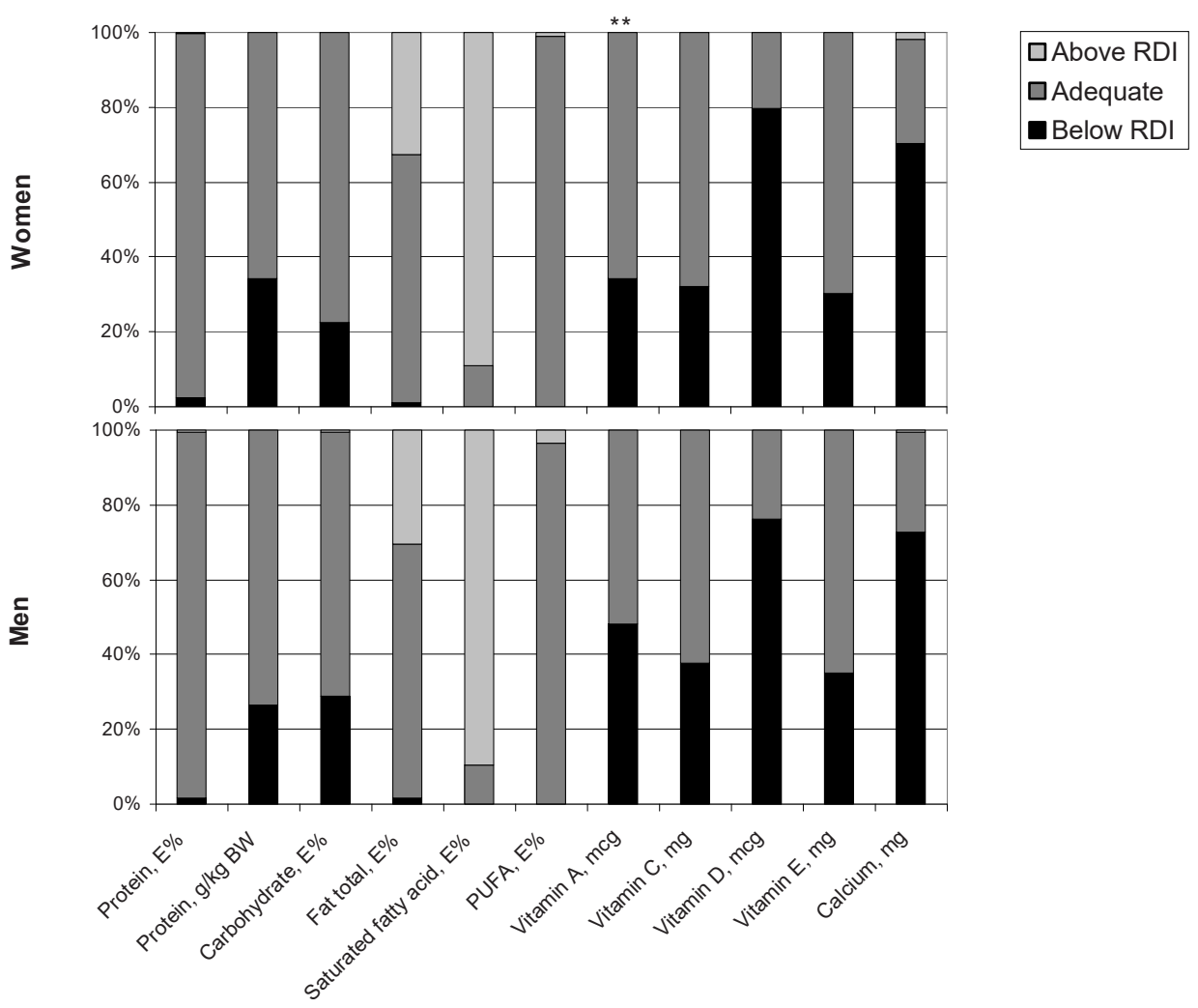

Figure 1. Quality of macro- and micronutrient intake, stratified by gender.

Legend: Quality of dietary intake was compared by the chi squared test between men $(n=319)$ and women ( $n$ =245). Results of statistical analysis showed that men differed from women in quality of dietary intake of vitamin A. Symbols: Asterisks indicate a significant difference between groups: ${ }^{*} P<0.05, * * P<0.01$.

\section{Inadequate vitamin D intake}

As vitamin D was identified as a major dietary deficiency (78\% of patients), sub-analyses were performed to further compare dietary intake between patients with adequate and inadequate vitamin D intake (Figure 2). The subgroup with inadequate vitamin D intake had a significantly higher prevalence of too low intake of protein per kg body weight $(P$ $=0.02$ ), vitamin $A, C$ and $E$ and calcium (all at $P<0.001$ ). On the contrary, the prevalence of a PUFA intake above recommendations was significantly lower $(P=0.02)$. 

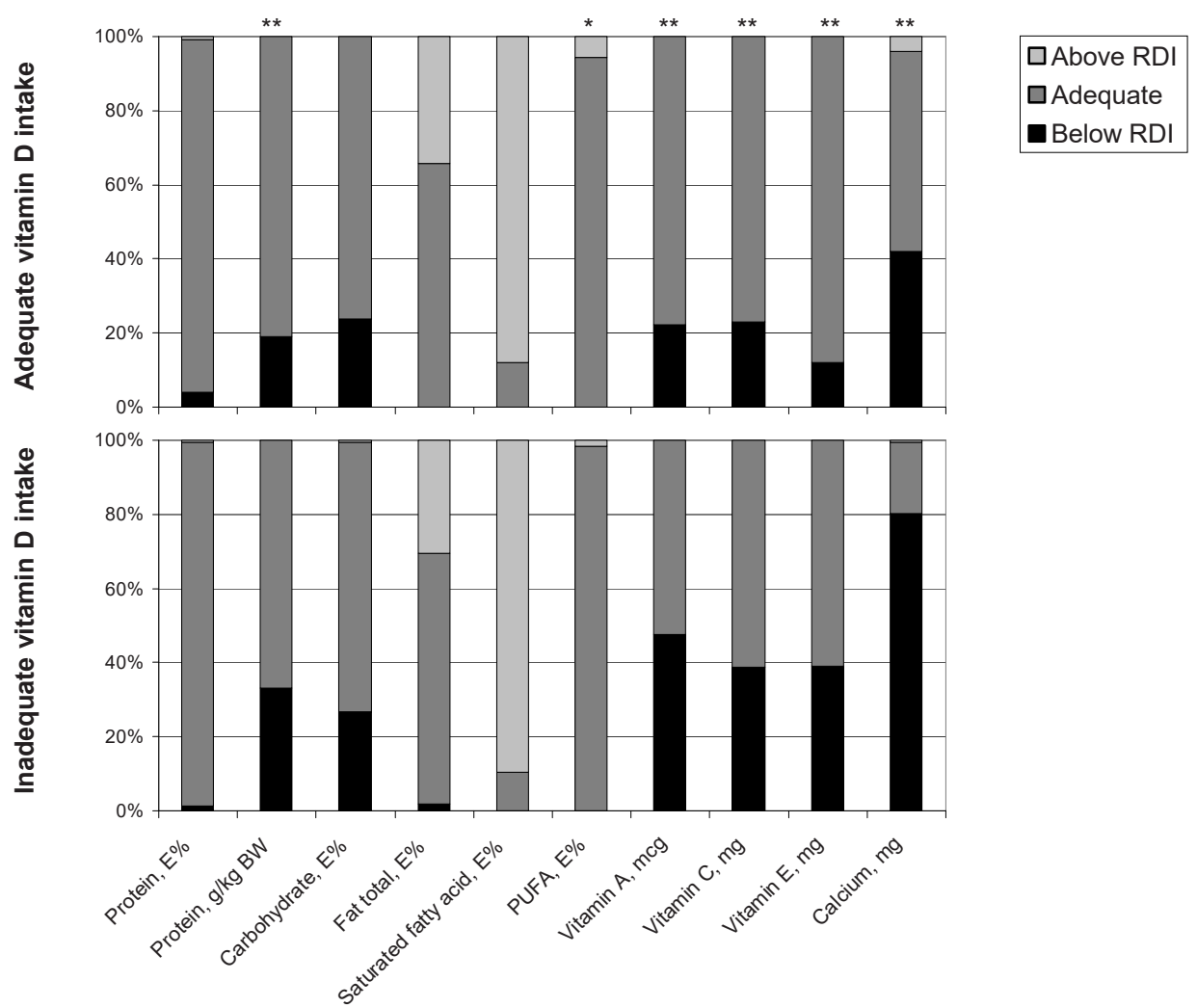

Figure 2. Quality of macro- and micronutrient intake, stratified by adequacy of vitamin D intake.

Legend: Quality of dietary intake was compared by the chi squared test between patients with $(n=126)$ and without ( $n=438$ ) an adequate vitamin D intake. Results of statistical analysis showed that patients with inadequate intake of vitamin $D$ differed from patients with adequate of vitamin $D$ in quality of dietary intake of protein ( $\mathrm{g} / \mathrm{kg}$ bodyweight), PUFA, vitamin A, C, D and E and calcium. Symbols: Asterisks indicate a significant difference between groups: ${ }^{*} P<0.05, * * P<0.01$.

\section{LoW FFMI}

Almost a quarter of the total patient group had a low FFMI (FFMI $<16 \mathrm{~kg} / \mathrm{m}^{2}$ for men and $<15 \mathrm{~kg} / \mathrm{m}^{2}$ for women). This subgroup was characterized by younger age and higher degree of airflow limitation than the subgroup with normal FFMI (see supplemental data). Table 3 shows dietary intake after stratification for FFMI. Patients with low FFMI reported significantly higher energy intake. Although patients with a low FFMI had a lower protein intake expressed in E\%, protein intake per kg bodyweight was higher. Patients with low FFMI also had a higher carbohydrate intake, but comparable fat intake. Interestingly, micronutrient intake tended to be higher in patients with a low FFMI, although this was only significant for vitamin A and calcium. 


\section{Chapter 4}

Table 3. Dietary intake after stratification for low FFMI and after stratification for abdominal obesity.

\begin{tabular}{|c|c|c|c|}
\hline & Normal FFMI $(n=435)$ & Low FFMI $(n=129)$ & P-value \\
\hline Total energy, kcal & $1983(1630-2432)$ & $2171(1765-2747))$ & 0.001 \\
\hline Protein, E\% & $15(14-17)$ & $14(12-16)$ & $<0.001$ \\
\hline Protein, g/kg BW & $1.0(0.8-1.3)$ & $1.3(1.0-1.8)$ & $<0.001$ \\
\hline $\mathrm{CHO}, \mathrm{E} \%$ & $44(39-49)$ & $46(41-51)$ & 0.026 \\
\hline Fat total, E\% & $37(34-41)$ & $37(33-41)$ & 0.329 \\
\hline Saturated FA, E\% & $14(12-16)$ & $13(11-17)$ & 0.154 \\
\hline PUFA, E\% & $7(6-9)$ & $7(5-8)$ & 0.006 \\
\hline Vitamin A, mcg & $947(743-1212)$ & $1122(796-1458)$ & 0.022 \\
\hline Vitamin C, mg & $85(57-118)$ & $104(57-137)$ & 0.198 \\
\hline Vitamin D, mcg & $4(3-6)$ & $5(3-8)$ & 0.197 \\
\hline Vitamin $\mathrm{E}, \mathrm{mg}$ & $12-(8-16)$ & $13(8-20)$ & 0.270 \\
\hline \multirow[t]{2}{*}{ Calcium, mg } & $857(652-1153)$ & $966(704-1370)$ & 0.002 \\
\hline & Non-abdominal obese $(n=97)$ & Abdominal obese $(n=337)$ & P-value \\
\hline Total energy, kcal & $2316(1881-2833)$ & $1957(1594-2311)$ & $<0.001$ \\
\hline Protein, E\% & $14(12-16)$ & $15(13-17)$ & $<0.001$ \\
\hline Protein, g/kg BW & $1.4(1.1-1.8)$ & $1.0(0.8-1.2)$ & $<0.001$ \\
\hline $\mathrm{CHO}, \mathrm{E} \%$ & $47(41-51)$ & $44(40-49)$ & 0.049 \\
\hline Fat total, E\% & $37(34-41)$ & $37(34-41)$ & 0.527 \\
\hline Saturated FA, E\% & $14(11-16)$ & $13(11-16)$ & 0.338 \\
\hline PUFA, E\% & $7(6-9)$ & $7(6-8)$ & 0.851 \\
\hline Vitamin A, mcg & $1090(778-1415)$ & $937(730-1227)$ & 0.006 \\
\hline Vitamin C, mg & $97(57-138)$ & $83(55-118)$ & 0.385 \\
\hline Vitamin D, mcg & $6(4-8)$ & $4(3-6)$ & $<0.001$ \\
\hline Vitamin $\mathrm{E}, \mathrm{mg}$ & $14(9-22)$ & $12(8-16)$ & 0.001 \\
\hline Calcium, mg & $961(726-1392)$ & $846(651-1132)$ & 0.001 \\
\hline
\end{tabular}

Results are presented as median (interquartile range) and were compared by the Student's t test for independent samples. Results of statistical analysis showed that patients with low FFMI differed from patients with normal FFMI in dietary intake of protein, carbohydrates, PUFA, vitamin A and calcium. Abdominal obese patients differed from non-abdominal obese patients in dietary intake of protein, carbohydrates, vitamin $A, D$, $\mathrm{E}$ and calcium. Abbreviations: $\mathrm{BW}=$ body weight; $\mathrm{CHO}=$ carbohydrate; $\mathrm{FA}=$ fatty acid; $\mathrm{PUFA}=$ poly unsaturated fatty acid.

Nutritional supplements were used by one third of the patients with a low FFMI in an attempt to meet their dietary requirements. Nonetheless, the percentage of patients with intakes of protein, carbohydrate and micronutrients below recommendations was lower in those using nutritional supplements than in those not using nutritional supplements (data not shown). 


\section{Abdominal obesity}

More than $75 \%$ of the patients were abdominal obese (android/gynoid \%fat mass $>1.0$ for men and $>0.8$ for women). This subgroup was characterized by older age and lower degree of airflow limitation than the non-abdominal obese subgroup (see supplemental data).

Table 3 shows dietary intake after stratification for abdominal obesity. Abdominal obese patients reported significantly lower energy intake. Apart from a comparable fat intake, abdominal obese patients received proportionally more energy from protein intake and less from carbohydrate intake than non-abdominal obese patients. On the level of micronutrients, dietary intake of vitamin A, D, E and calcium was significantly lower in abdominal obese patients.

\section{Low FFMI and abdominal obesity}

As stratification for body composition revealed a substantial overlap in patients with low FFMI and abdominal obesity, sub-analyses were performed to further compare characteristics (see supplemental data) and dietary intake in patients with different body composition profiles (Figure 3).

Only $15 \%$ of the patients had a normal body composition (normal FFMI + nonabdominal obese), while the majority (63\%) had a normal FFMI but was abdominal obese. Merely $8.3 \%$ of the patients had a low FFMI only while almost $15 \%$ showed both a low FFMI and abdominal obesity.

There were significant differences in dietary intake between the different body compositional profiles. The patients with normal body composition had the lowest prevalence of protein intake below recommendations ( $\mathrm{g} / \mathrm{kg}$ body weight), as opposed to patients with both low FFMI and abdominal obesity, who had the highest prevalence. On top of this, abdominal obese patients with a low FFMI more often had an intake of vitamin A, $D, E$ and calcium lower than recommended than non-abdominal obese patients with a low FFMI. 

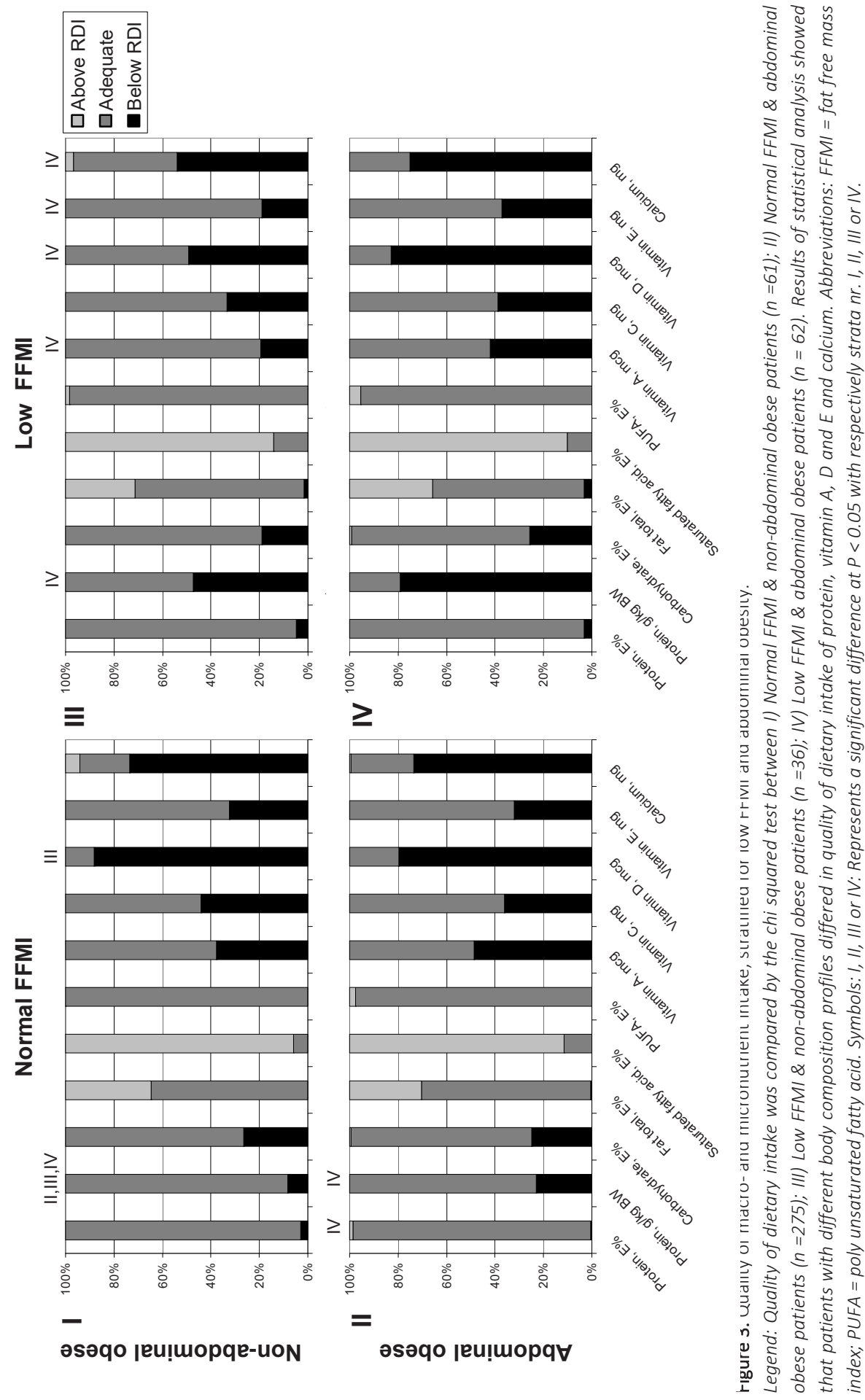


\section{DISCUSSION}

The present study highlights a poor dietary quality in a substantial part of COPD patients referred for pulmonary rehabilitation. Moreover, disturbances in body composition were associated with striking differences in macro- and micronutrient intake.

The results of a too low intake of protein (per kg body weight), carbohydrate, vitamins (especially vitamin D) and calcium, next to a too high intake of (saturated) fat, typically reflects the Western diet, which not only increases cardiovascular risk but has also been associated with the risk and progression of respiratory disease (12).

Unfortunately, no data are yet available on dietary intake in Dutch elderly ( $>70$ years). However, according to the Dutch National Food Consumption survey 2007-2010, 17 $21 \%$ of Dutch older adults (51-69 years) had a low intake of vitamin A, a small percentage had a low intake of vitamin C, E and calcium, and median total vitamin D intake was below RDI (27). In the current COPD patients, the reported percentages of patients with micronutrient intake below recommendations were remarkably higher and vitamin $D$ was identified as the major deficiency.

The current finding of a high prevalence of inadequate intake of vitamin $D$ in COPD patients $(78 \%)$ was in accordance with earlier findings in a small group $(n=17)$ of Swedish underweight (BMI $\leq 20 \mathrm{~kg} / \mathrm{m}^{2}$ ) elderly with established severe COPD. They found that intake of vitamin D was below recommendations, which may contribute to osteoporosis (15). Also in a Spanish group of 275 moderate-to-severe COPD patients merely $11 \%$ accomplished the daily recommendations of $10 \mathrm{mg} / \mathrm{d}$ vitamin D intake, comparable with the Dutch RDI (16). Nonetheless, it was suggested in that study that the elevated sunlight exposure in Mediterranean countries may complete the low dietary intake by a high vitamin D dermic synthesis. However, the included subjects in the present study all lived in the Netherlands, with less sun exposure than in Spain. Together with the fact that elderly already have a poorer ability of the skin to synthesize vitamin D (28), our population might be at risk of inadequate vitamin $D$ intake and production. Indeed, recent data from patients entering our pulmonary rehabilitation centre have shown that vitamin D deficiency, measured as plasma 25(OH)D concentration below $50 \mathrm{nmol} / \mathrm{l}$, was present in 58\% (29), which is higher than the reported $40 \%$ in healthy Dutch adults (30). Unfortunately, we did not have data on vitamin D status in the present study, thus no correlation between vitamin $D$ intake and its plasma levels could be made. Nonetheless, previous research could not detect a correlation (29).

Our finding of a low vitamin $D$ intake deserved further investigation since vitamin $D$ deficiency not only appears to be involved in the development of osteoporosis (29), but also in several other COPD-related disease features including impaired lung function (31), compromised immune function, and impaired muscle strength and function (32). Patients with inadequate vitamin $\mathrm{D}$ intake had a less balanced dietary intake, as reflected 
by protein and micronutrients. Dietary sources for vitamin D are fatty fish, butter, dairy products and cheese, as is calcium. Vitamin A is particularly present in animal products and liver, vitamin $\mathrm{C}$ in fruit and vegetables and vitamin $\mathrm{E}$ in vegetable oils, nuts, seeds, fruit and vegetables. Consequently, low vitamin D intake appears to reflect a poor dietary quality in general and simply recommending a vitamin $D$ supplement would likely not cover all dietary needs in these patients. As it is also suggested that a dietary shift to higher-antioxidant food intake may be associated with improvement in lung function (33), more attention for dietary quality is warranted in COPD management.

According to the recent Cochrane review there is moderate-quality evidence for nutritional supplementation in the management of malnourished patients with COPD (34). In the current study, almost $25 \%$ of the patients were characterized by a low FFMI. There was a specific interest in protein intake in this subgroup as a potential limiting factor for muscle protein synthesis (35) and in view of the reported elevated whole body protein turnover (36). More than $60 \%$ of the patients with low FFMI had an inadequate protein intake (nutrition + supplements) per kg body weight considering a recommended lower limit of $1.5 \mathrm{~g} / \mathrm{kg}$ body weight. This level of protein intake, if possible in combination with physical exercise, is necessary to achieve a positive protein balance. Nonetheless, the prevalence of an inadequate dietary intake was lower in the patients using nutritional supplements, confirming that nutrition supplementation is able to enhance dietary intake from a qualitative perspective.

Cardiovascular disease is the major cause of death in mild to moderate COPD and abdominal obesity is a well-established risk factor (5). A very high proportion of $77 \%$ of the study population met the criteria for abdominal obesity. Although the general population reported a high fat intake, abdominal obese patients did not have a higher fat intake compared to non-abdominal obese patients. In general, abdominal obese patients had a higher prevalence of inadequate micronutrient intake. We had no data on specific food product intake, but from these results it can be suggested that the patients with abdominal obesity consume less nutrient rich products compared to patients without abdominal obesity. Up till now, no studies reported nutrient intake in a specific subgroup of abdominal obese COPD patients. Only, in the Spanish cohort lower levels of energy and calcium intake were reported in patients with a $\mathrm{BMI} \geq 30 \mathrm{~kg} / \mathrm{m}^{2}$ compared with the remaining patients (16). However, a study with healthy Mexican elderly, confirmed our findings that micronutrient intake was inadequate in obese subjects (37).

Additionally, stratification for body composition revealed a subgroup of abdominal patients with low FFMI, characterized by less adequate protein and micronutrient intake. Patients with this body composition profile deserve specific attention as the combination of low FFMI and abdominal obesity can lead to adverse metabolic health (38).

Some shortcomings of the current study need to be considered. Unfortunately, no healthy control group could be included in the present analyses in order to directly 
compare the classification of macro- and micronutrient intake between COPD patients and healthy subjects. Nonetheless, results were compared with findings in general Dutch older adults from the Dutch National Food Consumption Survey (27). Additionally, no data were available on vitamin D status to compare with vitamin D uptake, although previous research could not detect a correlation (29). Furthermore, the assessment of dietary intake could have led to some information bias, as dietary (fat) intake might be under-estimated in obese subjects (39) and overestimated in underweight subjects. However, we incline to rule out the possibility of overestimation of dietary intake in patients with low FFMI, as previous research provided proof of accurate reporting of food intake in depleted COPD patients (7). Furthermore, a higher energy intake can be expected in patients with a low FFMI because of their risk of increased energy expenditure (40). In the present study the cross-check dietary history technique was applied by trained dieticians and has the advantage that it provides a profile of the habitual dietary intake, contrary to food records and 24 hour-recalls. The food frequency method is generally applied in order to assess the quality of dietary intake, because it is able to provide clear insight into particular food product groups. Nonetheless, food consumption might be missed by the focus on food product groups rather than specific food products. Overall, the reliability and validity of the dietary history with cross-check are generally accepted (41). However, we cannot rule out that the lower energy intake in abdominal obese patients found in the present study is no result of under- and overestimation.

In conclusion, we demonstrated that daily intake of macro- and micronutrient was often below recommendations in COPD patients. The greatest deficiency identified was vitamin $D$, which reflected a poorer dietary quality in general. Furthermore, disturbances in body composition were associated with differences in micro- and macronutrient intake. The lowest quality of dietary intake was found in the patients with abdominal obesity on top of a low FFMI. Our findings implicate that dieticians should not only be aware of patients with low FFMI needing nutritional energy or protein rich supplementation, but also of inadequate micronutrient intake such as vitamin D, A, E and calcium in all patients. 


\section{REFERENCES}

1. Vestbo J, Hurd SS, Agusti AG, Jones PW, Vogelmeier C, Anzueto A, Barnes PJ, Fabbri LM, Martinez FJ, Nishimura M, Stockley RA, Sin DD, Rodriguez-Roisin R. Global strategy for the diagnosis, management, and prevention of chronic obstructive pulmonary disease: Gold executive summary. Am J Respir Crit Care Med 2013;187:347-365.

2. Antonelli-Incalzi R, Imperiale C, Bellia V, Catalano F, Scichilone N, Pistelli R, Rengo F. Do gold stages of copd severity really correspond to differences in health status? Eur Respir J 2003;22:444-449.

3. Patel AR, Hurst JR. Extrapulmonary comorbidities in chronic obstructive pulmonary disease: State of the art. Expert Rev Respir Med 2011;5:647-662.

4. Rutten EP, Breyer MK, Spruit MA, Hofstra T, van Melick PP, Schols AM, Wouters EF. Abdominal fat mass contributes to the systemic inflammation in chronic obstructive pulmonary disease. Clin Nutr 2010;29:756-760.

5. van den Borst B, Gosker HR, Koster A, Yu B, Kritchevsky SB, Liu Y, Meibohm B, Rice TB, Shlipak M, Yende $S$, Harris TB. The influence of abdominal visceral fat on inflammatory pathways and mortality risk in obstructive lung disease. Am J Clin Nutr 2012;96:516-526.

6. Gronberg AM, Slinde F, Engstrom CP, Hulthen L, Larsson S. Dietary problems in patients with severe chronic obstructive pulmonary disease. J Hum Nutr Diet 2005;18:445-452.

7. Goris AH, Vermeeren MA, Wouters EF, Schols AM, Westerterp KR. Energy balance in depleted ambulatory patients with chronic obstructive pulmonary disease: The effect of physical activity and oral nutritional supplementation. Br J Nutr 2003;89:725-731.

8. Schols AM, Wouters EF. Nutritional abnormalities and supplementation in chronic obstructive pulmonary disease. Clin Chest Med 2000;21:753-762.

9. Shaheen SO, Jameson KA, Robinson SM, Boucher BJ, Syddall HE, Sayer AA, Cooper C, Holloway JW, Dennison EM. Relationship of vitamin d status to adult lung function and copd. Thorax 2011;66:692-698.

10. McKeever TM, Lewis SA, Cassano PA, Ocke M, Burney P, Britton J, Smit HA. The relation between dietary intake of individual fatty acids, fev1 and respiratory disease in dutch adults. Thorax 2008;63:208-214.

11. Hirayama F, Lee AH, Binns CW, Zhao Y, Hiramatsu T, Tanikawa Y, Nishimura K, Taniguchi H. Soy consumption and risk of copd and respiratory symptoms: A case-control study in japan. Respir Res 2009;10:56.

12. Varraso R, Fung TT, Hu FB, Willett W, Camargo CA. Prospective study of dietary patterns and chronic obstructive pulmonary disease among us men. Thorax 2007;62:786-791.

13. Schols AM, Soeters PB, Mostert R, Saris WH, Wouters EF. Energy balance in chronic obstructive pulmonary disease. Am Rev Respir Dis 1991;143:1248-1252.

14. Bray GA, Paeratakul S, Popkin BM. Dietary fat and obesity: A review of animal, clinical and epidemiological studies. Physiol Behav 2004;83:549-555.

15. Andersson I, Gronberg A, Slinde F, Bosaeus I, Larsson S. Vitamin and mineral status in elderly patients with chronic obstructive pulmonary disease. Clin Respir J 2007;1:23-29.

16. de Batlle J, Romieu I, Anto JM, Mendez M, Rodriguez E, Balcells E, Ferrer A, Gea J, Rodriguez-Roisin R, Garcia-Aymerich J. Dietary habits of firstly admitted spanish copd patients. Respir Med 2009;103:19041910.

17. Lee H, Kim S, Lim Y, Gwon H, Kim Y, Ahn JJ, Park HK. Nutritional status and disease severity in patients with chronic obstructive pulmonary disease (copd). Arch Gerontol Geriatr 2013;56:518-523.

18. Spruit MA, Vanderhoven-Augustin I, Janssen PP, Wouters EF. Integration of pulmonary rehabilitation in copd. Lancet 2008;371:12-13.

19. Schols AM, Soeters PB, Dingemans AM, Mostert R, Frantzen PJ, Wouters EF. Prevalence and characteristics of nutritional depletion in patients with stable copd eligible for pulmonary rehabilitation. Am Rev Respir Dis 1993;147:1151-1156.

20. Bjorntorp P. Regional patterns of fat distribution. Ann Intern Med 1985;103:994-995.

21. Gezondheidsraad. Richtlijnen goede voeding 2006. Den Haag: Gezondheidsraad, ; 2006; publicatie nr 2006/21. ISBN 90-5549-627-8. 
22. Wolfe RR, Miller SL, Miller KB. Optimal protein intake in the elderly. Clin Nutr 2008;27:675-684.

23. Gezondheidsraad. Voedingsnormen energie, eiwitten, vetten en verteerbare koolhydraten. Den Haag: Gezondheidsraad, ; 2001; publicatie nr 2001/19. ISBN 90-5549-384-8.

24. Gezondheidsraad. Naar een adequate inname van vitamine a. Den Haag: Gezondheidsraad, ; 2008; publicatienr. 2008/26. ISBN 978-90-5549-738-6.

25. Gezondheidsraad. Naar een toereikende inname van vitamine d. Den Haag: Gezondheidsraad, ; 2008; publicatienr. 2008/15. ISBN 978-90-5549-729-4

26. Gezondheidsraad. Voedingsnormen. Den Haag: Gezondheidsraad, ; 2000; publicatie nr 2000/12. ISBN 90-5549-323-6

27. Dutch national food consumption survey 2007-2010.: National Institute for Public Health and the Environment; 2011 No. 350050006/2011.

28. MacLaughlin J, Holick MF. Aging decreases the capacity of human skin to produce vitamin d3. J Clin Invest 1985;76:1536-1538.

29. Romme EA, Rutten EP, Smeenk FW, Spruit MA, Menheere PP, Wouters EF. Vitamin d status is associated with bone mineral density and functional exercise capacity in patients with chronic obstructive pulmonary disease. Ann Med 2013;45:91-96.

30. Voedingsstatus van hindoestaanse en creoolse surinamers en autochtone nederlanders in nederland. Het sunset-onderzoek.: Rijksinstituut voor Volksgezondheid en Milieum (RIVM); 2011 No. $350070003 / 2011$.

31. Zosky GR, Berry LJ, Elliot JG, James AL, Gorman S, Hart PH. Vitamin d deficiency causes deficits in lung function and alters lung structure. Am J Respir Crit Care Med 2011;183:1336-1343.

32. Dirks-Naylor AJ, Lennon-Edwards S. The effects of vitamin d on skeletal muscle function and cellular signaling. J Steroid Biochem Mol Biol 2011;125:159-168.

33. Keranis E, Makris D, Rodopoulou P, Martinou H, Papamakarios G, Daniil Z, Zintzaras E, Gourgoulianis KI. Impact of dietary shift to higher-antioxidant foods in copd: A randomised trial. Eur Respir J 2010;36:774780.

34. Ferreira IM, Brooks D, White J, Goldstein R. Nutritional supplementation for stable chronic obstructive pulmonary disease. Cochrane Database Syst Rev 2012;12:CD000998.

35. Volpi E, Kobayashi H, Sheffield-Moore M, Mittendorfer B, Wolfe RR. Essential amino acids are primarily responsible for the amino acid stimulation of muscle protein anabolism in healthy elderly adults. Am J Clin Nutr 2003;78:250-258.

36. Engelen MP, Deutz NE, Wouters EF, Schols AM. Enhanced levels of whole-body protein turnover in patients with chronic obstructive pulmonary disease. Am J Respir Crit Care Med 2000;162:1488-1492.

37. Martin-Del-Campo F, Nava-Jimenez D, Batis-Ruvalcaba C, Cortes-Sanabria L, Rojas-Campos E, MartinezRamirez HR, Cueto-Manzano AM. Anthropometric and dietary evaluations in a sample of "healthy" mexican older adults. J Nutr Elder 2009;28:287-300.

38. van den Borst B, Gosker HR, Schols AM. Central fat and peripheral muscle: Partners in crime in chronic obstructive pulmonary disease. Am J Respir Crit Care Med 2013;187:8-13.

39. Goris AH, Westerterp-Plantenga MS, Westerterp KR. Undereating and underrecording of habitual food intake in obese men: Selective underreporting of fat intake. Am J Clin Nutr 2000;71:130-134.

40. Creutzberg EC, Schols AM, Bothmer-Quaedvlieg FC, Wouters EF. Prevalence of an elevated resting energy expenditure in patients with chronic obstructive pulmonary disease in relation to body composition and lung function. Eur J Clin Nutr 1998;52:396-401.

41. van Staveren WA, de Boer JO, Burema J. Validity and reproducibility of a dietary history method estimating the usual food intake during one month. Am J Clin Nutr 1985;42:554-559. 
Chapter 4

\section{SUPPLEMENTAL DATA}

Supplementary table 1. Patient characteristics after stratification for low FFMI or abdominal obesity.

\begin{tabular}{|c|c|c|c|}
\hline & $\begin{array}{l}\text { Normal FFMI } \\
(n=435)\end{array}$ & $\begin{array}{l}\text { Low FFMI } \\
(n=129)\end{array}$ & $P$-value \\
\hline Male, $\%$ & 62.5 & 36.4 & $<0.001$ \\
\hline Age, years & $65.0(59.0-73.0)$ & $63.0(57.0-68.5)$ & 0.008 \\
\hline Length, cm & $168.0(161.0-174.5)$ & $164.0(158.0-172.0)$ & 0.003 \\
\hline Weight, kg & $72.6(64.5-82.5)$ & $55.2(49.5-64.1)$ & $<0.001$ \\
\hline BMI, $\mathrm{kg} / \mathrm{m}^{2}$ & $26.2(23.3-29.2)$ & $20.9(19.0-22.6)$ & $<0.001$ \\
\hline FFM, kg & $51.0(43.3-56.8)$ & $38.7(34.6-45.1)$ & $<0.001$ \\
\hline FFMI, $\mathrm{kg} / \mathrm{m}^{2}$ & $17.8(16.6-19.1)$ & $14.6(13.9-15.2)$ & $<0.001$ \\
\hline Abdominal obese, $\%$ & 81.8 & 63.3 & \\
\hline $\mathrm{FEV}_{1}, \%$ of predicted & $49.0(35.0-65.0)$ & $38.0(26.0-56.5)$ & $<0.001$ \\
\hline $\mathrm{FEV}_{1} / \mathrm{VC}, \%$ & $38.0(31.0-48.0)$ & $34.0(27.0-42.5)$ & 0.001 \\
\hline \multirow[t]{2}{*}{ FVC, $\%$ of predicted } & $98.0(83.0-115.0)$ & $90.0(76.0-107.5)$ & $<0.001$ \\
\hline & $\begin{array}{l}\text { Non-abdominal obese } \\
(n=97)\end{array}$ & $\begin{array}{l}\text { Abdominal obese } \\
(n=337)\end{array}$ & P-value \\
\hline Male, \% & 51.5 & 59.3 & NS \\
\hline Age, years & $62.0(54.5-72.0)$ & $65.0(59.0-72.0)$ & 0.026 \\
\hline Length, cm & $167.0(160.0$ - 175.5) & $168.0(160.6$ - 174.0) & NS \\
\hline Weight, kg & $56.4(51.8-66.3)$ & $71.9(63.8-82.8)$ & $<0.001$ \\
\hline BMI, kg/m² & $20.8(19.2-22.3)$ & $25.8(23.4-29.3)$ & $<0.001$ \\
\hline FFM, kg & $45.2(38.6-53.3)$ & $48.9(41.3-56.0)$ & 0.005 \\
\hline FFMI, $\mathrm{kg} / \mathrm{m}^{2}$ & $16.1(14.8-17.6)$ & $17.5(15.7-19.1)$ & $<0.001$ \\
\hline Abdominal obese, $\%$ & 37.1 & 18.4 & $<0.001$ \\
\hline $\mathrm{FEV}_{1}, \%$ of predicted & $43.0(29.5-61.0)$ & $48.0(33.3-65.0)$ & 0.043 \\
\hline $\mathrm{FEV}_{1} / \mathrm{VC}, \%$ & $36.0(26.5-43.5)$ & $38.0(31.0-49.0)$ & 0.028 \\
\hline FVC, $\%$ of predicted & $98.0(80.0-117.5)$ & $98.0(80.0-113.0)$ & NS \\
\hline
\end{tabular}

Results are presented as median (interquartile range) and were compared by the Student's t test for independent samples. Results of statistical analysis showed that patients with low FFMI differed from patients with normal FFMI in age, length, weight, BMI, FFM, FFMI and airflow limitation. Abdominal obese patients differed from non-abdominal obese patients in age, weight, BMI, FFM, FFMI and airflow limitation. Abbrevia-

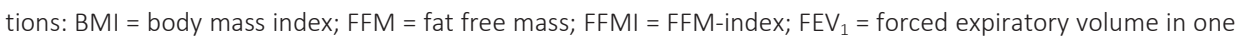
second; FVC = forced vital capacity; NS = not significant. 
Quality of dietary intake in relation to body composition in COPD

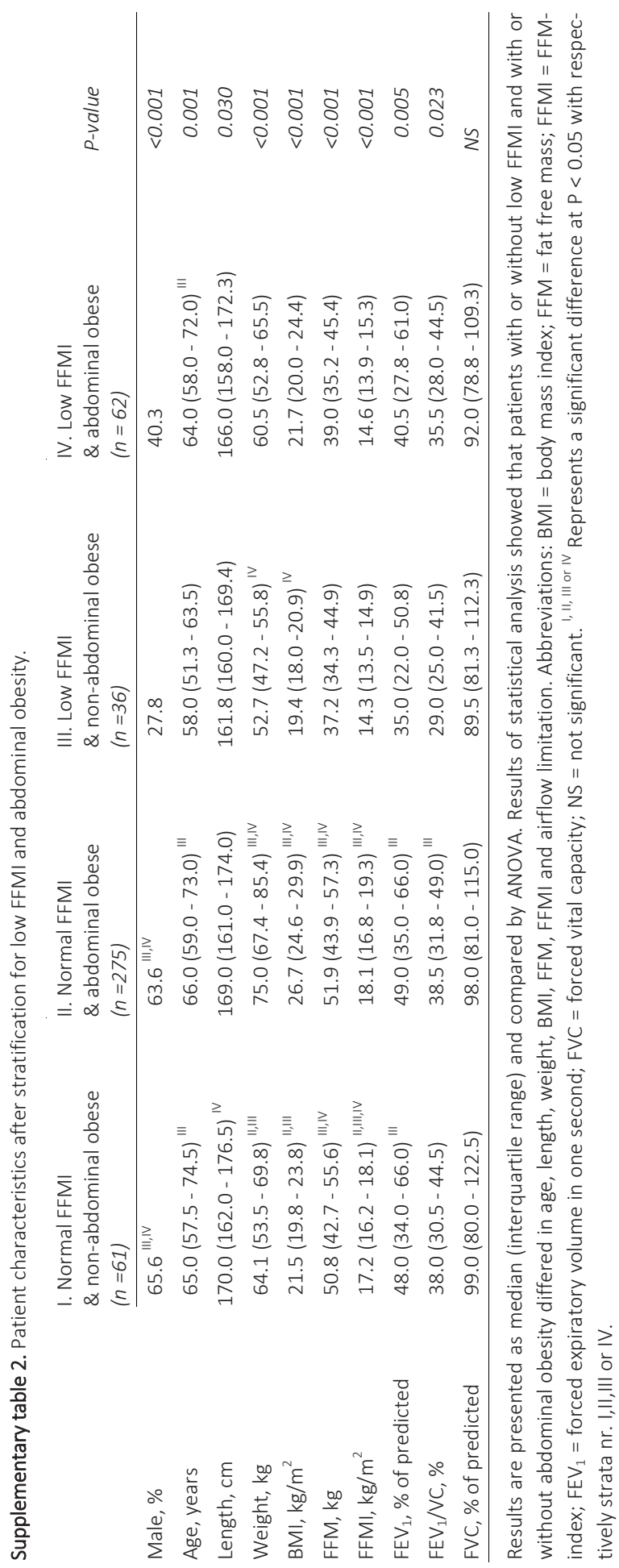





\section{Chapter}

\section{Nutritional targets to enhance exercise performance in COPD}




\section{ABSTRACT}

Purpose of review: This review presents current knowledge regarding the rationale and efficacy of nutrition as an ergogenic aid to enhance the effects of exercise and training in chronic obstructive pulmonary disease (COPD).

Recent findings: Altered body composition and skeletal muscle dysfunction in COPD suggest that exercise capacity can be targeted via several metabolic routes. Muscle metabolic alterations in COPD include a reduced oxidative metabolism and enhanced susceptibility for oxidative stress. Muscle wasting may be associated with deficiencies of vitamin D and low branched-chain amino acids (BCAA) levels. Exercise training is of established benefit in COPD but clear-cut clinical trial evidence to support the performance enhancing effect of nutritional intervention is lacking. One randomized controlled trial (RCT) suggested that augmentation of training with poly unsaturated fatty acids (PUFA) may improve exercise capacity. Conflicting results are reported on dietary creatine supplementation in patients with COPD receiving pulmonary rehabilitation (PR) and results from acute intervention studies do not directly imply long-term effects of glutamate or glutamine supplementation as an ergogenic aid in COPD. Recent data indicate that not only muscle but also visceral fat maybe an important additional target for combined nutrition and exercise intervention in COPD to improve physical performance and decrease cardio-metabolic risk.

Summary: There is a clear need for adequately powered and controlled intervention and maintenance trials to establish the role of nutritional supplementation in the enhancement of exercise performance and training and the wider management of the systemic features of the disease. 


\section{INTRODUCTION}

Whilst lung damage is the initiating event in COPD, the severity of lung function impairment relates poorly to physical incapacity and symptoms. Disability in COPD is now recognized as the consequence of a complex chain of events centering around the "disability spiral" (Figure 1) in which exercise related breathlessness results in activity avoidance, deconditioning and worsening exercise intolerance. The pathophysiological consequence is impaired skeletal muscle function (particularly in the locomotor muscles) and there is now compelling evidence that this is a key determinant of exercise intolerance and activity limitation in COPD. This is important because skeletal muscle impairment is a potentially treatable feature of a disease where the primary pulmonary pathophysiology is largely irreversible. PR with exercise training as core intervention is effective in improving exercise performance in COPD and provides proof of concept that this approach is profitable (1). However, there is considerable interest in other nutritional or anabolic therapies that might improve exercise capacity either by augmenting the physical training component of PR or delivering benefits to patients who are unable to access PR or have other barriers (e.g. musculoskeletal conditions) to perform whole body exercise training. Besides increased resting energy expenditure (EE), activity-induced EE is increased, which is a important contributor to elevated total daily EE (2) and may be explained by a decreased mechanical efficiency, the chemical conversion of energy to mechanical work, during lower limb exercise (3). In line, higher adenosine triphosphate (ATP) costs of muscle contraction in COPD patients versus controls were recently reported (4). Consequently, exercise training is not only a stimulus for skeletal muscle but may also increase energy requirements that can induce weight loss in susceptible patients.

Nutritional strategies therefore, can be considered as ergogenic aids to enhance efficacy of PR but may also target specific muscle pathology in COPD including muscle wasting and altered regulation of muscle oxidative metabolism.

In this review we will primarily consider the use of nutrition as an ergogenic aid to enhance the effects of exercise and training. It should be born in mind however, that nutritional depletion itself is an important clinical manifestation of COPD and therefore maintaining or improving nutritional status is an important therapeutic goal in this population. It is generally considered important to enhance nutritional therapy with an anabolic stimulus such as exercise, which is the converse of the approach we will consider in this article, and has different objectives (improvement in body mass index (BMI) and lean mass as opposed to exercise performance). Although both objectives may be considered clinically important, the target patient population and outcome measures will differ depending on the overall aims of the intervention. 


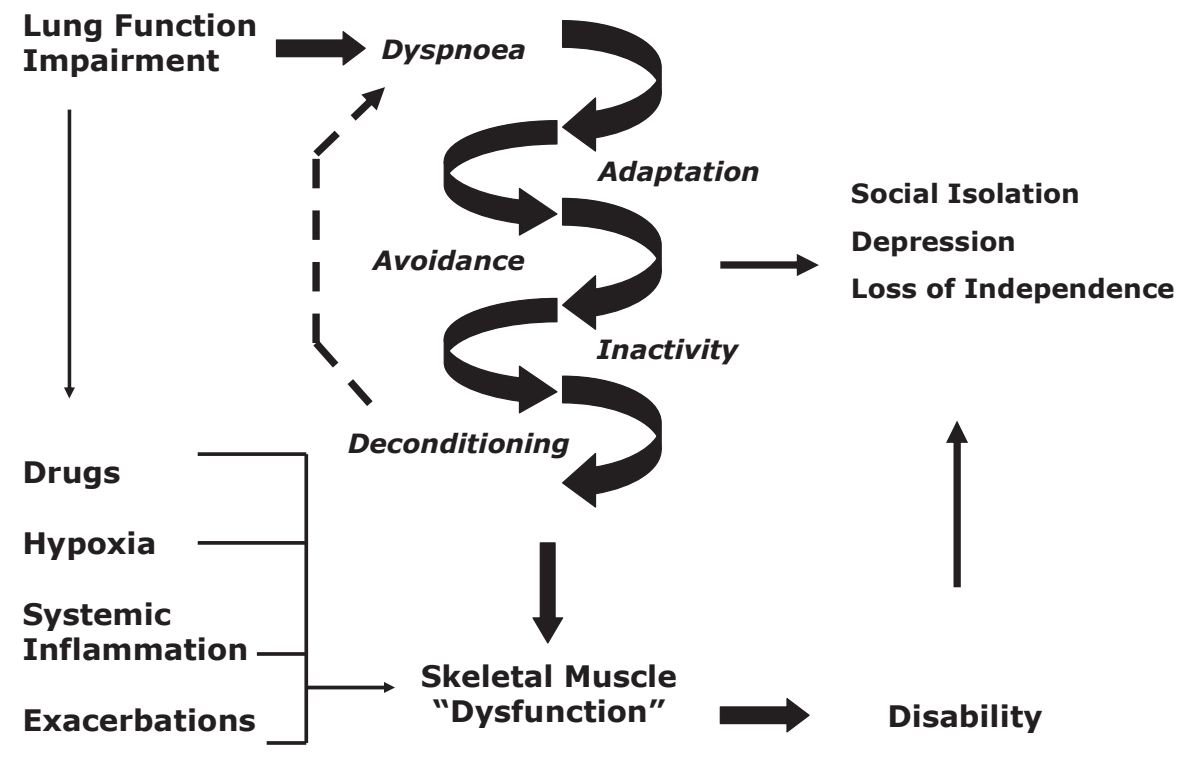

Figure 1. The Disability spiral in COPD.

This figure illustrates the multifactorial nature of disability in COPD. In this model, lung damage leads to exercise induced dyspnoea, adaptation of lifestyle to avoid physical activity and subsequent loss of fitness and further dyspnoea, the so called "spiral of disability". The consequence of this process is impaired skeletal muscle function which may also be influenced by other disease features.

\section{Altered body composition and skeletal muscle pathology}

Skeletal muscle dysfunction is characterized by loss of muscle mass, strength and endurance together with intrinsic abnormalities in peripheral skeletal muscle morphology and metabolism. Muscle wasting is not only confined to weight-losing patients but also seen in weight-stable COPD patients (5). Recent studies have suggested that although fat mass may be preserved relative to muscle mass, fat is redistributed to the visceral compartment (6-8). Increased visceral fat results in a higher cardio-metabolic risk, which may also be heightened by decreased insulin sensitivity in normal-weight patients and be an important additional target of exercise training $(9,10)$.

Structural and functional abnormalities in the skeletal muscles of patients with COPD include reductions in the proportion of type I fibres (11), mitochondrial oxidative enzyme concentrations (12) and mitochondrial density (13). The functional consequence is excessive glycolytic and reduced oxidative metabolism during exercise, which is associated with early lactate rise and adenine nucleotide loss, even at the low absolute exercise intensities patients with COPD can achieve (14).

The cause of skeletal muscle dysfunction in COPD is probably multifactorial, involving the interaction of lifestyle changes (reduced habitual physical activity, smoking $(15,16)$ ) 
with disease-specific factors (e.g. hypoxia, systemic inflammation, oxidative stress and drug therapy such as beta agonists or corticosteroids). Nutritional factors may also be implicated as calorie intake, which may be reduced in some patients due to poor appetite, respiratory discomfort during meals due to hyperinflation and socio-economic factors impairing the quality of the diet. Generally, reduced calorie intake in relation to expenditure leads to alterations in the fat compartment rather than the lean compartment and can more easily be overcome by calorie supplementation.

Skeletal muscle dysfunction in patients with COPD can be at least partially reversed by physical training $(17,18)$. Training adaptations are generally mode specific with improvements in muscle strength and mass seen following resistance training and muscle oxidative capacity improving following aerobic training. Controversy remains about whether skeletal muscle function can be returned to the healthy state by physical training. In practice this is difficult to ascertain given the wide range of normal muscle physiology in healthy older people. Moreover, practical barriers to the delivery of sustained, high intensity exercise training in patients with a chronic disease such as COPD mean that the potential to enhance physical training with adjunctive nutritional interventions remains. This is further supported by the practice of elite athletes in paying careful attention to nutritional intake during training and competition. A caveat to the translation of this technology to the field of COPD are the generally small increments in performance athletes aim to achieve which in all likelihood would be insufficient to deliver meaningful benefits in a clinical rehabilitation setting. In the remainder of this review we will consider specific macro- and micro-nutritional interventions that have been tested in COPD.

\section{Scientific evidence for nutritional interventions}

Both macro- and micronutrients are of interest as ergogenic aids to enhance the effects of exercise and training in COPD.

\section{Carbohydrate supplementation}

Early concerns about adverse effects of carbohydrate supplementation in COPD, due to increased $\mathrm{CO} 2$ production resulting from carbohydrate $(\mathrm{CHO})$ oxidation loading ventilation, have not been substantiated in more recent studies (19). Moreover, from the perspective of enhancing physical performance, there is a strong rationale for prioritizing $\mathrm{CHO}$ intake during exercise training in COPD. Deconditioned subjects may be unable to utilize fat as energy substrate and are thus highly reliant on $\mathrm{CHO}$. This is likely to apply to generally inactive and deconditioned COPD patients with a decreased fat oxidative metabolism (20). Moreover, oral nutritional supplements with a higher carbohydrate and lower fat composition may be beneficial, as digestible carbohydrates are a rapid energy source in the muscle. They empty rapidly from the stomach, thereby limiting satiety that 
will reduce normal food intake. This is especially relevant for COPD patients who experience poor appetite because of post-prandial shortness of breath, since carbohydrate-rich supplements induce less shortness of breath than fat-rich supplements (19).

Steiner et al. (21) investigated the impact of CHO-rich supplementation during outpatient PR versus placebo. Improvements in body weight were seen in the supplemented group, but principally in the fat compartment. Patients allocated to placebo lost weight during rehabilitation, suggesting significant energy cost of the program which could be overcome with supplementation. No improvement in muscle mass was seen, but this might have been due to the nature of the exercise program which comprised low intensity aerobic rather than resistance training. Gains in whole body exercise performance were seen only in well nourished patients and improvements in exercise capacity were correlated with the increased $\mathrm{CHO}$ intake. These findings suggest that carbohydrate supplementation may be a fruitful approach to enhance exercise training, but the observation of a positive effect in a subgroup only requires replication in further trials before recommendations can be made for clinical practice.

\section{Protein and amino acid supplementation}

Given that lean tissue wasting and muscle weakness are important systemic features of COPD, augmenting muscle protein synthesis with additional dietary protein is an attractive approach. Furthermore, enhanced levels of resting whole body protein turnover have been consistently reported in $\operatorname{COPD}(22,23)$, associated with an elevated resting metabolic rate. Dietary amino acids stimulate protein synthesis in health although this effect may be blunted in older people, a phenomenon termed "anabolic resistance" (24). The optimal protein feeding at the time of exercise may be an effective method for facilitating the anabolic effect of dietary supplementation in undernourished or weightlosing patients. This may also be particularly relevant in view of a suppressed wholebody protein and urea turnover after low intensity exercise in COPD patients with emphysema $(25,26)$. Evidence that anabolic resistance is of importance in COPD is lacking, indeed studies of amino acid feeding in COPD suggest that protein synthesis was stimulated. Despite the appearance that supplementation of dietary protein (>1.5 g/kg/day) is generally advised to increase muscle mass (27), the optimal amount of protein to stimulate net protein synthesis in wasted COPD patients is still not determined.

Apart from protein metabolism, there is an increased interest in specific amino acid metabolism in the context of loss of muscle mass. Indeed, COPD patients with muscle atrophy have been shown to have low plasma levels of BCAA, especially leucine, compared to age-matched controls. Additionally, plasma levels of BCAA positively correlate with fat free mass (FFM) in patients with COPD (28). It is generally acknowledged that BCAA, in particular leucine, is able to stimulate the anabolic mammalian target of rapamycin (mTOR) signaling cascade and protein synthesis (29). Recently, it was elegantly 
shown in vitro that leucine supplementation stimulates myofibrillar protein rather than generic protein accretion in skeletal muscle, and that this involves pretranslational control of myosin heavy chain (MyHC) expression of leucine in an mTOR-independent and dependent manner (30). Glutamate is another (nonessential) amino acid known to play an important role in metabolic routes in skeletal muscle. Glutamate is a precursor for the first and rate-limiting step in glutathione (an important antioxidant in muscle) synthesis and is also involved in preserving high-energy phosphates in muscle at rest and during exercise $(31,32)$. Decreased muscle glutamate concentration in COPD is consistently reported and is associated with decreased muscle glutathione concentration and early lactic acidosis (33), whereas plasma glutamate concentration is positively associated with FFM (34).

Although most caloric intervention studies used protein-rich supplements (35), only few studies specifically explored the impact of protein supplementation in COPD. Baldi et al. (36) randomized COPD patients with weight loss to receive an amino acid mixture with high BCAA concentrations (total protein intake $>1.5 \mathrm{~g} / \mathrm{kg}$ ) embedded in a 12-week rehabilitation program or no supplementation. Body weight and FFM significantly increased in the essential amino acid supplementation group but not in the control group. These results are in line with an acute experiment in normal-weight COPD patients with mild muscle wasting (37), in which BCAA supplementation to soy protein enhanced whole body protein synthesis and altered interorgan protein metabolism in favor of the peripheral (muscle) compartment. The effect was more pronounced in COPD than in healthy age-matched controls. Conversely, continuous oral glutamate ingestion for 80 min did not lead to acute effects on skeletal muscle substrate metabolism and muscle performance in COPD patients as well as in healthy age-matched controls (38). In line with this, Marwood et al. (39) hypothesized that glutamine supplementation prior to exercise would enhance $\mathrm{V}(\mathrm{O} 2)$ peak, $\mathrm{V}(\mathrm{O} 2)$ at lactate threshold and speed pulmonary oxygen uptake kinetics in COPD. Subjects consumed $0.125 \mathrm{~g} / \mathrm{kg}$ of L-glutamine one hour before exercise, but no improvement of oxidative metabolism were observed.

\section{Poly unsaturated fatty acid supplementation}

Research by Remels et al. (40) demonstrated reduced peroxisome proliferator-activated receptor-c coactivator-1a (PGC-1 $\alpha$ ) messenger ribonucleic acid (mRNA) expression, peroxisome proliferator-activated receptor (PPAR) $\delta$-protein levels and mitochondrial transcription factor A content in skeletal muscle of COPD patients. Since these are important regulators of mitochondrial biogenesis, skeletal muscle oxidative capacity and fibre-type shifting towards more oxidative fibres, these findings imply disturbed regulation of muscular oxidative capacity. They also produced experimental and clinical evidence for the effect of inflammation on skeletal muscle oxidative capacity in a nuclear factor kappa B (NFkB)-dependent manner, next to known factors as inactivity and hy- 
poxia (41). Experimental research has shown that PUFA improve muscle maintenance by modulating systemic inflammation and NF-kB (42). PUFA are furthermore natural ligands of PPARs and dietary intake of $n-3$ and $n-6$ fatty acids is associated with serum inflammatory markers. Specifically, higher (anti-inflammatory) n-3 fatty acid intake was related with lowered serum tumor necrosis factor a (TNF $\alpha$ ), whereas (proinflammatory) n-6 fatty acid intake was related with elevated interleukin (IL)-6 and creactive protein (CRP) (43).

Early nutritional supplementation studies used fat-rich supplements not for their immune modulating properties but because of concerns about adverse effects of carbohydrate on ventilation in COPD. Sugawara et al. (44) divided patients into a nutritional supplementation with low-intensity exercise group and a control group without intervention. The nutritional supplements (400 kcal/day, 15:60:25 as energy percentages of protein:carbohydrate:fat) were enriched with $0.6 \mathrm{~g}$ n-3 PUFA (unspecified source) and $248 \mathrm{mg}$ vitamin A, resulting in decreased systemic inflammatory markers including CRP, TNF $\alpha$ and IL-8, and increased quadriceps muscle force and 6-min walking distance (6MWD) after 3 months. A placebo-controlled RCT by Broekhuizen et al. (45) investigated the effect of an n-3/n-6 PUFA mixture on top of PR. This study did not show a positive effect on the systemic inflammatory profile, which could be related to the short 8 weeks intervention duration. However, they did show a significantly enhanced improvement in endurance exercise capacity independent of muscle mass and strength, which could imply a stimulating effect on muscle fat oxidative metabolism.

\section{Vitamin D supplementation}

Recent data showed that vitamin D deficiency occurs very frequently in patients with COPD (46). Vitamin D is involved in several COPD-related disease features, including impaired lung function (47), osteoporosis (48) and compromised immune function, but is also suggested to affect muscle strength and function (49). Responsible processes for cellular effects of vitamin D on muscle cells include calcium homeostasis, cell proliferation and differentiation, protection of skeletal muscle cells against insulin resistance, and arachidonic acid mobilization (49). Both genomic as rapid non-genomic mechanisms mediate these processes via the vitamin $D$ receptor (50). In line with previous findings, a cross-sectional study by Romme et al. (48) detected vitamin D deficiency (plasma 25(OH)D concentration $<50 \mathrm{nmol} / \mathrm{L}$ ) in the majority of the moderate-to-very severe COPD patients, and reported a positive association of plasma 25(OH)D concentration with bone mineral density and exercise capacity. However, a recent study by Jackson et al. (51) investigated whether vitamin D levels contribute to muscle dysfunction in COPD, but an association was not found. A meta-analysis in healthy adults defined a positive effect of vitamin D supplementation on muscle strength in subjects with 
plasma 25(OH)D concentrations $<25 \mathrm{nmol} / \mathrm{L}$, although supplementation had no effect in subjects with plasma 25(OH)D above this concentration (52).

To date, no studies have explored the impact of vitamin D supplementation on exercise performance or the outcome of exercise training in COPD. In a single centre RCT, vitamin D supplementation did not reduce exacerbation frequency or improve lung function in COPD (53). Measures of exercise capacity or body composition were not reported in this study. Nevertheless, well-designed RCTs are needed to determine whether vitamin D supplementation benefits the treatment of exercise limitation in COPD.

\section{Creatine supplementation}

Creatine is a widely available nutritional supplement, which in its phosphorylated form enhances performance by increasing the phosphagen pool available for rapid resynthesis of ATP from adenosine diphosphate during periods of high ATP turnover.

Several studies have explored the potential enhancing effect of dietary creatine supplementation in COPD patients receiving PR with conflicting results. In the study by Fuld et al. (54) creatine supplementation led to increases in FFM, peripheral muscle strength and endurance, but not exercise capacity. In contrast, two other studies $(55,56)$ did not show an enhancing effect. These differences are probably due to dissimilarities in the studied patient characteristics and the content of the exercise training programs. In a subsequent systematic review (57) the authors conclude that creatine supplementation cannot currently be advised as an adjunct to PR.

\section{Antioxidant supplementation}

The process of oxidative stress results from an imbalance between oxidants and antioxidant capacity and is a well-known feature in COPD. Moreover, oxidative stress is linked to peripheral muscle dysfunction (58-60) and exercise intolerance (61). Taken together, data from studies on muscle oxidative damage indicate that COPD peripheral muscle fibres are exposed to oxidative stress. The excessive reactive oxygen species mainly target mitochondria and myofilaments, resulting in muscle apoptosis, dysfunction of mitochondrial respiratory chain, and altered contractile properties of myofilaments (59). Pressurized whey has antioxidant and nutritional properties, which may improve exercise tolerance and enhance the effects of exercise training in patients with COPD.

Laviolette et al. (62) provided their COPD patients with $20 \mathrm{~g}$ active pressurized whey or placebo (casein) daily for a 16-week period, accompanied by an exercise training program in the last 8 weeks. Endurance time improved statistically significant, but surprisingly systemic inflammatory and oxidative stress markers were not significantly modified. 


\section{Nutritional rehabilitation as part of integrated care}

It is now recognised that patients with COPD are best managed through multimodal therapies delivered through an integrated health care system. These interventions may include pharmacological therapies, PR, oxygen therapy and smoking cessation. Muscle wasting is not necessarily limited to advanced disease and therefore may be of benefit when incorporated into such integrated care programs.

An INTERdisciplinary COMmunity-based COPD management program (INTERCOM) consisting of 4 months exercise training and standardized nutritional supplements followed by a 20-month maintenance program (nutritional counselling and supplements upon indication) was also effective in COPD patients with exercise impairment but less advanced airflow obstruction (63). Additionally, a prescheduled post-hoc analysis of muscle wasted COPD patients participating in INTERCOM resulted in significant long term effects on FFM, skeletal muscle function and 6MWD compared to usual care (64). Moreover, cost-analysis revealed significantly lower hospital admission costs in the intervention group (65). Since the control group received usual care, the relative influence of exercise and nutrition could not be identified. At the other end of the disease spectrum, Pison et al. (66) studied the impact of a multi-component intervention (nutritional supplementation, exercise and testosterone therapy) in a cohort of patients with respiratory failure. Improvements in exercise performance and health status were seen in the treatment group. Tantalizingly although not statistically significant in the intention to treat analysis, the intervention improved survival when patients who completed the protocol were considered.

\section{CONCLUSION}

Nutritional strategies can be considered as ergogenic aids to enhance efficacy of PR, but may also target specific muscle pathology in COPD including muscle wasting and altered regulation of muscle oxidative metabolism. Although the rationale for both BCAA and vitamin D supplementation seems highly promising, remarkably few studies specifically explored the impact of supplementation on exercise performance or the outcome of exercise training in COPD. There is good evidence from one RCT that PUFA on top of PR may improve exercise capacity (45), but this should be confirmed in other trials. Conflicting results are reported on dietary creatine supplementation in patients with COPD receiving PR and results from acute intervention studies do not directly imply long-term effects of glutamate or glutamine supplementation as ergogenic aid in COPD. Furthermore, altered visceral fat distribution is an additional target for combined nutrition and training in COPD. There is a clear need for adequately powered intervention and maintenance trials to establish the role of nutritional supplementation in the enhancement of exercise performance and training and the wider management of the systemic features of the disease. 


\section{REFERENCES}

1. Nici L, Donner C, Wouters E, Zuwallack R, Ambrosino N, Bourbeau J, Carone M, Celli B, Engelen M, Fahy B, Garvey C, Goldstein R, Gosselink R, Lareau S, Maclntyre N, Maltais F, Morgan M, O'Donnell D, Prefault C, Reardon J, Rochester C, Schols A, Singh S, Troosters T. American thoracic society/european respiratory society statement on pulmonary rehabilitation. Am J Respir Crit Care Med 2006;173:1390-1413.

2. Slinde F, Ellegard L, Gronberg AM, Larsson S, Rossander-Hulthen L. Total energy expenditure in underweight patients with severe chronic obstructive pulmonary disease living at home. Clin Nutr 2003;22:159-165.

3. Richardson RS, Leek BT, Gavin TP, Haseler LJ, Mudaliar SR, Henry R, Mathieu-Costello O, Wagner PD. Reduced mechanical efficiency in chronic obstructive pulmonary disease but normal peak vo2 with small muscle mass exercise. Am J Respir Crit Care Med 2004;169:89-96.

4. Layec G, Haseler LJ, Hoff J, Richardson RS. Evidence that a higher atp cost of muscular contraction contributes to the lower mechanical efficiency associated with copd: Preliminary findings. Am J Physiol Regul Integr Comp Physiol 2011;300:R1142-1147.

5. Vestbo J, Prescott E, Almdal T, Dahl M, Nordestgaard BG, Andersen T, Sorensen TI, Lange P. Body mass, fat-free body mass, and prognosis in patients with chronic obstructive pulmonary disease from a random population sample: Findings from the copenhagen city heart study. Am J Respir Crit Care Med 2006;173:79-83.

6. Rutten EP, Breyer MK, Spruit MA, Hofstra T, van Melick PP, Schols AM, Wouters EF. Abdominal fat mass contributes to the systemic inflammation in chronic obstructive pulmonary disease. Clin Nutr 2010;29:756-760.

7. Furutate R, Ishii T, Wakabayashi R, Motegi T, Yamada K, Gemma A, Kida K. Excessive visceral fat accumulation in advanced chronic obstructive pulmonary disease. Int J Chron Obstruct Pulmon Dis 2011;6:423430.

8. Van den Borst B, Gosker H, Koster A, Yu B, Kritchevsky SB, Liu Y, Meibohm B, Rice T, Shlipak M, Yende S, Harris TB, Schols AM. The influence of abdominal visceral fat on inflammatory pathways and mortality in obstructive lung disease. Am J Clin Nutr 2012; [epub ahead of print].

9. Franssen FM, Sauerwein HP, Ackermans MT, Rutten EP, Wouters EF, Schols AM. Increased postabsorptive and exercise-induced whole-body glucose production in patients with chronic obstructive pulmonary disease. Metabolism 2011;60:957-964.

10. van den Borst B, Gosker HR, Wesseling G, de Jager W, Hellwig VA, Snepvangers FJ, Schols AM. Low-grade adipose tissue inflammation in patients with mild-to-moderate chronic obstructive pulmonary disease. Am J Clin Nutr 2011;94:1504-1512.

11. Gosker HR, Zeegers MP, Wouters EF, Schols AM. Muscle fibre type shifting in the vastus lateralis of patients with copd is associated with disease severity: A systematic review and meta-analysis. Thorax 2007;62:944-949.

12. Maltais F, LeBlanc P, Whittom F, Simard C, Marquis K, Belanger M, Breton MJ, Jobin J. Oxidative enzyme activities of the vastus lateralis muscle and the functional status in patients with copd. Thorax 2000;55:848-853.

13. Gosker HR, Hesselink MK, Duimel H, Ward KA, Schols AM. Reduced mitochondrial density in the vastus lateralis muscle of patients with copd. Eur Respir J 2007;30:73-79.

14. Steiner MC, Evans R, Deacon SJ, Singh SJ, Patel P, Fox J, Greenhaff PL, Morgan MD. Adenine nucleotide loss in the skeletal muscles during exercise in chronic obstructive pulmonary disease. Thorax 2005;60:932-936.

15. Gosker HR, Langen RC, Bracke KR, Joos GF, Brusselle GG, Steele C, Ward KA, Wouters EF, Schols AM. Extrapulmonary manifestations of chronic obstructive pulmonary disease in a mouse model of chronic cigarette smoke exposure. Am J Respir Cell Mol Biol 2009;40:710-716. 


\section{Chapter 5}

16. van den Borst B, Koster A, Yu B, Gosker HR, Meibohm B, Bauer DC, Kritchevsky SB, Liu Y, Newman AB, Harris TB, Schols AM. Is age-related decline in lean mass and physical function accelerated by obstructive lung disease or smoking? Thorax 2011;66:961-969.

17. Bronstad E, Rognmo O, Erik Tjonna A, Henrich Dedichen H, Kirkeby-Garstad I, Haberg AK, Bjork Ingul C, Wisloff $U$, Steinshamn S. High intensity knee extensor training restores skeletal muscle function in copd patients. Eur Respir J 2012.

18. Guzun R, Aguilaniu B, Wuyam B, Mezin P, Koechlin Ramonatxo C, Auffray C, Saks V, Pison C. Effects of training at mild exercise intensities on quadriceps muscle energy metabolism in patients with chronic obstructive pulmonary disease. Acta Physiol (Oxf) 2012;205:236-246.

19. Vermeeren MA, Wouters EF, Nelissen LH, van Lier A, Hofman Z, Schols AM. Acute effects of different nutritional supplements on symptoms and functional capacity in patients with chronic obstructive pulmonary disease. Am J Clin Nutr 2001;73:295-301.

20. Remels AH, Gosker HR, Schrauwen P, Langen RC, Schols AM. Peroxisome proliferator-activated receptors: A therapeutic target in copd? Eur Respir J 2008;31:502-508.

21. Steiner MC, Barton RL, Singh SJ, Morgan MD. Nutritional enhancement of exercise performance in chronic obstructive pulmonary disease: A randomised controlled trial. Thorax 2003;58:745-751.

22. Engelen MP, Deutz NE, Wouters EF, Schols AM. Enhanced levels of whole-body protein turnover in patients with chronic obstructive pulmonary disease. Am J Respir Crit Care Med 2000;162:1488-1492.

23. Kao CC, Hsu JW, Bandi V, Hanania NA, Kheradmand F, Jahoor F. Resting energy expenditure and protein turnover are increased in patients with severe chronic obstructive pulmonary disease. Metabolism 2011;60:1449-1455.

24. Cuthbertson D, Smith K, Babraj J, Leese G, Waddell T, Atherton P, Wackerhage H, Taylor PM, Rennie MJ. Anabolic signaling deficits underlie amino acid resistance of wasting, aging muscle. FASEB J 2005;19:422-424.

25. Engelen MP, Wouters EF, Deutz NE, Does JD, Schols AM. Effects of exercise on amino acid metabolism in patients with chronic obstructive pulmonary disease. Am J Respir Crit Care Med 2001;163:859-864.

26. Engelen MP, Deutz NE, Mostert R, Wouters EF, Schols AM. Response of whole-body protein and urea turnover to exercise differs between patients with chronic obstructive pulmonary disease with and without emphysema. Am J Clin Nutr 2003;77:868-874.

27. Op den Kamp CM, Langen RC, Haegens A, Schols AM. Muscle atrophy in cachexia: Can dietary protein tip the balance? Curr Opin Clin Nutr Metab Care 2009;12:611-616.

28. Engelen MP, Wouters EF, Deutz NE, Menheere PP, Schols AM. Factors contributing to alterations in skeletal muscle and plasma amino acid profiles in patients with chronic obstructive pulmonary disease. Am J Clin Nutr 2000;72:1480-1487.

29. Drummond MJ, Rasmussen BB. Leucine-enriched nutrients and the regulation of mammalian target of rapamycin signalling and human skeletal muscle protein synthesis. Curr Opin Clin Nutr Metab Care 2008;11:222-226.

30. Haegens A, Schols AM, van Essen AL, van Loon LJ, Langen RC. Leucine induces myofibrillar protein accretion in cultured skeletal muscle through mtor dependent and -independent control of myosin heavy chain mrna levels. Mol Nutr Food Res 2012;56:741-752.

31. Engelen MP, Schols AM. Altered amino acid metabolism in chronic obstructive pulmonary disease: New therapeutic perspective? Curr Opin Clin Nutr Metab Care 2003;6:73-78.

32. Rutten EP, Engelen MP, Schols AM, Deutz NE. Skeletal muscle glutamate metabolism in health and disease: State of the art. Curr Opin Clin Nutr Metab Care 2005;8:41-51.

33. Engelen MP, Schols AM, Does JD, Deutz NE, Wouters EF. Altered glutamate metabolism is associated with reduced muscle glutathione levels in patients with emphysema. Am J Respir Crit Care Med 2000;161:98-103.

34. Rutten EP, Franssen FM, Engelen MP, Wouters EF, Deutz NE, Schols AM. Greater whole-body myofibrillar protein breakdown in cachectic patients with chronic obstructive pulmonary disease. Am J Clin Nutr 2006;83:829-834.

35. Collins PF, Stratton RJ, Elia M. Nutritional support in chronic obstructive pulmonary disease: A systematic review and meta-analysis. Am J Clin Nutr 2012. 
36. Baldi S, Aquilani R, Pinna GD, Poggi P, De Martini A, Bruschi C. Fat-free mass change after nutritional rehabilitation in weight losing copd: Role of insulin, c-reactive protein and tissue hypoxia. Int J Chron Obstruct Pulmon Dis 2010;5:29-39.

37. Engelen MP, Rutten EP, De Castro CL, Wouters EF, Schols AM, Deutz NE. Supplementation of soy protein with branched-chain amino acids alters protein metabolism in healthy elderly and even more in patients with chronic obstructive pulmonary disease. Am J Clin Nutr 2007;85:431-439.

38. Rutten EP, Engelen MP, Gosker H, Bast A, Cosemans K, Vissers YL, Wouters EF, Deutz NE, Schols AM. Metabolic and functional effects of glutamate intake in patients with chronic obstructive pulmonary disease (copd). Clin Nutr 2008;27:408-415.

39. Marwood S, Jack S, Patel M, Walker P, Bowtell J, Calverley P. No effect of glutamine ingestion on indices of oxidative metabolism in stable copd. Respir Physiol Neurobiol 2011;177:41-46.

40. Remels AH, Schrauwen P, Broekhuizen R, Willems J, Kersten S, Gosker HR, Schols AM. Peroxisome proliferator-activated receptor expression is reduced in skeletal muscle in copd. Eur Respir J 2007;30:245-252.

41. Remels AH, Gosker HR, Schrauwen P, Hommelberg PP, Sliwinski P, Polkey M, Galdiz J, Wouters EF, Langen RC, Schols AM. Tnf-alpha impairs regulation of muscle oxidative phenotype: Implications for cachexia? FASEB J 2010;24:5052-5062.

42. Komatsu W, Ishihara K, Murata M, Saito H, Shinohara K. Docosahexaenoic acid suppresses nitric oxide production and inducible nitric oxide synthase expression in interferon-gamma plus lipopolysaccharidestimulated murine macrophages by inhibiting the oxidative stress. Free Radic Biol Med 2003;34:1006-1016.

43. de Batlle J, Sauleda J, Balcells E, Gomez FP, Mendez M, Rodriguez E, Barreiro E, Ferrer JJ, Romieu I, Gea J, Anto JM, Garcia-Aymerich J. Association between omega3 and omega6 fatty acid intakes and serum inflammatory markers in copd. J Nutr Biochem 2011.

44. Sugawara K, Takahashi H, Kasai C, Kiyokawa N, Watanabe T, Fujii S, Kashiwagura T, Honma M, Satake M, Shioya T. Effects of nutritional supplementation combined with low-intensity exercise in malnourished patients with copd. Respir Med 2010;104:1883-1889.

45. Broekhuizen R, Wouters EF, Creutzberg EC, Weling-Scheepers CA, Schols AM. Polyunsaturated fatty acids improve exercise capacity in chronic obstructive pulmonary disease. Thorax 2005;60:376-382.

46. Janssens W, Bouillon R, Claes B, Carremans C, Lehouck A, Buysschaert I, Coolen J, Mathieu C, Decramer $\mathrm{M}$, Lambrechts D. Vitamin d deficiency is highly prevalent in copd and correlates with variants in the vitamin d-binding gene. Thorax 2010;65:215-220.

47. Zosky GR, Berry LJ, Elliot JG, James AL, Gorman S, Hart PH. Vitamin d deficiency causes deficits in lung function and alters lung structure. Am J Respir Crit Care Med 2011;183:1336-1343.

48. Romme EA, Rutten EP, Smeenk FW, Spruit MA, Menheere PP, Wouters EF. Vitamin d status is associated with bone mineral density and functional exercise capacity in patients with chronic obstructive pulmonary disease. Ann Med 2012.

49. Dirks-Naylor AJ, Lennon-Edwards $\mathrm{S}$. The effects of vitamin $d$ on skeletal muscle function and cellular signaling. J Steroid Biochem Mol Biol 2011;125:159-168.

50. Ceglia L. Vitamin d and its role in skeletal muscle. Curr Opin Clin Nutr Metab Care 2009;12:628-633.

51. Jackson AS, Shrikrishna D, Kelly JL, Hart N, Moxham J, Polkey MI, Kemp P, Hopkinson NS. Vitamin d and skeletal muscle strength and endurance in chronic obstructive pulmonary disease. Eur Respir J 2012.

52. Stockton KA, Mengersen K, Paratz JD, Kandiah D, Bennell KL. Effect of vitamin d supplementation on muscle strength: A systematic review and meta-analysis. Osteoporos Int 2011;22:859-871.

53. Lehouck A, Mathieu C, Carremans C, Baeke F, Verhaegen J, Van Eldere J, Decallonne B, Bouillon R, Decramer $M$, Janssens $W$. High doses of vitamin d to reduce exacerbations in chronic obstructive pulmonary disease: A randomized trial. Ann Intern Med 2012;156:105-114.

54. Fuld JP, Kilduff LP, Neder JA, Pitsiladis Y, Lean ME, Ward SA, Cotton MM. Creatine supplementation during pulmonary rehabilitation in chronic obstructive pulmonary disease. Thorax 2005;60:531-537.

55. Deacon SJ, Vincent EE, Greenhaff PL, Fox J, Steiner MC, Singh SJ, Morgan MD. Randomized controlled trial of dietary creatine as an adjunct therapy to physical training in chronic obstructive pulmonary disease. Am J Respir Crit Care Med 2008;178:233-239. 


\section{Chapter 5}

56. Faager G, Soderlund K, Skold CM, Rundgren S, Tollback A, Jakobsson P. Creatine supplementation and physical training in patients with copd: A double blind, placebo-controlled study. Int J Chron Obstruct Pulmon Dis 2006;1:445-453.

57. Al-Ghimlas F, Todd DC. Creatine supplementation for patients with copd receiving pulmonary rehabilitation: A systematic review and meta-analysis. Respirology 2010;15:785-795.

58. Barreiro E, Schols AM, Polkey MI, Galdiz JB, Gosker HR, Swallow EB, Coronell C, Gea J. Cytokine profile in quadriceps muscles of patients with severe copd. Thorax 2008;63:100-107.

59. Couillard A, Prefaut C. From muscle disuse to myopathy in copd: Potential contribution of oxidative stress. Eur Respir J 2005;26:703-719.

60. Gosker HR, Bast A, Haenen GR, Fischer MA, van der Vusse GJ, Wouters EF, Schols AM. Altered antioxidant status in peripheral skeletal muscle of patients with copd. Respir Med 2005;99:118-125.

61. Koechlin C, Couillard A, Simar D, Cristol JP, Bellet H, Hayot M, Prefaut C. Does oxidative stress alter quadriceps endurance in chronic obstructive pulmonary disease? Am J Respir Crit Care Med 2004;169:1022-1027.

62. Laviolette L, Lands LC, Dauletbaev N, Saey D, Milot J, Provencher S, LeBlanc P, Maltais F. Combined effect of dietary supplementation with pressurized whey and exercise training in chronic obstructive pulmonary disease: A randomized, controlled, double-blind pilot study. J Med Food 2010;13:589-598.

63. van Wetering CR, Hoogendoorn M, Mol SJ, Rutten-van Molken MP, Schols AM. Short- and long-term efficacy of a community-based copd management programme in less advanced copd: A randomised controlled trial. Thorax 2010;65:7-13.

64. van Wetering CR, Hoogendoorn M, Broekhuizen R, Geraerts-Keeris GJ, De Munck DR, Rutten-van Molken MP, Schols AM. Efficacy and costs of nutritional rehabilitation in muscle-wasted patients with chronic obstructive pulmonary disease in a community-based setting: A prespecified subgroup analysis of the intercom trial. J Am Med Dir Assoc 2010;11:179-187.

65. Hoogendoorn M, van Wetering CR, Schols AM, Rutten-van Molken MP. Is interdisciplinary communitybased copd management (intercom) cost-effective? Eur Respir J 2010;35:79-87.

66. Pison CM, Cano NJ, Cherion C, Caron F, Court-Fortune I, Antonini MT, Gonzalez-Bermejo J, Meziane L, Molano LC, Janssens JP, Costes F, Wuyam B, Similowski T, Melloni B, Hayot M, Augustin J, Tardif C, Lejeune $\mathrm{H}$, Roth $\mathrm{H}$, Pichard C. Multimodal nutritional rehabilitation improves clinical outcomes of malnourished patients with chronic respiratory failure: A randomised controlled trial. Thorax 2011;66:953-960. 


\section{Chapter}

\section{A randomised clinical trial investigating the efficacy of targeted nutrition as adjunct to exercise training in COPD}

Coby van de Bool, Erica P.A. Rutten, Ardy van Helvoort, Frits M.E. Franssen, Emiel F.M. Wouters, Annemie M.W.J. Schols 


\section{ABSTRACT}

Background: Evidence regarding the efficacy of nutritional supplementation to enhance exercise training responses in muscle wasted COPD patients is limited.

Objective: The objective was to study if nutritional supplementation targeting muscle derangements enhances outcome of exercise training in muscle wasted COPD patients.

Methods: 81 muscle wasted COPD patients, admitted to out-patient pulmonary rehabilitation, randomly received oral nutritional supplementation, enriched with leucine, vitamin D and omega-3 fatty acids (NUTRITION) or PLACEBO as adjunct to 4 months supervised high intensity exercise training.

Results: The study population (51\% males) showed moderate airflow limitation, decreased diffusion capacity, normal protein intake, low plasma vitamin D and docosahexaenoic acid. Intention-to-treat analysis revealed significant differences favouring NUTRITION for body mass $(+1.5 \pm 0.6 \mathrm{~kg}, \mathrm{P}<0.05)$, plasma vitamin $\mathrm{D}(+24 \%, \mathrm{P}=0.004)$, eicosapentaenoic acid (+91\%, $\mathrm{P}<0.001)$, docosahexaenoic acid $(+31 \%, \mathrm{P}<0.001)$ and steps/day $(+24 \%, P<0.05)$. Both groups improved skeletal muscle mass $(+0.4 \pm 0.1 \mathrm{~kg}$, $\mathrm{P}<0.001)$, quadriceps muscle strength $(+12.3 \pm 2.3 \mathrm{Nm}, \mathrm{P}<0.001)$ and cycle endurance time $(+191.4 \pm 34.3 \mathrm{~s}, \mathrm{P}<0.001)$. Inspiratory muscle strength only improved in NUTRITION $(+0.5 \pm 0.1 \mathrm{kPa}, \mathrm{P}=0.001)$ and steps/day declined in PLACEBO $(-18 \%, \mathrm{P}<0.01)$.

Conclusion: High intensity exercise training is effective in improving lower limb muscle strength and exercise performance in muscle wasted COPD patients with moderate airflow obstruction. Specific nutritional supplementation had additional effects on nutritional status, inspiratory muscle strength and physical activity compared to placebo. 


\section{INTRODUCTION}

It is well established that extra-pulmonary pathology enhances the disease burden and mortality risk in patients with COPD. Muscle wasting is common, in particular in emphysema, and associated with a high prevalence of osteoporosis, impaired exercise performance and higher mortality risk (1). Furthermore muscle wasting often coincides with a decreased oxidative metabolism due to a shift in muscle fibre type composition (2).

Treatment of muscle dysfunction to alleviate progressive disability has been subject of intensive research in COPD. Exercise training is considered as cornerstone of pulmonary rehabilitation (PR) for improving lower limb muscle function (3). The latest Cochrane meta-analysis by Ferreira et al. (4) concludes that nutritional supplementation promotes weight gain and fat-free mass as proxy of muscle mass among patients with COPD, especially if undernourished and when combined with exercise training. However, the potential of nutritional supplementation to enhance efficacy of exercise training is not well established. Limited studies are available that differ in COPD target population and nutrient composition and most of them are underpowered (5).

In this randomized placebo-controlled multi-centre NUTRAIN-trial, we aimed to determine the efficacy of specific nutritional supplementation targeting muscle derangements as adjunct to exercise training in muscle wasted COPD patients. Based on available evidence regarding the mode of action of specific nutrients on skeletal muscle maintenance combined with reported deficiencies in COPD, we chose a multimodal approach including high quality protein enriched with leucine $(6,7)$, vitamin $D(8)$ and omega-3 (n-3) poly-unsaturated fatty acids (PUFA) (9). We hypothesize that COPD patients with low muscle mass eligible for out-patient PR show more pronounced improvement in muscle strength, endurance and nutritional status after an exercise training program including targeted nutritional support.

\section{METHODS}

A detailed methodology can be found in the supplemental data.

\section{Study design}

This double blind placebo controlled multi-centre NUTRAIN-trial was integrated in the out-patient PR program performed in 7 hospitals of the Centre of expertise for chronic organ failure (CIRO) network in the South East of the Netherlands. The study was registered at clinicaltrials.gov (NCT01344135) and the Medical Ethics Committee from Maastricht University Medical Centre granted ethical approval (NL34927068.10/MEC 11-3- 
004). The NUTRAIN-trial also comprised an exploratory maintenance program with a wider scope which will be reported separately.

\section{Patients}

Patients with COPD (post-bronchodilator $\mathrm{FEV}_{1} / \mathrm{FVC}<0.7$ ) referred for PR between September 2011-April 2014 were eligible for participation when they had low muscle mass (defined as FFMI under the sex- and age-specific $25^{\text {th }}$ percentile FFMI values (10)), were admitted to out-patient PR, did not meet any of the exclusion criteria (see supplemental data) and gave written informed consent. The target sample size (alpha 0.05, power $80 \%$ ) was based on data from the INTERCOM-study (11) assuming a 10\% difference in peak torque between the groups assuming maintenance of skeletal muscle strength in PLACEBO during follow-up and a SD of $5 \mathrm{Nm}$ in peak torque, revealing $n=60$ in each group including $25 \%$ drop-out. Patient inclusion was prematurely discontinued due to discontinuation of the supply of one of the ingredients the active formula could not be produced within the appropriate quality specification, but justifiable based on other RCTs published in the meantime as argued in the discussion.

To explore if the nutrient supplementation treated a deficient status or not, baseline plasma nutrient status was compared with a healthy control group (see supplemental data for details).

\section{Procedures}

The nutritional intervention was integrated in a 4-month standardized outpatient PR program (see supplemental data for PR components). Patients from both the PLACEBO and NUTRITION group were advised to consume 2-3 portions of the supplement daily. Randomization and masking procedures are described in the supplemental data. Per volume serving of $125 \mathrm{~mL}$ unit, the NUTRITION product provided $187.5 \mathrm{kCal}$ in a distribution of 20 energy percent (EN\%) protein; 60EN\% carbohydrate (CHO); 20EN\% fat, and was enriched with leucine, n-3 PUFA and vitamin D (Nutricia NV, Zoetermeer, the Netherlands, for details see supplemental table 1). The PLACEBO product did not comprise the investigated active components, but consisted of a flavoured non-caloric aqueous solution.

\section{Outcomes}

Measurements were performed at CIRO before entering PR, as part of a 3-day baseline assessment and after completion of the PR during a 2-day outcome assessment (3) with quadriceps muscle strength (QMS) as primary outcome. Secondary outcomes included body composition measured by Dual Energy X-ray Absorptiometry (DEXA), cycle endur- 
ance time (CET), inspiratory muscle strength (IMS), daily steps by accelerometry, habitual dietary intake using a validated cross-check dietary history method and fasting plasma levels of vitamin D (25-hydroxycholecalciferol), branched-chain amino acids (BCAA's) and fatty acid profile in phospholipids. Furthermore, post-bronchodilator forced expiratory volume in $1 \mathrm{~s}\left(\mathrm{FEV}_{1}\right)$, forced vital capacity (FVC), static lung volumes and diffusing capacity of the lung for carbon monoxide (DLCO) were assessed. Exploratory outcomes included 6-min walk distance (6MWD) and mood assessment (HADS: Hospital Anxiety and Depression scale).

\section{Statistical Analyses}

Intention-to-treat (ITT) analysis was performed using the Statistical Package for Social Sciences (SPSS version 20.0 for Windows, Inc.), using all available change-values (every subject completing the PR and outcome assessment), independently of dropping out of the nutritional intervention. Within group treatment outcomes were compared by Paired samples T-test for continuous normally distributed data or Wilcoxon Signed Rank Test for continuous non-normally distributed data. Between-group differences were compared by ANCOVA taking pre-treatment value as covariate, the 4 month posttreatment value as response, and considering treatment as a factor (12). Two-sided pvalues $<0.05$ were considered statistically significant. Results are presented as mean \pm standard error of the mean (SEM).

\section{RESULTS}

\section{Patients}

Between September 2011 and April 2014, 81 patients were enrolled in the trial and randomized to NUTRITION or PLACEBO. A patient flowchart is shown in (figure 1).

At baseline, the study population (51\% male, aged $62.5 \pm 0.9$ ) were characterized by low diffusion capacity (DLCO: $49.4 \pm 1.7 \%$ ), on average moderate airflow limitation (FEV1: $55.1 \pm 2.2 \%$ predicted), a BMI of $22.7 \pm 0.3 \mathrm{~kg} / \mathrm{m} 2$ and fat-free mass index (FFMI) of $15.8 \pm 0.2 \mathrm{~kg} / \mathrm{m} 2$. The majority of the patients $(88.8 \%)$ had vitamin D insufficiency/deficiency and average plasma DHA level was decreased compared to controls ($12.4 \%$ ), but the plasma level of total BCAA was comparable with healthy age matched volunteers (figure 2a). Mean protein intake was well above recommended daily intake (RDI) $(1.4 \pm 0.1 \mathrm{~g} / \mathrm{kg} B W)$, whereas intake of vitamin $\mathrm{D}$ and calcium were below RDI in respectively 92.4 and $72.2 \%$ of the participants. Although baseline CET and 6MWD tended to be higher in NUTRITION, no significant differences in baseline characteristics were found between the NUTRITION and PLACEBO group (table 1). 


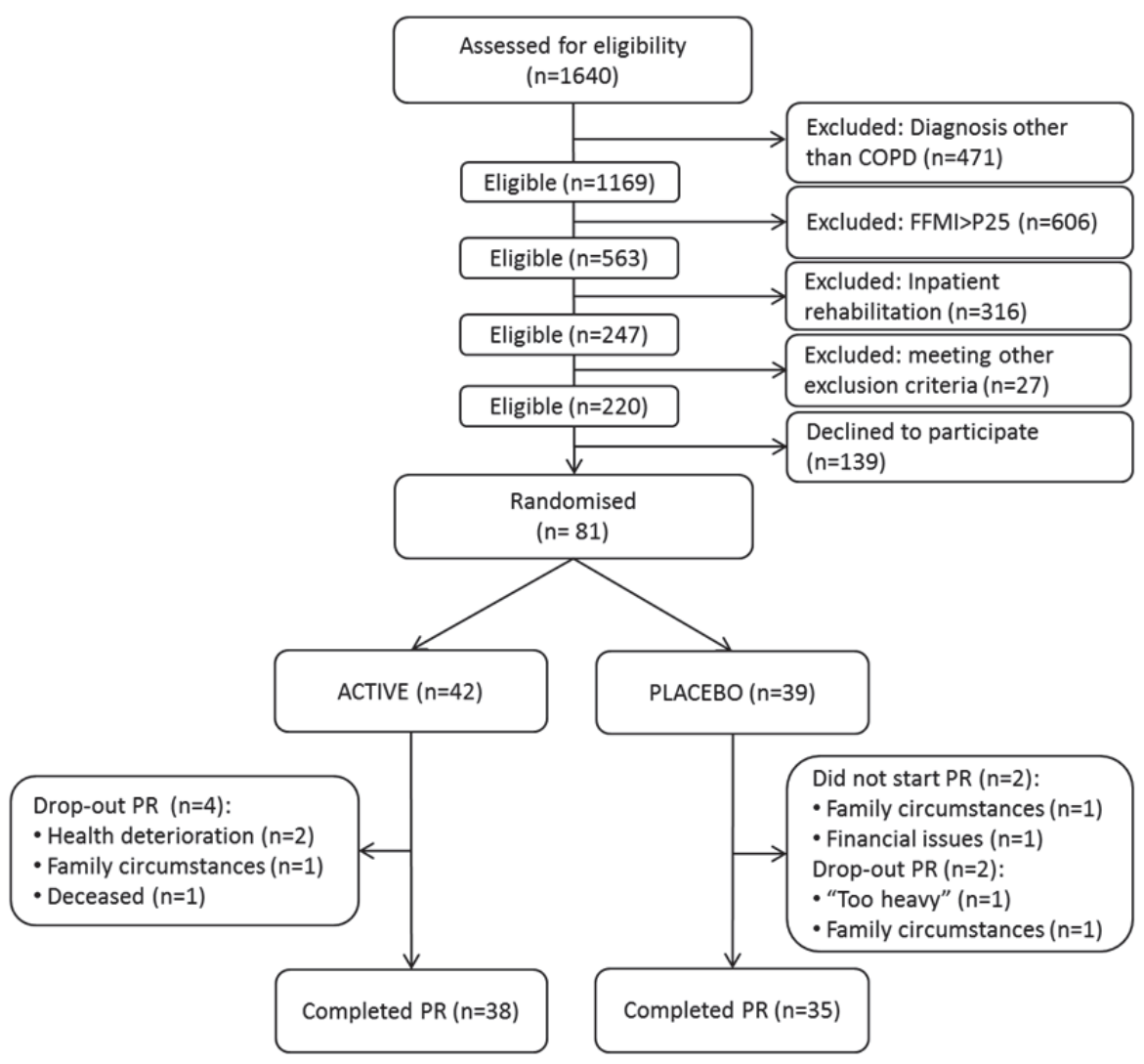

Figure 1: NUTRAIN-flowchart. A total of 1640 patients referred for pulmonary rehabilitation were assessed for trial eligibility. COPD patients (post-bronchodilator FEV1/FVC <0.7) were eligible when muscle wasted (FFMI < sex- and age-specific 25th percentile FFMI values) and referred for outpatient rehabilitation. 1420 patients were excluded and 139 eligible patients declined to participate. 81 patients were enrolled in the trial and randomized to NUTRITION or PLACEBO. Two of the 81 randomized patients did not start the treatment. During the PR the drop-out rate was 9.5\% (4 patients) in NUTRITION and 5.4\% (2 patients) in PLACEBO.

Two of the 81 randomized patients did not start the treatment. During the PR the dropout rate was $9.5 \%$ (4 patients) in NUTRITION and 5.4\% (2 patients) in PLACEBO. Mean supplement intake reached 2.1 \pm 0.1 portions/day. Reported side-effects included stomach-ache ( $\mathrm{n}=3$ in NUTRITION, $\mathrm{n}=1$ in PLACEBO), constipation ( $\mathrm{n}=2$ in NUTRITION) and undesirable weight loss ( $n=5$ in PLACEBO). Nonetheless, neutral or positive product rating was revealed in the majority of patients regarding taste, sweetness, mouthfeel and thickness of the NUTRITION and PLACEBO supplement. The aftertaste of the NUTRITION supplement was equally rated pleasant or unpleasant. A high satiety after consuming the supplement was reported by $\pm 70 \%$ in NUTRITION vs. $\pm 17 \%$ in PLACEBO $(\mathrm{P}<0.001)$. 
Table 1: Baseline characteristics of the Randomized Study Population

\begin{tabular}{|c|c|c|c|c|c|}
\hline & & \multicolumn{2}{|c|}{ PLACEBO $(n=39)$} & \multicolumn{2}{|c|}{ NUTRITION $(n=42)$} \\
\hline & & $\mathrm{N}$ & Mean \pm SEM & $\mathrm{N}$ & Mean \pm SEM \\
\hline \multirow[t]{5}{*}{ General } & Gender, \% male & & $59.0 \%$ & & $42.9 \%$ \\
\hline & Current smokers, \% & & $31.6 \%$ & & $19.0 \%$ \\
\hline & Age, years & 39 & $62.2 \pm 1.3$ & 42 & $62.8 \pm 1.3$ \\
\hline & Self-reported co-morbidities, $n$ & 39 & $2.5 \pm 0.3$ & 42 & $2.5 \pm 0.2$ \\
\hline & Exacerbations in last 12 months, $n$ & 39 & $1.4 \pm 0.3$ & 42 & $1.1 \pm 0.2$ \\
\hline \multirow[t]{6}{*}{ Lung function } & DLCO, \%predicted & 36 & $47.1 \pm 2.5$ & 42 & $51.4 \pm 2.2$ \\
\hline & $\mathrm{FEV}_{1}, \%$ predicted & 39 & $53.0 \pm 2.8$ & 42 & $57.0 \pm 3.3$ \\
\hline & FVC, \%predicted & 39 & $100.6 \pm 2.7$ & 42 & $102.8 \pm 2.9$ \\
\hline & $\mathrm{FEV}_{1} / \mathrm{FVC}, \%$ & 39 & $41.6 \pm 1.8$ & 42 & $44.4 \pm 2.0$ \\
\hline & FRC, \%predicted & 36 & $146.7 \pm 5.9$ & 42 & $139.1 \pm 4.3$ \\
\hline & Residual volume, \%predicted & 36 & $153.1 \pm 8.5$ & 42 & $143.4 \pm 6.3$ \\
\hline \multirow{9}{*}{$\begin{array}{l}\text { Plasma nutrient } \\
\text { levels }\end{array}$} & $\mathrm{BCAA}, \mu \mathrm{mol} / \mathrm{L}$ & 39 & $466.6 \pm 10.9$ & 41 & $448.0 \pm 10.8$ \\
\hline & Vitamin $\mathrm{D}, \mathrm{nmol} / \mathrm{L}$ & 39 & $45.3 \pm 3.1$ & 41 & $54.0 \pm 4.5$ \\
\hline & Vitamin D insufficiency, \% & & $23.1 \%$ & & $39.0 \%$ \\
\hline & Vitamin D deficiency, \% & & $69.2 \%$ & & $46.3 \%$ \\
\hline & AA, $\%$ of total FA & 37 & $11.3 \pm 0.4$ & 36 & $10.4 \pm 0.4$ \\
\hline & EPA, \% of total FA & 37 & $1.2 \pm 0.1$ & 36 & $1.1 \pm 0.1$ \\
\hline & DHA, \% of total FA & 37 & $3.2 \pm 0.2$ & 36 & $2.9 \pm 0.2$ \\
\hline & $\mathrm{N}-3 \mathrm{FA}, \%$ of total FA & 37 & $5.5 \pm 0.3$ & 36 & $5.2 \pm 0.2$ \\
\hline & N-6 FA, \% of total FA & 37 & $34.8 \pm 0.4$ & 36 & $34.7 \pm 0.4$ \\
\hline \multirow[t]{6}{*}{ Body composition } & Total body mass, kg & 39 & $65.0 \pm 1.7$ & 42 & $64.3 \pm 1.6$ \\
\hline & $\mathrm{BMI}, \mathrm{kg} / \mathrm{m}^{2}$ & 39 & $22.6 \pm 0.5$ & 42 & $22.9 \pm 0.4$ \\
\hline & $\mathrm{FM}, \mathrm{kg}$ & 39 & $19.0 \pm 1.3$ & 42 & $20.0 \pm 1.0$ \\
\hline & Lean mass, kg & 39 & $43.6 \pm 1.2$ & 42 & $42.0 \pm 1.3$ \\
\hline & SMM, kg & 39 & $18.4 \pm 0.6$ & 42 & $17.4 \pm 0.6$ \\
\hline & BMC, g & 39 & $2414.7 \pm 82.3$ & 42 & $2331.3 \pm 73.0$ \\
\hline \multirow[t]{7}{*}{ Dietary intake } & Total energy, kcal/day & 39 & $2361.7 \pm 161.3$ & 40 & $2188.8 \pm 111.4$ \\
\hline & Protein, g/kg BW/day & 39 & $1.4 \pm 0.1$ & 40 & $1.4 \pm 0.1$ \\
\hline & Protein $<1.0 \mathrm{~g} / \mathrm{kg} \mathrm{BW} /$ day & & $25.6 \%$ & & $25.0 \%$ \\
\hline & Vitamin D, $\mu \mathrm{g} /$ day & 39 & $5.1 \pm 0.5$ & 40 & $5.7 \pm 0.5$ \\
\hline & Vitamin D $<$ RDI, \% & & $89.7 \%$ & & $95.0 \%$ \\
\hline & Calcium, mg/day & 39 & $947.8 \pm 62.4$ & 40 & $998.1 \pm 56.9$ \\
\hline & Calcium <RDI, \% & & $74.4 \%$ & & $70.0 \%$ \\
\hline Lower limb muscle strength & QMS, Nm & 37 & $118.0 \pm 6.6$ & 39 & $121.5 \pm 6.4$ \\
\hline \multirow[t]{5}{*}{ Exercise performance } & Peak workload, Wmax & 39 & $72.5 \pm 3.8$ & 42 & $84.6 \pm 5.2$ \\
\hline & Peak workload, \%predicted & 39 & $57.0 \pm 3.4$ & 42 & $69.5 \pm 3.3^{* *}$ \\
\hline & CET, sec & 37 & $231.5 \pm 12.0$ & 41 & $319.0 \pm 35.2$ \\
\hline & 6MWD, m & 39 & $484.30 \pm 13.0$ & 42 & $501.4 \pm 13.1$ \\
\hline & 6MWD, \%predicted & 39 & $72.1 \pm 1.8$ & 42 & $77.2 \pm 1.7^{*}$ \\
\hline \multirow[t]{2}{*}{ Respiratory muscle strength } & IMS, kPa & 38 & $7.0 \pm 0.3$ & 42 & $6.8 \pm 0.4$ \\
\hline & IMS, \%predicted & 38 & $77.3 \pm 2.7$ & 42 & $79.4 \pm 3.8$ \\
\hline Physical activity level & PAL, steps/day & 37 & $4516.6 \pm 379.3$ & 38 & $4716.7 \pm 327.2$ \\
\hline
\end{tabular}

Data are mean \pm SEM or \%. BCAA: branched-chain amino acids; AA: arachidonic acid; EPA: eicosapentaenoic acid; DHA: docosahexaenoic acid; n-3 FA: omega 3 fatty acids; n-6 FA: omega 6 fatty acids; BMC: bone mineral content; SMM: skeletal muscle mass; FM: fat mass; QMS: quadriceps muscle strength; CET: cycle endurance time; 6MWD: 6 minute walking distance; IMS: inspiratory muscle strength; PAL: physical activity level. * $\mathrm{P}<0.05 ;{ }^{*} \mathrm{P}<0.01$ 


\section{Outcome assessment}

Outcomes of the intervention are presented in table 2. Change in plasma status of supplemented nutrients is shown in Figure 2B. Compared to baseline, plasma levels of vitamin D, EPA, DHA and total n-3 FA significantly increased in NUTRITION (respectively $+26 \%, \mathrm{P}<0.001$; +91\%, $\mathrm{P}<0.001 ;+27 \%, \mathrm{P}=0.001$; and $+38 \%, \mathrm{P}<0.001$ ), while AA and total n-6 FA significantly decreased $-10 \%, P<0.05$ and $-5 \%, P<0.001)$. In PLACEBO, DHA significantly decreased $(-9 \%, P=0.030)$, resulting in significant between-group difference in favour of NUTRITION in plasma vitamin D (+24\%, $P=0.004)$, EPA $(+91 \%, P<0.001)$, DHA $(+31 \%, P<0.001)$ and $n-3 F A(+42 \%, P<0.001)$. $A A$ and $n-6$ FA were significantly lower in NUTRITION than PLACEBO $(-11 \%, \mathrm{P}=0.019$; and $-6 \%, \mathrm{P}<0.001)$. No differences were found in plasma BCAAs.

A
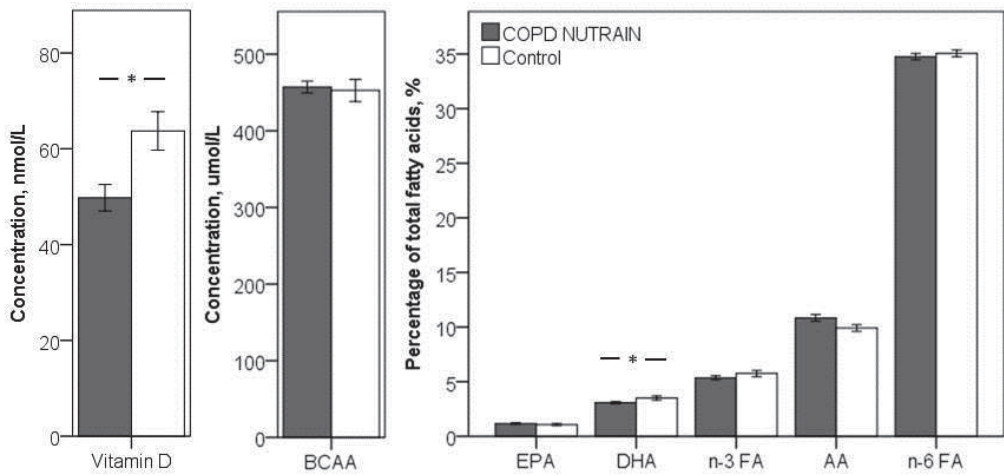

B
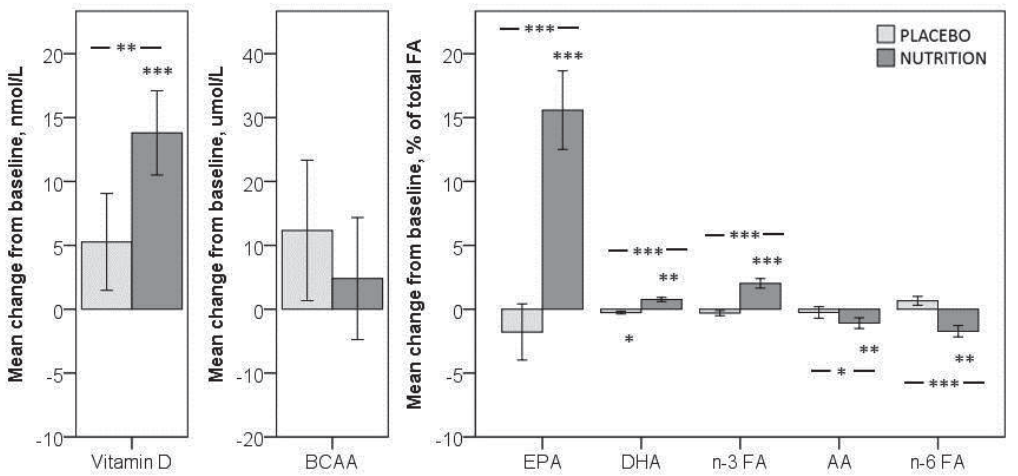

Figure 2: Plasma status of supplemented nutrients. A: Baseline plasma nutrient levels compared to healthy controls. Dark grey bars represent NUTRAIN-patients with COPD. White bars represent healthy controls. B: Mean change from baseline in plasma concentrations of supplemented nutrients. Light grey bars represent patients that received PLACEBO. Mid grey bars represent patients that received NUTRITION. * P<0.05; $* * \mathrm{P}<0.01 ; * * * \mathrm{P}<0.001$ 
Table 2: Outcomes of the intervention

\begin{tabular}{|c|c|c|c|c|c|}
\hline & \multicolumn{2}{|l|}{ PLACEBO $(n=35)$} & \multicolumn{2}{|c|}{ NUTRITION $(n=38)$} & \multirow{2}{*}{$\begin{array}{l}\text { Between } \\
\text { group } \\
\text { differences } \\
\text { (NUTRITION- } \\
\text { PLACEBO) } \\
\text { Adj. difference } \\
\pm \text { SEM }^{1}\end{array}$} \\
\hline & $\begin{array}{l}\text { Pre } \\
\text { Mean } \pm \text { SEM }\end{array}$ & $\begin{array}{l}\text { Post } \\
\text { Mean } \pm S E M\end{array}$ & $\begin{array}{l}\text { Pre } \\
\text { Mean } \pm S E M\end{array}$ & $\begin{array}{l}\text { Post } \\
\text { Mean } \pm S E M\end{array}$ & \\
\hline \multicolumn{6}{|l|}{ Plasma nutrient levels } \\
\hline BCAA, $\mu \mathrm{mol} / \mathrm{L}$ & $471.6 \pm 11.6$ & $483.9 \pm 15.5$ & $445.3 \pm 11.6$ & $450.1 \pm 10.3$ & $-14.4 \pm 14.2$ \\
\hline Vitamin D, nmol/L & $44.6 \pm 3.3$ & $49.9 \pm 4.0$ & $54.2 \pm 4.9$ & $68.0 \pm 3.6^{* * *}$ & $12.8 \pm 4.3^{* *}$ \\
\hline AA, $\%$ of total FA & $11.3 \pm 0.4$ & $11.0 \pm 0.5$ & $10.6 \pm 0.5$ & $9.5 \pm 0.3^{*}$ & $-1.2 \pm 0.5^{*}$ \\
\hline EPA, $\%$ of total FA & $1.2 \pm 0.1$ & $1.1 \pm 0.1$ & $1.1 \pm 0.1$ & $2.1 \pm 0.2^{* * *}$ & $1.0 \pm 0.2^{* * *}$ \\
\hline DHA, \% of total FA & $3.2 \pm 0.2$ & $2.9 \pm 0.1^{*}$ & $3.0 \pm 0.2$ & $3.8 \pm 0.1^{* * *}$ & $0.9 \pm 0.2^{* * *}$ \\
\hline N-3 FA, $\%$ of total FA & $5.5 \pm 0.3$ & $5.2 \pm 0.2$ & $5.3 \pm 0.3$ & $7.3 \pm 0.3^{* * *}$ & $2.2 \pm 0.4^{* * *}$ \\
\hline N-6 FA, \% of total FA & $34.8 \pm 0.4$ & $35.5 \pm 0.4$ & $35.1 \pm 0.3$ & $33.4 \pm 0.5^{* * *}$ & $-2.2 \pm 0.5^{* * *}$ \\
\hline \multicolumn{6}{|l|}{ Body composition } \\
\hline Total body mass, kg & $65.7 \pm 1.7$ & $66.0 \pm 1.7$ & $63.8 \pm 1.7$ & $65.7 \pm 1.7^{* * *}$ & $1.5 \pm 0.6^{*}$ \\
\hline $\mathrm{BMC}, \mathrm{g}$ & $2427.2 \pm 85.9$ & $2428.5 \pm 84.1$ & $2326.7 \pm 78.7$ & $2339.2 \pm 80.3$ & $10.0 \pm 17.7$ \\
\hline SMM, kg & $18.5 \pm 0.6$ & $18.8 \pm 0.6^{* *}$ & $17.2 \pm 0.6$ & $17.8 \pm 0.7^{* *}$ & $0.3 \pm 0.2$ \\
\hline $\mathrm{FM}, \mathrm{kg}$ & $19.4 \pm 1.4$ & $19.2 \pm 1.4$ & $19.8 \pm 1.1$ & $21.0 \pm 1.1^{* * *}$ & $1.6 \pm 0.5^{* *}$ \\
\hline \multicolumn{6}{|c|}{ Lower limb muscle function } \\
\hline QMS, Nm & $121.2 \pm 6.9$ & $132.0 \pm 7.2^{* *}$ & $121.7 \pm 6.9$ & $135.3 \pm 8.2^{* * *}$ & $2.8 \pm 4.6$ \\
\hline \multicolumn{6}{|l|}{ Exercise performance } \\
\hline CET, s & $237.9 \pm 12.3$ & $482.4 \pm 62.5^{* * *}$ & $323.2 \pm 38.8$ & $467.2 \pm 54.7^{* * *}$ & $-109.7 \pm 70.4$ \\
\hline 6MWD, m & $492.5 \pm 14.0$ & $492.0 \pm 16.6$ & $504.0 \pm 14.5$ & 500.317 .9 & $-3.9 \pm 12.2$ \\
\hline \multicolumn{6}{|c|}{ Respiratory muscle function } \\
\hline IMS, kPa & $7.1 \pm 0.3$ & $7.5 \pm 0.3$ & $6.7 \pm 0.4$ & $7.2 \pm 0.4^{* *}$ & $0.0 \pm 0.3$ \\
\hline \multicolumn{6}{|l|}{ Physical activity level } \\
\hline PAL, steps/day & $4664.7 \pm 415.9$ & $3841.9 \pm 393.4^{* *}$ & $4790.1 \pm 352.2$ & $4866.4 \pm 479.0$ & $929.5 \pm 459.2^{*}$ \\
\hline \multicolumn{6}{|l|}{ Mood } \\
\hline HADS total score & $11.1 \pm 1.2$ & $8.5 \pm 0.9 * *$ & $12.2 \pm 1.0$ & $9.2 \pm 1.1^{* * *}$ & $-0.2 \pm 1.0$ \\
\hline HADS anxiety score & $6.0 \pm 0.7$ & $4.1 \pm 0.5^{* *}$ & $6.3 \pm 0.7$ & $4.8 \pm 0.6^{* * *}$ & $0.4 \pm 0.6$ \\
\hline $\begin{array}{l}\text { HADS depression } \\
\text { score }\end{array}$ & $5.1 \pm 0.6$ & $4.4 \pm 0.5$ & $5.9 \pm 0.5$ & $4.4 \pm 0.6^{* *}$ & $-0.5 \pm 0.6$ \\
\hline
\end{tabular}

Data are mean \pm SEM or \%. BCAA: branched-chain amino acids; AA: arachidonic acid; EPA: eicosapentaenoic acid; DHA: docosahexaenoic acid; n-3 FA: omega 3 fatty acids; n-6 FA: omega 6 fatty acids; BMC: bone mineral content; SMM: skeletal muscle mass; FM: fat mass; QMS: quadriceps muscle strength; CET: cycle endurance time; 6MWD: 6 minute walking distance; IMS: inspiratory muscle strength; PAL: physical activity level ; HADS: Hospital anxiety and depression scale. ${ }^{*} \mathrm{P}<0.05 ;{ }^{*} \mathrm{P}<0.01 ;{ }^{* * *} \mathrm{P}<0.001 .{ }^{1}$ Between-group differences were compared by ANCOVA (taking pre-treatment value as covariate, the 4 month post-treatment value as response, and considering treatment as a factor in the statistical model). 
Body composition results showed significantly increased body mass increased by $1.9 \pm 0.4 \mathrm{~kg}(P<0.001), S M M$ by $0.5 \pm 0.2 \mathrm{~kg}(P=0.002)$ and $F M$ by $1.4 \pm 0.4 \mathrm{~kg}(P=0.001)$ compared to baseline (table 2$)$. Also in PLACEBO, SMM increased significantly $(+0.3 \pm 0.1$ $\mathrm{kg}, \mathrm{P}=0.003)$. After PR, NUTRITION showed significantly higher body mass $(66.5 \pm 0.4 \mathrm{vs}$. $65.0 \pm 0.4 \mathrm{~kg}, P=0.01)$ and $F M(21.0 \pm 0.3$ vs. $19.4 \pm 0.4 \mathrm{~kg}, P=0.002)$ than PLACEBO. No between-group differences were found in SMM.

Assessment of lower limb muscle strength and exercise performance showed comparable improvements in quadriceps muscle strength (PLACEBO: $+10.8 \pm 3.1 \mathrm{Nm}, \mathrm{P}=0.001$; NUTRITION: $+13.7 \pm 3.4 \mathrm{Nm}, \mathrm{P}<0.001$ ) and CET (PLACEBO: $+244.5 \pm 57.5 \mathrm{~s}, \mathrm{P}<0.001$; NUTRITION: +144.0 $\pm 38.7 \mathrm{~s}, \mathrm{P}<0.001$ ) after $P R$ (figure 3 ). No differences were found in $6 \mathrm{MWD}$ within or between groups (table 2).

A

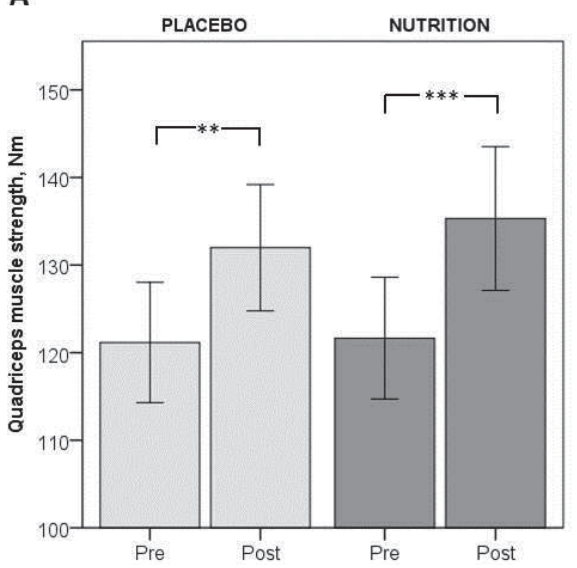

B

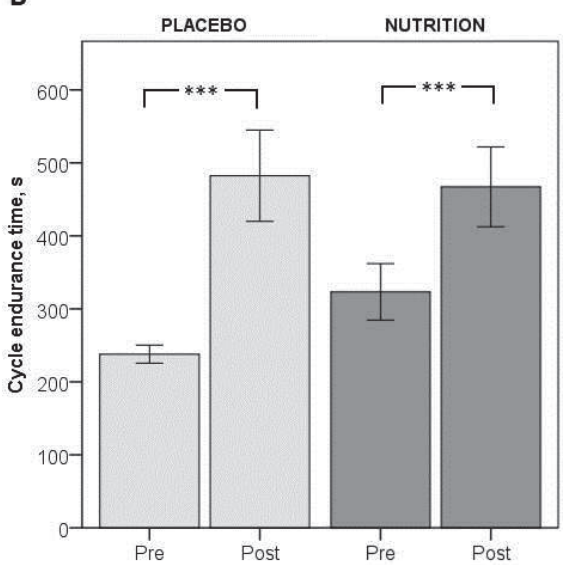

Figure 3: Mean pre- and post- values of A: Lower limb muscle strength; B: Exercise performance. Light grey bars represent patients that received PLACEBO. Mid grey bars represent patients that received NUTRITION. * $\mathrm{P}<0.05 ;{ }^{* *} \mathrm{P}<0.01 ;{ }^{* * *} \mathrm{P}<0.001$

Inspiratory muscle strength improved significantly only in NUTRITION $(+0.5 \pm 0.1 \mathrm{kPa}$, $\mathrm{P}=0.001$ ) (figure 4). After $\mathrm{PR}$, daily steps decreased significantly in PLACEBO by $822.8 \pm 283.8$ steps/day (-18\%; $P=0.005)$, but remained stable in NUTRITION $(76.4 \pm 385.1$ steps/day, $\mathrm{P}=0.767)$. This resulted in a significant between-group difference in favour of NUTRITION (4817.3 \pm 330.2 vs. $3887.8 \pm 319.0$ steps in PLACEBO, $P=0.048$ ). Assessment of mood showed significantly improved HADS depression score in NUTRITION, but not in PLACEBO (table 2). 
A

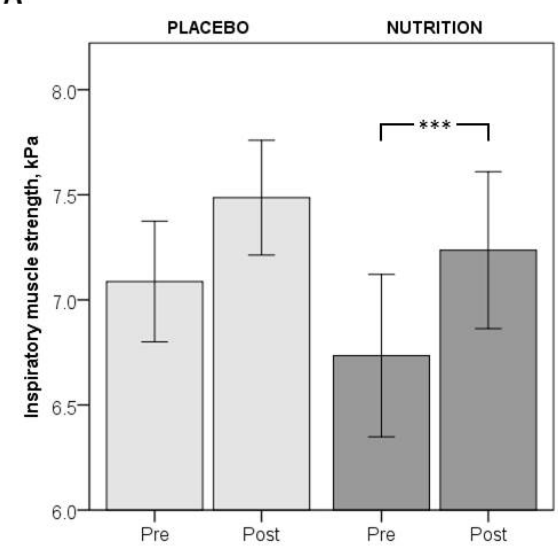

B

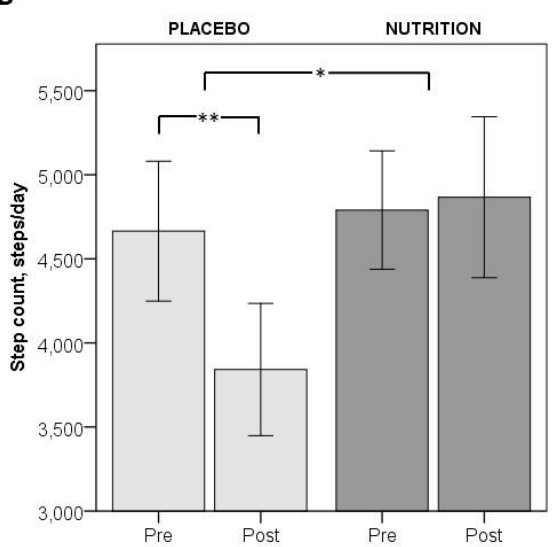

Figure 4: Mean pre- and post- values of A: Respiratory muscle strength; B: Physical activity level. Light grey bars represent patients that received PLACEBO. Mid grey bars represent patients that received NUTRITION. * $\mathrm{P}<0.05 ; * \mathrm{*}<0.01$

\section{DISCUSSION}

The NUTRAIN-trial showed that muscle wasted COPD patients with moderate airflow obstruction respond well to high intensity exercise training. In this population no additional effect of nutritional intervention was shown on lower limb muscle strength as primary outcome measure, but respiratory muscle strength (which was not a training target) improved in NUTRITION only. Between-group differences favouring NUTRITION were shown in body weight, plasma nutrient status and physical activity.

Earlier research on nutritional rehabilitation has mainly focused on providing enough energy and protein to improve or maintain body weight and muscle mass. Recent research has shifted towards the quality of dietary protein in terms of protein sources and supplementation of specific anabolic amino acids. Casein and whey, both high-quality proteins because of their high essential amino acid (EAA) content, are shown to comparably and efficiently stimulate muscle protein synthesis (13). Leucine is one of the BCAA's known to increase insulin secretion and influence molecular regulation of muscle protein synthesis (via the mTOR-pathway), thereby stimulating anabolism and muscle protein synthesis, provided sufficient supply of essential amino acids (EAA) to the muscles (6). The current supplement therefore provided equal amounts of casein and whey $(4.2 \mathrm{~g})$ for a balanced amino acid profile, enriched with $1.8 \mathrm{~g}$ leucine per serving volume of $125 \mathrm{ml}$. SMM increased after exercise training, but this response was not augmented by protein supplementation. Possibly protein supplementation is mainly effective in subjects with a deficient state of protein. Indeed patients with advanced COPD and muscle wasting are reported to have low plasma levels of BCAA's (especially 
leucine) compared to age-matched controls $(7,14)$, which could reflect a deficient state in muscle (7), but no evidence for a deficient BCAA state was found in our NUTRAINpatients with less advanced COPD. In a sample of 88 patients with severe COPD (GOLD 3-4) and $\mathrm{BMI}<23 \mathrm{~kg} / \mathrm{m}^{2}$ not receiving exercise training, 12 weeks of supplementation with an EAA (4g/day) mixture high in leucine led to higher FFM and muscle strength compared to an isocaloric placebo (15). Nonetheless, these patients were characterized by lower protein intake at baseline $(1.0 \pm 0.2 \mathrm{~g} / \mathrm{kg})$ than the current study population $(1.4 \pm 0.1 \mathrm{~g} / \mathrm{kg}$ BW). Constantin et al. (16) randomly allocated 59 COPD patients (FEV 1 $46.9 \pm 17.8 \%$ predicted) to receive $19 \mathrm{~g}$ protein and $49 \mathrm{~g}$ carbohydrate or placebo supplements during 8 weeks of resistance training. They found a strong response to the training component (lean mass and strength gain), but nutritional supplementation did not augment functional responses to resistance training. In line, we found a strong response to the exercise training in the present trial, reflected as significantly increased muscle mass, lower limb muscle strength and CET in both groups. All in all, it might be concluded that the augmenting value of protein fortification on skeletal muscle mass and quadriceps muscle strength is minimal in COPD with less advanced airflow obstruction when habitual protein intake is already adequate. Moreover, previous literature has suggested that further improvements on top of the effects of exercise training via "add-on" modalities may be challenging to obtain. Particularly muscle composition and function may have realistic ceilings in terms of the magnitude of expected improvement within a short time-period (17).

So-called pharmaco-nutrients have recently been proposed to enhance efficacy of nutritional supplementation on physical performance by targeting muscle metabolism (5). PUFA's are the natural ligands of peroxisome proliferator-activated receptors (PPARs) and PPAR-gamma coactivator (PGC)-1 $\alpha$, which are involved in regulation of skeletal muscle morphology and oxidative metabolism. A decreased expression of these regulators is reported in the skeletal muscle of advanced COPD patients compared with healthy controls (18). Broekhuizen et al. (9) demonstrated that PUFA modulation during an 8 week inpatient rehabilitation program was able to improve exercise capacity (peak workload and CET) to a larger extent than placebo in patients with severe COPD independent of lower limb muscle mass and strength. In the current NUTRAIN-trial peak workload was not assessed post-PR, but no group differences were found in CET. However, a comparison between studies is limited because of differences in CET protocol. Furthermore the population by Broekhuizen et al. consisted of patients with more advanced disease $\left(\mathrm{FEV}_{1} 37.3 \pm 13.8 \%\right.$ predicted) and with severe exercise impairment (41.3 $\pm 19.3 \%$ predicted).

The majority of the NUTRAIN-patients were vitamin D insufficient/deficient (88.8\%) providing a clear rationale for supplementation. In line with our study, a published posthoc subgroup analysis of 50 patients with COPD and vitamin D deficiency following a 3month outpatient PR (19), reported a similar dissociation between improvements in 
peripheral and respiratory muscle strength after vitamin D supplementation. Patients receiving a monthly dose of $100.000 \mathrm{IU}$ vitamin D had significantly larger improvements in inspiratory muscle strength and peak exercise tolerance, but not in quadriceps strength and 6-min walking distance (6MWD) compared to placebo. Median 25hydroxycholecalciferol level increased from $15 \mathrm{ng} / \mathrm{ml}(37.4 \mathrm{nmol} / \mathrm{L})$ to $51 \mathrm{ng} / \mathrm{ml}(127.3$ $\mathrm{nmol} / \mathrm{L}$ ), which exceeded the increase observed in the NUTRAIN-trial (+25\%), presumably by the 5-6 times higher administered dose. As respiratory muscle training was not part of the PR program in both trials, this might suggest a differential response of respiratory muscle following vitamin D and/or $n-3$ fatty acids supplemented nutrients than peripheral muscle possibly related to maintenance of muscle oxidative phenotype in respiratory muscles (20).

Exercise training significantly increased quadriceps muscle strength and CET in both groups. CET tended to increase to a smaller extent after supplementation, presumably because of a trend towards higher baseline value compared to the placebo group. Still the increase in CET exceeded the proposed minimal clinically important difference of 100-105 seconds (21). No changes were observed in 6MWD in the current study, but average 6MWD did not seem rigorously impaired at baseline (almost 500m) and also in the INTERCOM-trial, investigating a comparable group of COPD patients with less advanced disease, 6MWD maintained similar in the intervention group but deteriorated in muscle wasted patients receiving usual care (11). That was also the reason why 6MWD was only included as exploratory outcome in this trial.

Recently a more active lifestyle, reflected by objective assessment via accelerometry, has been proposed as novel and clinically important outcome measure of PR. According to the sparse literature available, the effects of current PR programs in terms of physical activity level are heterogeneous, which could be related to differences in studied population, type and intensity of the exercise training and incorporation of other interventions like nutritional or psychological interventions (22). The exercise training part of the NUTRAIN-trial primarily focused on high intensity resistance and endurance exercises, but no standardized behavioural change intervention for physical activity was incorporated. Despite concomitant increase in exercise capacity, the number of steps/day decreased in the placebo group, indicating a compensatory response to recover from the intensive exercise training sessions in daily physical activity. The observed dissociation between physical performance and daily physical activity has previously been reported in studies evaluating the effect of PR on daily physical activity (22) and suggests that changing physical activity behaviour requires a more comprehensive approach than only targeting exercise capacity (23). In contrast to the placebo group, no adaptive decrease in daily steps was shown by patients receiving nutritional supplementation. This could be related to specific nutrient effects on lower limb muscle metabolism resulting in decreased muscle fatigue or via the observed improvement in respiratory muscle function. Dal Negro et al. (15) reported increased number of steps after EAA supple- 
mentation in domiciliary severe COPD patients. Alternatively a positive effect of $n-3$ fatty acid enriched protein-dense supplements could be implicated as in cachectic patients with pancreatic cancer n-3 FA supplementation also increased physical activity level assessed by doubly labelled water independent of muscle mass (24). Next to exercise, n-3 FA additionally stimulate the PGC-1 $\alpha$-PPAR $\alpha / \delta$ pathway in muscle resulting not only in enhanced muscle (fat) oxidative metabolism (25) and decreased muscle fatigue, but also in enhanced conversion of peripheral kynurenine into kynurenic acid, which is unable to cross the blood-brain barrier (26). Reducing plasma kynurenine protects the brain by mediating resilience to stress induced depression. Some evidence for this hypothesis was provided in this trial by the HADS depression score, which improved significantly in NUTRITION but not in PLACEBO. Based on previous research nutritional supplementation consisted of 2-3 portions of $125 \mathrm{ml} /$ day, which in the current trial proved to be the maximal feasible dosage. Intention-to-treat analysis revealed an average supplement intake of 2.1 portions/day, accompanied by significantly increased percentages of EPA and DHA, which are suggested to be useful blood biomarkers for determining adherence in clinical studies because of the linear response to its intakes (27). No changes were found in habitual dietary intake after PR (see supplemental data), suggesting that patients in the NUTRITION group did not compensate for NS. Patients in the placebo group also did not compensate by increasing their energy intake for increased energy costs caused by the intensive exercise training, possibly implying that energy costs were compensated during the remainder of the day by an adaptive decreased number of daily steps. While the increase in FM resulting from extra caloric support may be protective in COPD patients prone to weight loss, it could be argued that attention should shift from macro- to targeted nutrient supplementation in weight stable but muscle wasted COPD patients. This may likely also improve compliance to nutritional support in some patients.

Based on the primary outcome measure the study was negative. There may have been a difference in muscle strength between the groups that wasn't detected as the study is potentially underpowered. It could additionally be argued that the studied population was too fit, since they had a moderate level of airflow obstruction, a mean 6MWD around 500 meters, and a well above recommended daily protein intake. The criterion applied for muscle wasting (FFMI-P25) was broader than defined by the ERS statement on nutritional assessment and therapy in COPD (1) but derived from the IRAD-2 trial. This trial showed favourable effects of 3 months of home rehabilitation combining health education, oral nutritional supplements, exercise and oral testosterone on body composition and exercise tolerance compared to usual care in muscle wasted patient with chronic respiratory failure (28). Nevertheless to explore potential deviating intervention responses following the applied criteria for muscle wasting, we performed a post-hoc subgroup analysis in which we compared outcomes between $n=44$ patients with a FFMI $<10^{\text {th }}$ percentile values (according to the ERS statement) and $n=37$ a FFMI 
$10^{\text {th }}-25^{\text {th }}$ percentile values. ANCOVA did not show differences in any of the outcomes between the groups. Although the NUTRAIN-trial did not reach the targeted sample size $(n=120)$ and was not designed to disentangle the mechanism behind the observed dissociation between physical performance and daily physical activity, it does provide new interesting leads for further research regarding the potential of nutritional modulation in COPD beyond skeletal muscle maintenance. Furthermore, adequate clinical trials in COPD are needed to explore nutritional strategies for maintaining the effects of exercise training after a pulmonary rehabilitation program. Data of the exploratory maintenance program of the NUTRAIN-trial will be reported separately.

In conclusion, this RCT shows that exercise training is successful in improving lower limb muscle strength and cycle exercise performance in muscle wasted COPD patients with moderate airflow obstruction provided a sufficient protein intake. Additional specific nutritional supplementation had beneficial effects on nutritional status and inspiratory muscle strength and positively influenced physical activity. 


\section{REFERENCES}

1. Schols AM, Ferreira IM, Franssen FM, Gosker HR, Janssens W, Muscaritoli M, Pison C, Rutten-van Molken M, Slinde F, Steiner MC, Tkacova R, Singh SJ. Nutritional assessment and therapy in copd: A european respiratory society statement. Eur Respir J 2014.

2. van de Bool C, Gosker HR, van den Borst B, Op den Kamp CM, Slot IG, Schols AM. Muscle quality is more impaired in sarcopenic patients with chronic obstructive pulmonary disease. J Am Med Dir Assoc 2016;17:415-420.

3. Spruit MA, Singh SJ, Garvey C, ZuWallack R, Nici L, Rochester C, Hill K, Holland AE, Lareau SC, Man WD, Pitta F, Sewell L, Raskin J, Bourbeau J, Crouch R, Franssen FM, Casaburi R, Vercoulen JH, Vogiatzis I, Gosselink R, Clini EM, Effing TW, Maltais F, van der Palen J, Troosters T, Janssen DJ, Collins E, GarciaAymerich J, Brooks D, Fahy BF, Puhan MA, Hoogendoorn M, Garrod R, Schols AM, Carlin B, Benzo R, Meek P, Morgan M, Rutten-van Molken MP, Ries AL, Make B, Goldstein RS, Dowson CA, Brozek JL, Donner CF, Wouters EF. An official american thoracic society/european respiratory society statement: Key concepts and advances in pulmonary rehabilitation. Am J Respir Crit Care Med 2013;188:e13-64.

4. Ferreira IM, Brooks D, White J, Goldstein R. Nutritional supplementation for stable chronic obstructive pulmonary disease. Cochrane Database Syst Rev 2012;12:CD000998.

5. van de Bool C, Steiner MC, Schols AM. Nutritional targets to enhance exercise performance in chronic obstructive pulmonary disease. Curr Opin Clin Nutr Metab Care 2012;15:553-560.

6. Drummond MJ, Rasmussen BB. Leucine-enriched nutrients and the regulation of mammalian target of rapamycin signalling and human skeletal muscle protein synthesis. Curr Opin Clin Nutr Metab Care 2008;11:222-226.

7. Engelen MP, Wouters EF, Deutz NE, Menheere PP, Schols AM. Factors contributing to alterations in skeletal muscle and plasma amino acid profiles in patients with chronic obstructive pulmonary disease. Am J Clin Nutr 2000;72:1480-1487.

8. Romme EA, Rutten EP, Smeenk FW, Spruit MA, Menheere PP, Wouters EF. Vitamin d status is associated with bone mineral density and functional exercise capacity in patients with chronic obstructive pulmonary disease. Ann Med 2013;45:91-96.

9. Broekhuizen R, Wouters EF, Creutzberg EC, Weling-Scheepers CA, Schols AM. Polyunsaturated fatty acids improve exercise capacity in chronic obstructive pulmonary disease. Thorax 2005;60:376-382.

10. Schutz Y, Kyle UU, Pichard C. Fat-free mass index and fat mass index percentiles in caucasians aged 18-98 y. Int J Obes Relat Metab Disord 2002;26:953-960.

11. van Wetering CR, Hoogendoorn M, Broekhuizen R, Geraerts-Keeris GJ, De Munck DR, Rutten-van Molken MP et al. Efficacy and costs of nutritional rehabilitation in muscle-wasted patients with chronic obstructive pulmonary disease in a community-based setting: a prespecified subgroup analysis of the INTERCOM trial. J Am Med Dir Assoc. 2010;11(3):179-87.

12. Bland JM, Altman DG. Best (but oft forgotten) practices: Testing for treatment effects in randomized trials by separate analyses of changes from baseline in each group is a misleading approach. Am J Clin Nutr 2015;102:991-994.

13. Jonker R, Deutz NE, Erbland ML, Anderson PJ, Engelen MP. Hydrolyzed casein and whey protein meals comparably stimulate net whole-body protein synthesis in copd patients with nutritional depletion without an additional effect of leucine co-ingestion. Clin Nutr 2014;33:211-220.

14. Ubhi BK, Riley JH, Shaw PA, Lomas DA, Tal-Singer R, MacNee W, Griffin JL, Connor SC. Metabolic profiling detects biomarkers of protein degradation in copd patients. Eur Respir J 2012;40:345-355.

15. Dal Negro RW, Testa A, Aquilani R, Tognella S, Pasini E, Barbieri A, Boschi F. Essential amino acid supplementation in patients with severe copd: A step towards home rehabilitation. Monaldi Arch Chest Dis 2012;77:67-75.

16. Constantin D, Menon MK, Houchen-Wolloff L, Morgan MD, Singh SJ, Greenhaff P, Steiner MC. Skeletal muscle molecular responses to resistance training and dietary supplementation in copd. Thorax 2013;68:625-633. 
17. Camillo CA, Osadnik CR, van Remoortel H, Burtin C, Janssens W, Troosters T. Effect of "add-on" interventions on exercise training in individuals with COPD: a systematic review. ERJ open research. 2016;2(1). doi:10.1183/23120541.00078-2015.

18. Remels A, Schrauwen P, Broekhuizen R, Willems J, Kersten S, Gosker H, Schols A. Expression and content of ppars is reduced in skeletal muscle of copd patients. European Respiratory Journal 2007:09031936.00144106.

19. Hornikx M, Van Remoortel H, Lehouck A, Mathieu C, Maes K, Gayan-Ramirez G, Decramer M, Troosters $\mathrm{T}$, Janssens $\mathrm{W}$. Vitamin d supplementation during rehabilitation in copd: A secondary analysis of a randomized trial. Respir Res 2012;13:84.

20. Caron MA, Debigare R, Dekhuijzen PN, Maltais F. Comparative assessment of the quadriceps and the diaphragm in patients with copd. J Appl Physiol (1985) 2009;107:952-961.

21. Casaburi R. Factors determining constant work rate exercise tolerance in copd and their role in dictating the minimal clinically important difference in response to interventions. COPD 2005;2:131-136.

22. Watz H, Pitta F, Rochester CL, Garcia-Aymerich J, ZuWallack R, Troosters T, Vaes AW, Puhan MA, Jehn M, Polkey MI, Vogiatzis I, Clini EM, Toth M, Gimeno-Santos E, Waschki B, Esteban C, Hayot M, Casaburi R, Porszasz J, McAuley E, Singh SJ, Langer D, Wouters EF, Magnussen H, Spruit MA. An official european respiratory society statement on physical activity in copd. Eur Respir J 2014;44:1521-1537.

23. Thorpe O, Johnston K, Kumar S. Barriers and enablers to physical activity participation in patients with copd: A systematic review. J Cardiopulm Rehabil Prev 2012;32:359-369.

24. Moses AW, Slater C, Preston T, Barber MD, Fearon KC. Reduced total energy expenditure and physical activity in cachectic patients with pancreatic cancer can be modulated by an energy and protein dense oral supplement enriched with n-3 fatty acids. Br J Cancer 2004;90:996-1002.

25. Schoonjans K, Staels B, Auwerx J. The peroxisome proliferator activated receptors (ppars) and their effects on lipid metabolism and adipocyte differentiation. Biochim Biophys Acta 1996;1302:93-109.

26. Agudelo LZ, Femenia T, Orhan F, Porsmyr-Palmertz M, Goiny M, Martinez-Redondo V, Correia JC, Izadi M, Bhat M, Schuppe-Koistinen I, Pettersson AT, Ferreira DM, Krook A, Barres R, Zierath JR, Erhardt S, Lindskog M, Ruas JL. Skeletal muscle pgc-1alpha1 modulates kynurenine metabolism and mediates resilience to stress-induced depression. Cell 2014;159:33-45.

27. Patterson AC, Chalil A, Aristizabal Henao JJ, Streit IT, Stark KD. Omega-3 polyunsaturated fatty acid blood biomarkers increase linearly in men and women after tightly controlled intakes of $0.25,0.5$, and $1 \mathrm{~g} / \mathrm{d}$ of epa + dha. Nutr Res 2015;35:1040-1051.

28. Pison CM, Cano NJ, Cherion C, Caron F, Court-Fortune I, Antonini MT, Gonzalez-Bermejo J, Meziane L, Molano LC, Janssens JP, Costes F, Wuyam B, Similowski T, Melloni B, Hayot M, Augustin J, Tardif C, Lejeune $\mathrm{H}$, Roth $\mathrm{H}$, Pichard $\mathrm{C}$. Multimodal nutritional rehabilitation improves clinical outcomes of malnourished patients with chronic respiratory failure: A randomised controlled trial. Thorax 2011;66:953960. 


\section{SUPPLEMENTAL DATA}

\section{Detailed methodology}

\section{Study design}

This double blind placebo controlled multi-centre NUTRAIN-trial was integrated in the out-patient PR programme performed in the hospitals of the CIRO network in the South East of the Netherlands (Sint Anna hospital in Geldrop, Laurentius hospital in Roermond, Maxima Medical Centre in Veldhoven (until March 2013), Sint Jans Gasthuis hospital in Weert, Elkerliek hospital in Helmond, Maastricht University Medical Centre and Catharina hospital in Eindhoven).

\section{Study population}

\section{Exclusion criteria}

Patients were excluded in case of allergy or intolerance to components of the study product or participating in any other study involving investigational or marketed products concomitantly or within two weeks prior to entry into the study. Other exclusion criteria were pregnancy, life expectancy $<6$ months and investigator's uncertainty about the willingness or ability of the patient to comply with the protocol requirements.

\section{Control group}

To explore if the nutrient supplementation treated a deficient status or not, baseline plasma nutrient status was compared with a healthy control group, consisting of 34 subjects (59.4\% male, aged $62.5 \pm 1.4$, BMI $24.6 \pm 0.6 \mathrm{~kg} / \mathrm{m}^{2}$ ) recruited via local newspapers advertisement. Absence of diseases was verified through history-taking by a physician, and absence of airflow limitation was verified by spirometry (post-bronchodilator FEV1/FVC $\geq 0.7$ ). All control subjects were included in July 2007-July 2010 and March 2009-April 2010 for participation in 1 out of 2 cross-sectional studies of which data has been previously published $(2,3)$.

\section{Procedures}

The nutritional intervention was integrated in a 4-month standardised outpatient PR programme consisting of 40 training sessions supervised by trained physiotherapists, 23 times a week according to the ATS/ERS statement on PR (4), including high intensity endurance exercise by cycle ergometry and treadmill walking and progressive resistance exercise of upper and lower body at $75 \%$ of the 1 repetition maximum. All patients received education about COPD, exercise, healthy nutrition and smokers were assigned to the respiratory nurse for standardized smoking cessation support. Patients from both the PLACEBO and NUTRITION group were advised to consume 2-3 portions of the supplement daily. Per volume serving of $125 \mathrm{~mL}$ unit, the NUTRITION product provided $187.5 \mathrm{kCal}, 9.4 \mathrm{~g}$ proteins, $28.1 \mathrm{~g}$ carbohydrates and $4.1 \mathrm{~g}$ fat, resulting in a distribution 
of 20EN\% protein; 60EN\% carbohydrate (CHO); 20EN\% fat, and was enriched with leucine, n-3 PUFA and vitamin D (Nutricia NV, Zoetermeer, the Netherlands, for details see supplemental table 1). The PLACEBO product did not comprise the investigated active components, but consisted of a flavoured non-caloric aqueous solution. Consumption of the nutritional supplements directly after the sessions was monitored. Furthermore, compliance regarding the nutritional supplementation was tracked on a calendar, but also calculated based on supplements provided and returned.

\section{Randomisation and masking}

The randomization sequence was generated using the PLAN procedure of SAS statistical software (Enterprise Guide version 4.3) by a statistician from Nutricia Research who had no further involvement in the conduct of the study. The permuted block randomization was stratified for site, with a 1:1 allocation ratio of NUTRITION and PLACEBO product. All details of the randomization, including block size, were unknown to the investigator, site staff, and study staff, except for the statistician who was responsible for generating the randomization sequence, and the supplies manager who needed to be unblinded in order to label the study products and to create unblinding envelopes, etc. The packaging of the test product and control product were identical in appearance. The study product was labelled using product numbers. Which product numbers corresponded to which treatment was only known to the statistician who was responsible for generating the randomization sequence and the clinical studies supplies manager of Nutricia Research. 


\section{Chapter 6}

Supplemental table 1: Nutrient composition of NUTRITION and PLACEBO products per $125 \mathrm{ml}$ serving (mocha and strawberry flavour).

\begin{tabular}{|c|c|c|c|c|}
\hline & & Unit & NUTRITION & PLACEBO \\
\hline Energy & & kcal & 187.5 & 0.8 \\
\hline \multirow[t]{4}{*}{ Protein } & & g & 9.4 & 0.0 \\
\hline & Casein & g & 4.2 & \\
\hline & Whey & $\mathrm{g}$ & 4.2 & \\
\hline & Leucine & g & 0.9 & \\
\hline \multirow[t]{8}{*}{ Fat } & & g & 4.2 & 0.0 \\
\hline & LA & $\mathrm{mg}$ & 672.7 & \\
\hline & ALA & $\mathrm{mg}$ & 367.9 & \\
\hline & GLA & $\mathrm{mg}$ & 250.1 & \\
\hline & SA & $\mathrm{mg}$ & 139.1 & \\
\hline & $\mathrm{AA}$ & $\mathrm{mg}$ & 12.4 & \\
\hline & EPA & $\mathrm{mg}$ & 248.8 & \\
\hline & DHA & $\mathrm{mg}$ & 118.5 & \\
\hline Carbohydrates & & g & 28.3 & 0.1 \\
\hline \multirow[t]{6}{*}{ Minerals } & $\mathrm{Na}$ & $\mathrm{mg}$ & 72.5 & 8.8 \\
\hline & $\mathrm{K}$ & $\mathrm{mg}$ & 137.5 & 3.8 \\
\hline & $\mathrm{Cl}$ & $\mathrm{mg}$ & 75.0 & 7.5 \\
\hline & $\mathrm{Ca}$ & $\mathrm{mg}$ & 193.8 & 7.5 \\
\hline & $\mathrm{P}$ & $\mathrm{mg}$ & 125.0 & 0.0 \\
\hline & $\mathrm{Mg}$ & $\mathrm{mg}$ & 18.8 & 0.9 \\
\hline \multirow[t]{9}{*}{ Trace elements } & $\mathrm{Fe}$ & $\mathrm{mg}$ & 3.8 & \\
\hline & $\mathrm{Zn}$ & $\mathrm{mg}$ & 2.8 & \\
\hline & $\mathrm{Cu}$ & $\mu \mathrm{g}$ & 450.0 & \\
\hline & $\mathrm{Mn}$ & $\mathrm{mg}$ & 0.6 & \\
\hline & $\mathrm{F}$ & $\mathrm{mg}$ & 0.2 & \\
\hline & Mo & $\mu \mathrm{g}$ & 21.1 & \\
\hline & $\mathrm{Se}$ & $\mu g$ & 18.8 & \\
\hline & $\mathrm{Cr}$ & $\mu g$ & 16.3 & \\
\hline & 1 & $\mu \mathrm{g}$ & 33.8 & \\
\hline \multirow[t]{15}{*}{ Vitamins } & vitamin A & $\mu \mathrm{g} R \mathrm{E}$ & 158.8 & \\
\hline & carotenoids & $\mathrm{mg}$ & 0.8 & \\
\hline & vitamin D & $\mu \mathrm{g}$ & 6.7 & \\
\hline & vitamin $\mathrm{E}$ & mg-alpha-TE & 5.6 & \\
\hline & vitamin $\mathrm{K}$ & $\mu \mathrm{g}$ & 13.8 & \\
\hline & vitamin B1 & $\mathrm{mg}$ & 0.4 & \\
\hline & vitamin B2 & $\mathrm{mg}$ & 0.4 & \\
\hline & niacin (added) & $\mathrm{mg}$ & 4.5 & \\
\hline & pantothenic acid & $\mathrm{mg}$ & 1.4 & \\
\hline & vitamin B6 & $\mathrm{mg}$ & 0.4 & \\
\hline & folic acid & $\mu g$ & 66.3 & \\
\hline & vitamin B12 & $\mu \mathrm{g}$ & 0.6 & \\
\hline & biotin & $\mu g$ & 10.0 & \\
\hline & vitamin C & $\mathrm{mg}$ & 41.3 & \\
\hline & choline & mg & 92.5 & \\
\hline
\end{tabular}




\section{Outcomes}

Measurements were performed at CIRO before entering PR, as part of a 3-day baseline assessment and after completion of the PR during a 2-day outcome assessment (4). According to the study protocol, the primary outcome was quadriceps muscle strength (QMS), measured during volitional isometric contractions on a Biodex (System 4 Pro; Biodex Medical Systems, Inc., New York, USA). At baseline a supervised symptomlimited cardiopulmonary incremental cycle test (CPET) was conducted on an electronically braked cycle ergometer (Carefusion, Houten, the Netherlands) to determine peak workload (Wmax). Cycle endurance time (CET) was determined during Constant work rate cycling endurance test (CWRT) at 75\% of the peak workload. The best of two 6-min walk distance (6MWD) tests was selected for analysis of functional exercise capacity. Inspiratory muscle strength (IMS) was measured using the MS-PFT analyser unit (Masterlab $^{\circledR}$; Jaeger, Würzburg, Germany). Body composition was assessed using DEXA (Lunar Prodigy system; GE Healthcare, Madison, WI, USA). FFMI was calculated as [FFM (lean mass + bone mineral content) $/$ height $^{2}$ ], fat mass (FM) as [total weight - FFM] and SMM as [lean mass arms + lean mass legs]. PAL was measured using a tri-axial GT3X Actigraph accelerometer (Health One Technology, Fort Walton Beach, FL) worn on an elastic belt firmly attached around the waist for 7 consecutive days before and after the intervention period. Subjects were instructed to wear the accelerometer during the time they were not asleep, except when showering or bathing. Wear time was registered in diaries and validated against programmatically defined wear time. Only measurements of $\geq 5$ days of wear time were accepted as valid measurements (5). Mean steps/day was chosen as PAL outcome, representing a clinically meaningful outcome, but also reported to better reflect changes in physical activity following rehabilitation compared with other physical activity outcomes (5). Habitual dietary intake of the last month was assessed by trained dieticians using a validated cross-check dietary history method and calculated using the Dutch Food Composition Database. Protein intake $>1.2$ $\mathrm{g} / \mathrm{kg}$ body weight (BW) was regarded as adequate. Recommended daily intake (RDI) of vitamin D was 10 (<70y) and 20 mcg (70+y) and calcium <1.0 (31-50y), <1.1 (51-70y) or $<1.2 \mathrm{~g}(>70 \mathrm{y})$. Intake of study supplements was not included in the calculations at the end of the intervention period. Compliance was calculated from the amount of supplements provided and turned in after the supplementation period. Supplements characteristics were rated by a self-administered 7-point scale questionnaire. Fasting blood samples were collected in the morning and stored at minus $80^{\circ} \mathrm{C}$ for later analyses, including plasma levels of vitamin D (25-hydroxycholecalciferol), branched-chain amino acids (BCAA's) and fatty acid profile in phospholipids. Proteins and polypeptides were precipitated with perchloric acid and after centrifugation, the content of the individual amino acids in the supernatant was determined by UFLC (Shimadzu Corporation) using a pre-column derivatization with o-phtaldialdehyde and fluorimetry as detection. Vitamin D was analysed in serum by Chemoluminescention Micro-particle Immunoassay using Abbott Architect i2000 equipment. Phospholipids were separated from total cellu- 
lar lipids using Bond-Eluts solid-phase extraction columns and the Vac-Elut SPS 24t system. Phospholipid extracts were converted into methyl esters by using $10 \%$ BF3 in methanol at $1001 \mathrm{C}$ for $60 \mathrm{~min}$. After hexane extraction, derivatised phospholipids were dissolved in isooctane, and the fatty acid composition was analysed by gas chromatography using a capillary column ( $50 \mathrm{m0} 0.25 \mathrm{~mm}$, CPSIL88-fame). Peaks were identified by commercial reference standards. Vitamin D levels between $50-75 \mathrm{nmol}$ indicated insufficiency, $<50 \mathrm{nmol} / \mathrm{L}$ indicated deficiency. Furthermore, post-bronchodilator forced expiratory volume in $1 \mathrm{~s}\left(\mathrm{FEV}_{1}\right)$ and forced vital capacity (FVC) were assessed by standardised equipment (Masterlab ${ }^{\circledR}$; Jaeger, Würzburg, Germany), in accordance with the latest GOLD guidelines (6). Lung volumes were assessed by whole-body plethysmography and the single-breath method was used to assess diffusing capacity of the lung for carbon monoxide (DLCO).

Supplemental table 2: Habitual dietary intake.

\begin{tabular}{|c|c|c|c|c|c|}
\hline & \multicolumn{2}{|l|}{ PLACEBO } & \multicolumn{2}{|l|}{ NUTRITION } & \multirow{2}{*}{$\begin{array}{l}\text { Between group } \\
\text { differences } \\
\text { (NUTRITION- } \\
\text { PLACEBO) } \\
\text { Adj. Difference } \pm \\
\text { SE }\end{array}$} \\
\hline & $\begin{array}{l}\text { Pre } \\
\text { Mean } \pm S E\end{array}$ & $\begin{array}{l}\text { Post } \\
\text { Mean } \pm S E\end{array}$ & $\begin{array}{l}\text { Pre } \\
\text { Mean } \pm S E\end{array}$ & $\begin{array}{l}\text { Post } \\
\text { Mean } \pm S E\end{array}$ & \\
\hline Energy, kcal & $2442.8 \pm 174.2$ & $2426.0 \pm 168.0$ & $2228.4 \pm 117.2$ & $2139.6 \pm 117.0$ & $-134.4 \pm 141.4$ \\
\hline Protein, kcal & $359.4 \pm 21.8$ & $364.4 \pm 22.2$ & $341.3 \pm 15.7$ & $340.0 \pm 16.5$ & $-13.1 \pm 22.0$ \\
\hline Protein, g & $89.9 \pm 5.5$ & $91.1 \pm 5.5$ & $85.3 \pm 3.9$ & $85.0 \pm 4.1$ & $-3.3 \pm 5.5$ \\
\hline Protein, g/kg BW & $1.4 \pm 0.1$ & $1.4 \pm 0.1$ & $1.4 \pm 0.1$ & $1.3 \pm 0.1$ & $-0.1 \pm 0.1$ \\
\hline Carbohydrates, kcal & $1067.1 \pm 70.2$ & $1052.2 \pm 79.4$ & $989.5 \pm 64.0$ & $951.6 \pm 63.3$ & $-43.0 \pm 73.1$ \\
\hline Carbohydrates, g & $266.8 \pm 17.5$ & $263.1 \pm 19.9$ & $247.4 \pm 16.0$ & $237.9 \pm 15.8$ & $-10.8 \pm 18.3$ \\
\hline Fat, kcal & $948.1 \pm 110.3$ & $929.7 \pm 87.5$ & $835.0 \pm 51.9$ & $787.9 \pm 45.6$ & $-71.2 \pm 62.7$ \\
\hline Fat, g & $105.4 \pm 12.3$ & $103.1 \pm 9.8$ & $92.8 \pm 5.8$ & $86.7 \pm 5.1$ & $-8.4 \pm 7.0$ \\
\hline PUFA, g & $21.5 \pm 2.7$ & $20.2 \pm 2.0$ & $19.8 \pm 1.3$ & $18.2 \pm 0.9$ & $-1.1 \pm 1.5$ \\
\hline Cholesterol, mg & $239.1 \pm 25.2$ & $251.5 \pm 25.2$ & $192.8 \pm 15.0$ & $200.7 \pm 13.7$ & $-24.1 \pm 23.4$ \\
\hline Dietary fiber, g & $21.7 \pm 1.6$ & $21.9 \pm 1.3$ & $21.4 \pm 1.2$ & $22.1 \pm 1.2$ & $0.3 \pm 1.6$ \\
\hline Calcium, mg & $977.3 \pm 67.5$ & $1083.5 \pm 96.1$ & $999.4 \pm 56.5$ & $1017.5 \pm 73.7$ & $-76.2 \pm 114.1$ \\
\hline Vitamin A, $\mu \mathrm{g}$ & $1192.5 \pm 145.8$ & $1241.4 \pm 96.5$ & $1129.8 \pm 68.4$ & $1205.6 \pm 156.1$ & $-12.3 \pm 177.8$ \\
\hline Vitamin C, mg & $85.9 \pm 6.9$ & $84.1 \pm 6.1$ & $110.9 \pm 16.7$ & $102.8 \pm 9.4$ & $14.5 \pm 11.1$ \\
\hline Vitamin $D, \mu g$ & $5.1 \pm 0.6$ & $5.3 \pm 0.4$ & $5.8 \pm 0.5$ & $5.1 \pm 0.5$ & $-0.4 \pm 0.6$ \\
\hline Vitamin $\mathrm{E}, \mathrm{mg}$ & $13.9 \pm 1.2$ & $14.6 \pm 1.3$ & $17.6 \pm 1.5$ & $14.7 \pm 1.0$ & $-1.0 \pm 1.6$ \\
\hline
\end{tabular}

Data are mean $\pm \mathrm{SE} .{ }^{*} \mathrm{P}<0.05 ; * \mathrm{P}<0.01 ; * * * \mathrm{P}<0.001$

${ }^{1}$ Between group differences were compared by ANCOVA (taking pre-treatment value as covariate, the 4 month post-treatment value as response, and considering treatment as a factor in the statistical model). 


\section{REFERENCES}

1. van Wetering CR, Hoogendoorn M, Broekhuizen R, Geraerts-Keeris GJ, De Munck DR, Rutten-van Molken MP, Schols AM. Efficacy and costs of nutritional rehabilitation in muscle-wasted patients with chronic obstructive pulmonary disease in a community-based setting: A prespecified subgroup analysis of the intercom trial. J Am Med Dir Assoc 2010;11:179-187.

2. Op den Kamp CM, Langen RC, Snepvangers FJ, de Theije CC, Schellekens JM, Laugs F, Dingemans AM, Schols AM. Nuclear transcription factor kappa b activation and protein turnover adaptations in skeletal muscle of patients with progressive stages of lung cancer cachexia. Am J Clin Nutr 2013;98:738-748.

3. van den Borst B, Slot IG, Hellwig VA, Vosse BA, Kelders MC, Barreiro E, Schols AM, Gosker HR. Loss of quadriceps muscle oxidative phenotype and decreased endurance in patients with mild-to-moderate copd. J Appl Physiol (1985) 2013;114:1319-1328.

4. Spruit MA, Singh SJ, Garvey C, ZuWallack R, Nici L, Rochester C, Hill K, Holland AE, Lareau SC, Man WD, Pitta F, Sewell L, Raskin J, Bourbeau J, Crouch R, Franssen FM, Casaburi R, Vercoulen JH, Vogiatzis I, Gosselink R, Clini EM, Effing TW, Maltais F, van der Palen J, Troosters T, Janssen DJ, Collins E, GarciaAymerich J, Brooks D, Fahy BF, Puhan MA, Hoogendoorn M, Garrod R, Schols AM, Carlin B, Benzo R, Meek P, Morgan M, Rutten-van Molken MP, Ries AL, Make B, Goldstein RS, Dowson CA, Brozek JL, Donner CF, Wouters EF. An official american thoracic society/european respiratory society statement: Key concepts and advances in pulmonary rehabilitation. Am J Respir Crit Care Med 2013;188:e13-64.

5. Demeyer H, Burtin C, Van Remoortel H, Hornikx M, Langer D, Decramer M, Gosselink R, Janssens W, Troosters $T$. Standardizing the analysis of physical activity in patients with copd following a pulmonary rehabilitation program. Chest 2014;146:318-327.

6. Vestbo J, Hurd SS, Agusti AG, Jones PW, Vogelmeier C, Anzueto A, Barnes PJ, Fabbri LM, Martinez FJ, Nishimura M, Stockley RA, Sin DD, Rodriguez-Roisin R. Global strategy for the diagnosis, management, and prevention of chronic obstructive pulmonary disease: Gold executive summary. Am J Respir Crit Care Med 2013;187:347-365. 

Chapter

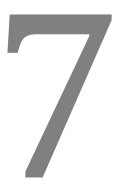

General discussion 
The main objective of the current thesis was to investigate in a randomized placebocontrolled multi-centre trial, the efficacy of specific nutritional supplementation targeting muscle derangements as adjunct to exercise training in COPD patients with low muscle mass. The rationale for the clinical trial was supported by a comprehensive characterization of the target population in additional studies. In chapter 2 we reported a high prevalence of low (appendicular) muscle mass in a large cohort of COPD patients eligible for pulmonary rehabilitation, which was associated with functional implications. The prevalence of sarcopenia was lower in an outpatient COPD population (chapter 3), but this study revealed a lower proportion of type I muscle fibers in sarcopenic compared with non-sarcopenic patients. Also, patients with a low muscle mass had a low dietary quality reflected by low intake of micronutrients, especially vitamin $D$, and a lower intake of protein (chapter 4). Based on review of available literature, the rationale for selection of multimodal nutrient supplementation is described in chapter 5 . The rationale to broaden the scope of nutritional rehabilitation from pulmonary cachexia and end stage disease to low muscle mass and less advanced disease was confirmed by results of a previous trial performed in the Netherlands. The INTERCOM trial $(1,2)$ compared an interdisciplinary community-based COPD management program including individualized education, exercise training and nutritional intervention (the latter only for muscle wasted patients) vs. usual care in COPD patients with less advanced disease (2). Overall results showed significantly better effects in the INTERCOM group compared with the usual care group in health status, exercise capacity, and perceived effectiveness but no differences were found for muscle function, and body composition. A prescheduled post-hoc analysis of the muscle-wasted subgroup furthermore showed a prolonged positive response on FFM, respiratory and lower limb muscle function compared with usual care, while the latter showed a progressive decline in 6MWD (1). All the included patients with less advanced COPD responded very well to the exercise training program, but the specific contribution of nutritional intervention could however not be disentangled as the multimodal intervention was compared to usual care.

The results of the NUTRAIN-trial (chapter 6) showed a clear muscle strength regain in both groups, confirming a strong response to exercise training in a population characterized by moderate airflow imitation. Nutritional supplementation on top of exercise training had no additional effect on muscle strength or exercise performance. Nutritional supplementation did have beneficial effects on nutritional status and inspiratory muscle strength and positively influenced daily physical activity, indicating dissociation between changes in physical performance and daily steps in favour of nutritional supplementation. Moreover, the results presented in this thesis led to the following discussion points. 


\section{CONSTITUTIONALLY LOW OR ACCELERATED DECLINE OF MUSCLE MASS?}

Muscle mass is determined by the net balance of muscle protein synthesis and protein breakdown. It is generally accepted that COPD patients are at increased risk for a below normal fat-free mass (FFM) (surrogate marker of muscle mass) than healthy controls in particular in more advanced disease stages (3). However, it is not well established whether this results from the fact that COPD patients generally have had a low body or muscle mass throughout their whole life or whether this results from accelerated loss of muscle mass beyond the normal ageing process (i.e. muscle wasting). A genome-wide association study in three independent COPD cohorts reported a genetic susceptibility for developing low body mass only in a subgroup of COPD patients (4). Furthermore, low body weight can be a risk factor for developing COPD, as shown in the Baltimore Longitudinal Study of Aging (5) and in never-smokers in the BOLD (Burden of Obstructive Lung Disease) study (6). Nevertheless, this cannot completely explain the high prevalence of low muscle mass in COPD patients. Evidence supporting the presence of muscle wasting is reported by Rutten et al. (7), describing an increased muscle protein degradation rate in COPD patients characterised by low BMI and low FFMI. Furthermore comprehensive muscle biopsy analysis by Kneppers et al. (8) in a large COPD cohort study recently showed that both muscle protein synthesis and protein degradation signalling (i.e. muscle protein turnover) in COPD was increased and even more prominent in the subgroup with low muscle mass. Together with an observed increased myogenic signalling response, this pattern mirrors molecular alterations associated with muscle repair and remodelling which could be the result of catabolic triggers as possibly induced during acute exacerbations of the disease. Indeed, fat-free mass decline in COPD has been associated with frequent exacerbations (9). In line, Rutten et al. recently reported a higher number of exacerbations in patients with continuous fat-free mass decline during a 3 year follow-up period in a COPD population involved in the ECLIPSE study (10). Although the prevalence of continuous (measured as three consecutive years) fat-free mass decline was small, it was higher in COPD patients compared with a non-COPD control group (7\% versus 5\%; P=0.04). Taken together these data suggest that accelerated decline of muscle mass is a trait in a small subset of COPD patients.

How can low muscle mass be measured and what are the correct reference values? For diagnoses of low muscle mass in normal to underweight Caucasian COPD patients, traditionally a fat-free mass index (FFMI) below sex-adjusted 10th-percentile values for healthy subjects ( $<17 \mathrm{~kg} / \mathrm{m}^{2}$ for males and $<15 \mathrm{~kg} / \mathrm{m}^{2}$ for females) was used to diagnose generalized low muscle wasting (3). Pison and co-workers (11) selected patients with chronic respiratory failure with a FFMI below $25^{\text {th }}$ percentile values and found favourable effects of 3 months of home rehabilitation combining health education, oral nutritional supplements, exercise and oral testosterone on body composition and exercise tolerance. In the NUTRAIN-trial we also selected patients with a FFMI below $25^{\text {th }}$ percentile 
values, to extend the population at risk for functional impairments related to low muscle mass. More recently, FFMI percentiles were proposed that also adjust for BMI (12), which could have been a worthy alternative for selection of patients with low muscle mass, as these are able to identify participants with relative imbalance in fat and fat-free mass also in patients that are obese. When applying these cut-off values on 2000 COPD patients from the ECLIPSE cohort, patients with sarcopenia and concurrent obesity had significantly reduced 6MWD, whereas those with sarcopenia but absence of obesity showed no reductions in 6MWD (13). Although no additional measures for functional performance or for muscle strength were included in that analysis, one could hypothesize that compared to whole body muscle mass, appendicular muscle mass constitutes a stronger predictor for physical functioning. This was confirmed in chapter 2 of this thesis. Nowadays dual energy X-ray absorptiometry (DEXA) allows assessment of fat mass (FM) and fat-free mass at regional level besides assessment of bone mass density. In the elderly population, an appendicular skeletal muscle mass index (ASMI) of $\geq 2$ standard deviations below the mean of healthy persons between 20 and 30 years of age of the same ethnic group is nowadays commonly used to define sarcopenia. In the general wellfunctioning aged population, sarcopenia according to this definition is prevalent in $15 \%$ (14), but is higher in COPD reflecting the suggested accelerated ageing in COPD (chapter 2 ). However, in contrast to $100 \%$ of COPD patients with a FFMI $<10^{\text {th }}$ percentile values meeting the criteria for sarcopenia (chapter 2), a lower percentage $(61.7 \%)$ of patients with a FFMl $<25^{\text {th }}$ percentile values from the NUTRAIN-patient sample (chapter 6) met the criteria for sarcopenia, leading to a discrepancy in the selection of patients based on low muscle mass in this thesis. Still, throughout the whole thesis results show that a low muscle mass (independent of its definition) is unfavourable, reflected as low quality of dietary intake (chapter 4), impaired physical functioning (chapter 2) and lower muscle oxidative capacity (chapter 3). Moreover, post-hoc analyses of the sarcopenic subgroup within the patients with low FFMI (chapter 6) learned that the presence of sarcopenia did not impact the response of exercise training in the NUTRAIN-trial, which is in line with recently reported findings by Jones et al. (15).

\section{A SHIFT FROM CALORIC SUPPLEMENTATION TO PROTEIN SUPPLEMENTATION?}

Currently the rationale for caloric supplementation in preventing and treating involuntary weight loss is well established (16). Due to decreased efficiency of lower-limb muscle contraction (17) and static and dynamic hyperinflation, daily energy requirements maybe elevated in part of the COPD patients (18). If energy requirements are not fully met this may contribute to weight loss and eventually loss of muscle mass, providing a convincing rationale for caloric supplementation to maintain or increase body weight. Oral nutritional supplements with a higher carbohydrate and lower fat composition 
have been recommended for COPD patients by Current ESPEN Guidelines (19). Carbohydrates are a rapid energy source in the muscle which empty rapidly from the stomach, thereby limiting satiety which is especially relevant for COPD patients who experience poor appetite because of post-prandial shortness of breath (20). Participants in the NUTRAIN-trial received a high-caloric formulation (2-3 times $187.5 \mathrm{kCal} /$ day), resulting from a distribution of 20:60:20 as energy percentages of protein:carbohydrate:fat. However, analyses of habituary dietary intake revealed that on average energy intake was already sufficient at baseline in both intervention groups. Combined with DEXAderived finding that $>75 \%$ of participants was abdominal obese, this suggests that additional caloric supplementation may have been redundant in part of this population (of muscle wasted COPD patients with less advanced COPD) and that macronutrient supplementation should have focused on providing merely protein.

Adequate protein intake is crucial to stimulate muscle protein synthesis and rebalance protein metabolism in order to maintain or restore muscle mass, but when is the effective timing of supplementation? In 2010, Baldi et al. (21) randomized 28 COPD patients with dynamic weight loss ( $>5 \%$ over the last 6 months) to receive $4 \mathrm{~g}$ essential amino acids (EAA) twice a day embedded in a 12-week rehabilitation program or to the same program without supplementation. After 12 weeks, 92\% of patients in the EAAs group and $15 \%$ of the control group increased their body weight by $3.8 \pm 2.6 \mathrm{~kg}(P=0.0002)$ and $-0.1 \pm 1.1 \mathrm{~kg}(\mathrm{P}=0.81)$ respectively. Increased FFM occurred in respectively $69 \%$ and $15 \%$ of EAAs and control patients, with an average increase of $1.5 \pm 2.6 \mathrm{~kg}(P=0.05)$ and $-0.1 \pm 2.3 \mathrm{~kg}(P=0.94)$. Compared to the NUTRAIN-population however, this population was characterised by lower $\mathrm{FEV}_{1}( \pm 42 \%$ predicted), 6MWD $( \pm 240 \mathrm{~m})$ and dietary intake $( \pm 1857 \mathrm{kcal} / 24 \mathrm{~h})$ at baseline. Also, a 13 -week intervention of a vitamin $\mathrm{D}$ and leucine-enriched whey protein supplementation among 380 sarcopenic elderly reported significant improvements in appendicular muscle mass (22). The observed between group difference was $0.17 \mathrm{~kg}$ compared to the control group receiving an iso-caloric product. In the NUTRAIN-trial exercise training alone already resulted in a $0.31 \mathrm{~kg}$ increase in SMM and the between group difference reached $0.26 \mathrm{~kg}$. Different from the NUTRAIN-trial was that median baseline protein intake in the former study reached 1.0 $\mathrm{g} / \mathrm{kg} \mathrm{BW} /$ day, which is below the recommendations for geriatric patients $(1.2-1.5 \mathrm{~g} / \mathrm{kg}$ $\mathrm{BW} /$ day).These trials suggest that protein supplementation is effective to counteract muscle decline in weight losing patients with an inadequate dietary intake, but might be less effective in weight stable patients with an adequate protein intake.

Supplementation should target provision of sufficient amino acids as stimulation of protein synthesis depends on the availability of amino acids in the blood stream. The availability of amino acids to peripheral tissues is critically influenced by their extraction by the intestine. Recently, a disturbed intestinal integrity was reported in patients with COPD (23). However, this does not seem to adversely affect the anabolic response to a meal in COPD as a decreased splanchnic extraction of amino acids was associated with 
an enhanced anabolic response to a protein rich meal in sarcopenic COPD patients (24, $25)$. But which protein should be provided as available evidence suggests that the type (i.e. source) of protein consumed may affect the anabolic response to resistance (26)? In the past decade, there has been an increased interest in the therapeutic modality of BCAAs. Plasma BCAA concentrations, particularly leucine, were often reduced in COPD (27). Furthermore, low plasma leucine concentrations were associated with low fat-free mass (28). BCAA and in particular leucine is known to regulate molecular mechanisms of muscle protein synthesis (mTOR pathway) and stimulate anabolism and muscle synthesis (29). The "high-quality" milk protein casein and whey (known for its high content of EAAs) offer an anabolic advantage over soy proteins. The anabolic response after casein intake was demonstrated to be even higher than during soy feeding to which BCAA were added to reach similar levels as present in casein (30), suggesting potential involvement of the absorption rate in the high anabolic capacity of casein. Although casein and whey are both high-quality proteins, studies comparing their anabolic capacity in healthy individuals show variable results. In 2012, Engelen et al. demonstrated that "continuous" ingestion of casein resulted in more protein anabolism than whey protein, indicating that the amino acid composition of casein is preferable over whey protein in inducing and maintaining protein anabolism during and following exercise in COPD (31). More recently, it was shown that a bolus meal of casein vs. whey protein, containing a similar amount of carbohydrates and with comparable absorption characteristics, stimulated net whole body protein synthesis comparably and efficiently in COPD patients characterized by nutritional depletion. Co-ingestion of leucine did not further stimulate the net whole-body protein synthesis response (24). Summarized, these data suggest that in particular the milk proteins casein and whey are of interest to improve anabolism, without a specific role for the amino acid leucine. A newer strategy proposed for nutritional intervention is beta-hydroxy-beta-methylbutyrate (HMB), a metabolite of leucine. Although effects have not been investigated in COPD yet, promising results come from a study in healthy older adults reporting that HMB supplementation was able to ameliorate muscle loss during 10 days of bed rest (32), but clearly more research is needed.

The nutritional supplement applied in the NUTRAIN-trial provided a protein composition of equal amounts of casein and whey for a balanced amino acid profile with a high percentage of essential amino acids. However, analyses of habituary dietary intake revealed that not every participant needed additional protein as only $25 \%$ of both intervention groups had a baseline protein $<1.0 \mathrm{~g} / \mathrm{kg}$ BW/day. As mentioned before DEXA is able to analyse the fat distribution and in particular abdominal obesity, which is receiving increasing attention in COPD as it has been positively related to low-grade systemic inflammation and risk factors for cardiovascular and metabolic disorders (33). In line with previous literature (34), a high prevalence of abdominal obesity (>75\%) was confirmed in COPD patients eligible for pulmonary rehabilitation (chapter 4). Likewise, 75\% 
of the NUTRAIN-patients had abdominal obesity, which was accompanied by an increased cardiometabolic risk compared to patients without abdominal obesity (35). In patients with this particular phenotype of low muscle mass coexisting with abdominal obesity, caloric supplementation could be redundant or even disadvantageous and should perhaps only provide a balanced mix of high quality protein. Indeed in the NUTRAIN-trial this was reflected by an increased fat mass only in the group that received the nutritional supplement.

Taken together these data of existing variations in body composition phenotypes throughout the COPD population (weight loss, low FFM, high FM), nutritional intervention should be more tailored based on individual body composition phenotype (36).

\section{QUALITY OF HABITUARY DIETARY INTAKE FROM A DEFICIENCY PERSPECTIVE}

Dyspnoea, fatigue, anxiety and depression are common symptoms of COPD that contribute to poor appetite and altered dietary intake. Consequently, diet represents another lifestyle factor next to physical inactivity and smoking, which is associated with or may accelerate existing abnormalities in body composition. For reasons outlined in the preceding paragraph, analysis of dietary intake in COPD was previously primarily focused on energy and protein balance in relation to weight loss and muscle wasting (37, 38). When analysing dietary intake of a large cohort of COPD patients referred for pulmonary rehabilitation investigated in (chapter 4), results showed that patients with a low muscle mass (FFMI $<16 \mathrm{~kg} / \mathrm{m}^{2}$ for men and $<15 \mathrm{~kg} / \mathrm{m}^{2}$ for women) more often had low intake of protein. Furthermore, patients with advanced COPD and muscle wasting are reported to have low plasma levels of BCAA's (28). In contrast, patients participating in the NUTRAIN-trial reported an adequate baseline habituary protein intake $(1.4 \mathrm{~g} / \mathrm{kg}$ body weight) and the plasma level of total BCAA was comparable with healthy age matched volunteers. However, when looking from a deficiency perspective, several shortages have been described in COPD. For instance, COPD patients have a poorer vitamin $\mathrm{D}$ status than the general population, possibly affecting several comorbidities. As such, muscle weakness and osteoporosis are common comorbidities in COPD that can be linked to vitamin D deficiency (39). The cohort of COPD patients referred for pulmonary rehabilitation in chapter 4 showed that daily intake of not only protein, but also of micronutrients was often below recommendations. The greatest deficiency identified was that of vitamin D. Moreover, a low intake of vitamin D reflected poorer dietary quality in general. Likewise, results of baseline dietary assessment from the NUTRAIN-patients showed a too low intake of vitamin D in $>90 \%$ of patients, which was accompanied by plasma vitamin D insufficiency/deficiency (89\%). 
Another common deficiency is associated with the often occurring comorbidity anemia in COPD, which is defined by low haemoglobin levels. Anemia is a common and simple clinical finding, but its physiological relevance in COPD may be underestimated. In COPD the prevalence ranges from about 13 to $23 \%(40,41)$, but is higher during exacerbations (42). Anemia in COPD may contribute to exercise limitation and dyspnoea (40) and is related with increased mortality and morbidity. Because of the effects of iron deficiency on haemoglobin concentration, iron deficiency may play a significant role in the progression of anemia. Iron deficiency can occur before the onset of anemia and is associated with hypoxia, more frequent exacerbations, decreased exercise tolerance, and diminished response to pulmonary rehabilitation $(43,44)$. A small study in 13 COPD patients reported that dietary intake of iron in COPD patients was about half that of normal controls (45). Although current data are limited (46), iron supplementation may be a relatively inexpensive and an effective treatment option. Consequently, specific attention should also be paid to iron deficiency and its intake in COPD, even in the absence of anemia. Taken together these findings suggest that habituary dietary intake should be accurately assessed in individual patients before starting a (nutritional) intervention.

\section{QUALITY OF HABITUARY DIETARY INTAKE FROM A CARDIOMETABOLIC PERSPECTIVE}

COPD patients are often burdened with abdominal obesity, even in the presence of low muscle mass. Even $75 \%$ of the NUTRAIN-patients (selected for their low muscle mass) had abdominal obesity, which was accompanied by an increased cardiometabolic risk compared to patients without abdominal obesity (35). When assessing dietary intake in COPD patients eligible for pulmonary rehabilitation (chapter 4), dietary fat intake was too high in almost one third of the patients. In particular, saturated fat was frequently consumed too much (89\% of patients). Furthermore, quality differences were found in relation to different body composition phenotypes. Abdominally obese patients more often had low intake of protein and most micronutrients compared to patients without abdominal obesity. Nevertheless, patients with both low FFMI and abdominal obesity appeared most often to be consuming a poor-quality diet. Their dietary intake was characterised by a lower intake of vitamins A, D and E and calcium than recommended compared with non-abdominally obese patients with a low FFMI. Summarized, quality of dietary intake in COPD should not only be explored from a deficiency perspective, but also from a cardiometabolic perspective. Moreover, patients with body composition abnormalities deserve specific attention, as the combination of low FFMI and abdominal obesity can lead to adverse metabolic health (47). 


\section{PHARMACONUTRITION TO IMPROVE METABOLIC HEALTH}

COPD patients are at increased risk of disturbances in metabolic health, because of decreased muscle oxidative capacity combined with selectively increased abdominal fat mass (47). Although high-intensity aerobic exercise has the capacity to induce mitochondrial biogenesis in skeletal muscle, the efficacy may be limited by ventilatory impairment in COPD. Alternatively, or as an adjunct to exercise, specific nutrients are suggested to have a pharmacologic potential. Two examples that were included in the nutritional supplement in the NUTRAIN-trial are poly unsaturated fatty acids (PUFA's) and vitamin D.

Mitochondrial biogenesis is promoted by peroxisome proliferator-activated receptors (PPARs) $\alpha$ and $\delta$ and their coactivator PPAR coactivator $1 \alpha$ (PGC-1 $\alpha$ ), together with mitochondrial transcription factor-A. Nonetheless, the expression of PPARs was decreased in COPD quadriceps muscle (48). Polyunsaturated fatty acids (found in oils, seafood, and walnuts) are the natural ligands of PPARs and may therefore have the pharmacologic potential to boost decreased muscle mitochondrial metabolism. Indeed a RCT by Broekhuizen et al. (49) demonstrated significantly enhanced improvement in endurance exercise capacity in COPD after PUFA supplementation as an adjunct to exercise training, implying a stimulating effect on muscle fat oxidative metabolism by inhibiting classic NF- kB signalling or stimulating PGC-1 a/PPAR signalling.

As a result of less outdoor activity, smoke-induced skin ageing, and insufficient intake vitamin D deficiency often occurs in COPD. Vitamin D has important roles in bone health and immune function (50). Furthermore, deficiency of vitamin $D$ has been associated with impaired exercise capacity (39), a higher drop-out risk from rehabilitation and a tendency towards reduced training benefits (51). In elderly, it is systematically demonstrated that a daily supplementation dose of 700-1000 IU/day vitamin D improves balance and reduces falls (52), but direct effects on muscle strength are less convincing. No consensus exists about minimum levels needed for extra-skeletal effects and high-dose supplementation has consequently been suggested. One intervention study explored whether supplementation with high doses of vitamin D (100.000 IU per month) could reduce the incidence of COPD exacerbations, but only found a significant reduction in participants with severe vitamin D deficiency (serum 25-[OH]D levels $<10 \mathrm{ng} / \mathrm{mL}$ ) at baseline (53). A post-hoc subgroup analysis of those undergoing a 3-month rehabilitation program showed that high dose vitamin $\mathrm{D}$ supplementation during rehabilitation counteracted vitamin $\mathrm{D}$ deficiency and may have mild additional benefits to training reflected as larger improvements in inspiratory muscle strength and trends for larger improvements in muscle strength and 6MWD (54). However, recently an U-shaped association between serum 25-[OH]D levels and the risk of adverse events (including cardiovascular disease (55) and all-cause mortality (56)) has been suggested. Together with the risk for hypercalcemia, these observations have led to the definition of a daily 
upper tolerable intake of 4000 IU for adults (57). Mouse model data suggests that high serum vitamin D levels may have deleterious effects on COPD onset and progression (58). Consequently, the need and safety for recommending higher doses of vitamin D to obtain potential beneficial extra-skeletal effects needs further exploration.

More recently, other nutrients have also been proposed to have a pharmacologic potential. Dietary nitrate $\left(\mathrm{NO}_{3}{ }^{-}\right)$has been demonstrated to improve exercise capacity in young healthy individuals by reducing the oxygen cost of exercise REFS. Dietary $\mathrm{NO}_{3}{ }^{-}$, found in green leafy vegetables and beetroots, exerts its effects as a result of its conversion to nitrite $\left(\mathrm{NO}_{2}{ }^{-}\right)$and subsequently to nitric oxide (NO). During exercise NO contributes to vasodilatation and matches blood flow and oxygen delivery to requirements in skeletal-muscle (59). Because supplementation of nitrate was demonstrated to have beneficial effects during exercise in hypoxic conditions (60) and to have the potential to improve the exercise capacity of older adults (61), nitrate supplementation became of interest for patients with COPD with decreased exercise capacity. Two recent trials in COPD demonstrated that acute nitrate supplementation via beetroot juice can increase $\mathrm{NO}_{3}{ }^{-}$and $\mathrm{NO}_{2}$ levels, reduce blood pressure and improve exercise capacity $(62,63)$. In contrary, another acute trial was not able to reproduce these beneficial effects on exercise performance (63) as were two trials providing 2-3 days of nitrate via beetroot juice $(64,65)$. More studies are needed to disentangle whether nitrate without possible confounding from additional substances (for example via a $\mathrm{NaNO}_{3}$ solution) and longer periods (>3 days) of supplementation might be more beneficial. Moreover, it would be interesting to explore whether dietary nitrate is able to enhance the impaired metabolic efficiency as a result of increased oxygen cost of breathing (66) and a loss of muscle oxidative capacity in COPD (67).

Another nutritional potential to boost mitochondria is resveratrol, which is a natural polyphenolic compound that is present in peanuts, grapes, and red wines. Resveratrol has antioxidant and anti-inflammatory properties and is suggested to mimic benefits of calorie restriction by activation of sirtuin (Sirt) 1, potentially resulting in improved metabolic and functional health $(68,69)$. Thirty days supplementation of resveratrol was recently shown to significantly reduce sleeping and resting metabolic rate, fasting glucose, triglycerides, systolic blood pressure and markers of systemic inflammation in healthy obese men (70). In skeletal muscle resveratrol induced activation of AMPK, increased Sirt1 and PGC-1 $\alpha$ protein levels and increased citrate synthase activity. As the mentioned outcome markers responding to resveratrol are often compromised in patients with COPD, it would be opportunistic to study supplementation effects in a cohort of COPD patients. Although data from animal studies look promising, the current number of clinical trials is limited and future human studies should determine the optimal dose, efficacy and chronic exposure effects of resveratrol. 


\section{NUTRITIONAL TARGETS TO ENHANCE PULMONARY REHABILITATION EFFICACY IN COPD}

In the NUTRAIN-trial we aimed to investigate the effects of a 4-month exercise training program including targeted nutritional support in COPD patients with muscle wasting eligible for out-patient PR on physical functioning and nutritional status. Muscle wasting was defined as a FFMI $<25^{\text {th }}$ percentile values to include patients "at risk" for muscle wasting and nutritional support included high caloric supplementation enriched with leucine and vitamin D. According to the latest scientific insights, one should be careful when applying "one size fits all" interventions in patients meeting eligibility criteria for low muscle mass or muscle wasting. In addition, low muscle mass often coincides with the presence of abdominal obesity, increasing cardiovascular risk. Nutritional interventions should therefore be tailored for carefully selected COPD patient subgroups defined according to distinct clinical phenotypes (36).

Furthermore, the strongest evidence of impact from pulmonary rehabilitation has been for improvement in symptoms, exercise performance, and quality of life in patients with COPD (71). Nonetheless, from a nutritional perspective beneficial effects on additional outcomes could be anticipated such as cognitive function. For example, docosahexaenoic acid (DHA) is highly concentrated in the brain and increased intake of PUFA is related to better performance of domain specific cognitive functions in adults (72). Also dietary nitrate has been proposed to potentially enhance cognitive function by modifying cerebral vasodilation and blood flow (73). Dietary nitrate has in addition been reported to improve regional white matter perfusion in brain areas involved in executive functioning in older adults (74).

As exercise training alone already was very effective, the potential of nutritional supplementation to augment exercise training response might be limited. It could therefore be postulated that nutritional intervention should perhaps focus less on boosting the effects of exercise training and more on muscle maintenance after a PR program potentially involving nutritional counselling (75).

\section{CONCLUSION}

In summary, this thesis describes the efficacy of specific nutritional supplementation targeting muscle derangements as adjunct to exercise training was studied in COPD patients with low muscle mass, as well as a comprehensive characterization of the target population. The potential of nutritional supplementation to augment exercise training response might be limited as exercise training alone is already very effective. Adequate clinical trials in COPD are needed to explore nutritional strategies for maintaining the effects of exercise training after a pulmonary rehabilitation program. The challenge 


\section{Chapter 7}

for future studies is to tailor nutritional interventions for carefully selected COPD patient subgroups defined according to distinct clinical phenotypes. Not only novel nutrients suggested to boost muscle mitochondrial metabolism and limit fat accumulation may be included, but also outcome measures beyond muscle. 


\section{REFERENCES}

1. van Wetering CR, Hoogendoorn M, Broekhuizen R, Geraerts-Keeris GJ, De Munck DR, Rutten-van Molken MP, Schols AM. Efficacy and costs of nutritional rehabilitation in muscle-wasted patients with chronic obstructive pulmonary disease in a community-based setting: A prespecified subgroup analysis of the intercom trial. J Am Med Dir Assoc 2010;11:179-187.

2. van Wetering CR, Hoogendoorn M, Mol SJ, Rutten-van Molken MP, Schols AM. Short- and long-term efficacy of a community-based copd management programme in less advanced copd: A randomised controlled trial. Thorax 2010;65:7-13.

3. Vestbo J, Prescott E, Almdal T, Dahl M, Nordestgaard BG, Andersen T, Sorensen TI, Lange P. Body mass, fat-free body mass, and prognosis in patients with chronic obstructive pulmonary disease from a random population sample: Findings from the copenhagen city heart study. Am J Respir Crit Care Med 2006;173:79-83.

4. Wan ES, Cho MH, Boutaoui N, Klanderman BJ, Sylvia JS, Ziniti JP, Won S, Lange C, Pillai SG, Anderson WH, Kong X, Lomas DA, Bakke PS, Gulsvik A, Regan EA, Murphy JR, Make BJ, Crapo JD, Wouters EF, Celli BR, Silverman EK, DeMeo DL. Genome-wide association analysis of body mass in chronic obstructive pulmonary disease. Am J Respir Cell Mol Biol 2011;45:304-310.

5. Harik-Khan RI, Fleg JL, Wise RA. Body mass index and the risk of copd. Chest 2002;121:370-376.

6. Lamprecht B, McBurnie MA, Vollmer WM, Gudmundsson G, Welte T, Nizankowska-Mogilnicka E, Studnicka M, Bateman E, Anto JM, Burney P, Mannino DM, Buist SA. Copd in never smokers: Results from the population-based burden of obstructive lung disease study. Chest 2011;139:752-763.

7. Rutten EP, Franssen FM, Engelen MP, Wouters EF, Deutz NE, Schols AM. Greater whole-body myofibrillar protein breakdown in cachectic patients with chronic obstructive pulmonary disease. Am J Clin Nutr 2006;83:829-834.

8. Kneppers A, Langen R, Gosker H, Leermakers P, Kelders M, de Theye C, Cebron Lipovec N, Omersa D, Lainscak M, Schols A. Impaired coordination of skeletal muscle protein turnover signalling in sarcopenic copd patients. European Respiratory Journal 2016;48.

9. Hopkinson NS, Tennant RC, Dayer MJ, Swallow EB, Hansel TT, Moxham J, Polkey MI. A prospective study of decline in fat free mass and skeletal muscle strength in chronic obstructive pulmonary disease. Respir Res 2007;8:25.

10. Rutten EP, Spruit MA, McDonald ML, Rennard S, Agusti A, Celli B, Miller BE, Crim C, Calverley PM, Hanson C, MacNee W, Franssen FM, Vanfleteren L, Wouters EF. Continuous fat-free mass decline in copd: Fact or fiction? Eur Respir J 2015;46:1496-1498.

11. Pison CM, Cano NJ, Cherion C, Caron F, Court-Fortune I, Antonini MT, Gonzalez-Bermejo J, Meziane L, Molano LC, Janssens JP, Costes F, Wuyam B, Similowski T, Melloni B, Hayot M, Augustin J, Tardif C, Lejeune $\mathrm{H}$, Roth $\mathrm{H}$, Pichard $\mathrm{C}$. Multimodal nutritional rehabilitation improves clinical outcomes of malnourished patients with chronic respiratory failure: A randomised controlled trial. Thorax 2011;66:953960.

12. Franssen FM, Rutten EP, Groenen MT, Vanfleteren LE, Wouters EF, Spruit MA. New reference values for body composition by bioelectrical impedance analysis in the general population: Results from the uk biobank. J Am Med Dir Assoc 2014.

13. Joppa P, Tkacova R, Franssen FM, Hanson C, Rennard SI, Silverman EK, McDonald ML, Calverley PM, TalSinger R, Spruit MA, Kenn K, Wouters EF, Rutten EP. Sarcopenic obesity, functional outcomes, and systemic inflammation in patients with chronic obstructive pulmonary disease. J Am Med Dir Assoc 2016;17:712-718.

14. Cherin P, Voronska E, Fraoucene N, de Jaeger C. Prevalence of sarcopenia among healthy ambulatory subjects: The sarcopenia begins from 45 years. Aging Clin Exp Res 2013.

15. Jones SE, Maddocks M, Kon SS, Canavan JL, Nolan CM, Clark AL, Polkey MI, Man WD. Sarcopenia in copd: Prevalence, clinical correlates and response to pulmonary rehabilitation. Thorax 2015;70:213-218. 
16. Ferreira IM, Brooks D, White J, Goldstein R. Nutritional supplementation for stable chronic obstructive pulmonary disease. Cochrane Database Syst Rev 2012;12:CD000998.

17. Layec G, Haseler LJ, Hoff J, Richardson RS. Evidence that a higher atp cost of muscular contraction contributes to the lower mechanical efficiency associated with copd: Preliminary findings. Am J Physiol Regul Integr Comp Physiol 2011;300:R1142-1147.

18. Schols AM, Soeters PB, Mostert R, Saris WH, Wouters EF. Energy balance in chronic obstructive pulmonary disease. Am Rev Respir Dis 1991;143:1248-1252.

19. Anker SD, John M, Pedersen PU, Raguso C, Cicoira M, Dardai E, Laviano A, Ponikowski P, Schols AM, Becker HF, Bohm M, Brunkhorst FM, Vogelmeier C. Espen guidelines on enteral nutrition: Cardiology and pulmonology. Clin Nutr 2006;25:311-318.

20. Vermeeren MA, Wouters EF, Nelissen LH, van Lier A, Hofman Z, Schols AM. Acute effects of different nutritional supplements on symptoms and functional capacity in patients with chronic obstructive pulmonary disease. Am J Clin Nutr 2001;73:295-301.

21. Baldi S, Aquilani R, Pinna GD, Poggi P, De Martini A, Bruschi C. Fat-free mass change after nutritional rehabilitation in weight losing copd: Role of insulin, c-reactive protein and tissue hypoxia. Int J Chron Obstruct Pulmon Dis 2010;5:29-39.

22. Bauer JM, Verlaan S, Bautmans I, Brandt K, Donini LM, Maggio M, McMurdo ME, Mets T, Seal C, Wijers SL, Ceda GP, De Vito G, Donders G, Drey M, Greig C, Holmback U, Narici M, McPhee J, Poggiogalle E, Power D, Scafoglieri A, Schultz R, Sieber CC, Cederholm T. Effects of a vitamin d and leucine-enriched whey protein nutritional supplement on measures of sarcopenia in older adults, the provide study: A randomized, double-blind, placebo-controlled trial. J Am Med Dir Assoc 2015;16:740-747.

23. Rutten EP, Lenaerts K, Buurman WA, Wouters EF. Disturbed intestinal integrity in patients with copd: Effects of activities of daily living. Chest 2014;145:245-252.

24. Jonker R, Deutz NE, Erbland ML, Anderson PJ, Engelen MP. Hydrolyzed casein and whey protein meals comparably stimulate net whole-body protein synthesis in copd patients with nutritional depletion without an additional effect of leucine co-ingestion. Clin Nutr 2014;33:211-220.

25. Engelen MP, De Castro CL, Rutten EP, Wouters EF, Schols AM, Deutz NE. Enhanced anabolic response to milk protein sip feeding in elderly subjects with copd is associated with a reduced splanchnic extraction of multiple amino acids. Clin Nutr 2012;31:616-624.

26. Tang JE, Phillips SM. Maximizing muscle protein anabolism: The role of protein quality. Curr Opin Clin Nutr Metab Care 2009;12:66-71.

27. Engelen MP, Schols AM. Altered amino acid metabolism in chronic obstructive pulmonary disease: New therapeutic perspective? Curr Opin Clin Nutr Metab Care 2003;6:73-78.

28. Engelen MP, Wouters EF, Deutz NE, Menheere PP, Schols AM. Factors contributing to alterations in skeletal muscle and plasma amino acid profiles in patients with chronic obstructive pulmonary disease. Am J Clin Nutr 2000;72:1480-1487.

29. Drummond MJ, Rasmussen BB. Leucine-enriched nutrients and the regulation of mammalian target of rapamycin signalling and human skeletal muscle protein synthesis. Curr Opin Clin Nutr Metab Care 2008;11:222-226.

30. Engelen MP, Rutten EP, De Castro CL, Wouters EF, Schols AM, Deutz NE. Supplementation of soy protein with branched-chain amino acids alters protein metabolism in healthy elderly and even more in patients with chronic obstructive pulmonary disease. Am J Clin Nutr 2007;85:431-439.

31. Engelen MP, Rutten EP, De Castro CL, Wouters EF, Schols AM, Deutz NE. Casein protein results in higher prandial and exercise induced whole body protein anabolism than whey protein in chronic obstructive pulmonary disease. Metabolism 2012.

32. Deutz NE, Pereira SL, Hays NP, Oliver JS, Edens NK, Evans CM, Wolfe RR. Effect of beta-hydroxy-betamethylbutyrate (hmb) on lean body mass during 10 days of bed rest in older adults. Clin Nutr 2013;32:704-712.

33. van den Borst B, Gosker HR, Koster A, Yu B, Kritchevsky SB, Liu Y, Meibohm B, Rice TB, Shlipak M, Yende $\mathrm{S}$, Harris TB. The influence of abdominal visceral fat on inflammatory pathways and mortality risk in obstructive lung disease. Am J Clin Nutr 2012;96:516-526. 
34. Rutten EP, Breyer MK, Spruit MA, Hofstra T, van Melick PP, Schols AM, Wouters EF. Abdominal fat mass contributes to the systemic inflammation in chronic obstructive pulmonary disease. Clin Nutr 2010;29:756-760.

35. Beijers R, van de Bool C, van den Borst B, Franssen F, Wouters E, Schols A. Cardiometabolic risk profile in muscle wasted copd patients with abdominal obesity and the effect of pulmonary rehabilitation. European Respiratory Journal 2016;48.

36. Schols AM, Ferreira IM, Franssen FM, Gosker HR, Janssens W, Muscaritoli M, Pison C, Rutten-van Molken M, Slinde F, Steiner MC, Tkacova R, Singh SJ. Nutritional assessment and therapy in copd: A european respiratory society statement. Eur Respir J 2014.

37. Goris AH, Vermeeren MA, Wouters EF, Schols AM, Westerterp KR. Energy balance in depleted ambulatory patients with chronic obstructive pulmonary disease: The effect of physical activity and oral nutritional supplementation. Br J Nutr 2003;89:725-731.

38. Schols AM, Wouters EF. Nutritional abnormalities and supplementation in chronic obstructive pulmonary disease. Clin Chest Med 2000;21:753-762.

39. Romme EA, Rutten EP, Smeenk FW, Spruit MA, Menheere PP, Wouters EF. Vitamin d status is associated with bone mineral density and functional exercise capacity in patients with chronic obstructive pulmonary disease. Ann Med 2013;45:91-96.

40. John M, Lange A, Hoernig S, Witt C, Anker SD. Prevalence of anemia in chronic obstructive pulmonary disease: Comparison to other chronic diseases. Int J Cardiol 2006;111:365-370.

41. Yohannes AM, Ershler WB. Anemia in copd: A systematic review of the prevalence, quality of life, and mortality. Respiratory care 2011;56:644-652.

42. Martinez-Rivera C, Portillo K, Munoz-Ferrer A, Martinez-Ortiz ML, Molins E, Serra P, Ruiz-Manzano J, Morera J. Anemia is a mortality predictor in hospitalized patients for copd exacerbation. COPD 2012;9:243-250.

43. Barberan-Garcia A, Rodriguez DA, Blanco I, Gea J, Torralba Y, Arbillaga-Etxarri A, Barbera JA, Vilaro J, Roca J, Orozco-Levi M. Non-anaemic iron deficiency impairs response to pulmonary rehabilitation in copd. Respirology 2015;20:1089-1095.

44. Nickol AH, Frise MC, Cheng HY, McGahey A, McFadyen BM, Harris-Wright T, Bart NK, Curtis MK, Khandwala S, O'Neill DP, Pollard KA, Hardinge FM, Rahman NM, Armitage AE, Dorrington KL, Drakesmith $H$, Ratcliffe PJ, Robbins PA. A cross-sectional study of the prevalence and associations of iron deficiency in a cohort of patients with chronic obstructive pulmonary disease. BMJ open 2015;5:e007911.

45. Obase Y, Mouri K, Shimizu H, Ohue Y, Kobashi Y, Kawahara K, Oka M. Nutritional deficits in elderly smokers with respiratory symptoms that do not fulfill the criteria for copd. Int J Chron Obstruct Pulmon Dis 2011;6:679-683.

46. Vasquez A, Logomarsino JV. Anemia in chronic obstructive pulmonary disease and the potential role of iron deficiency. COPD 2016;13:100-109.

47. van den Borst B, Gosker HR, Schols AM. Central fat and peripheral muscle: Partners in crime in chronic obstructive pulmonary disease. Am J Respir Crit Care Med 2013;187:8-13.

48. Remels AH, Schrauwen P, Broekhuizen R, Willems J, Kersten S, Gosker HR, Schols AM. Peroxisome proliferator-activated receptor expression is reduced in skeletal muscle in copd. Eur Respir J 2007;30:245-252.

49. Broekhuizen R, Wouters EF, Creutzberg EC, Weling-Scheepers CA, Schols AM. Polyunsaturated fatty acids improve exercise capacity in chronic obstructive pulmonary disease. Thorax 2005;60:376-382.

50. Janssens W, Lehouck A, Carremans C, Bouillon R, Mathieu C, Decramer M. Vitamin d beyond bones in chronic obstructive pulmonary disease: Time to act. Am J Respir Crit Care Med 2009;179:630-636.

51. Ringbaek T, Martinez G, Durakovic A, Thogersen J, Midjord AK, Jensen JE, Lange P. Vitamin d status in patients with chronic obstructive pulmonary disease who participate in pulmonary rehabilitation. J Cardiopulm Rehabil Prev 2011;31:261-267.

52. Bischoff-Ferrari HA, Dawson-Hughes B, Staehelin HB, Orav JE, Stuck AE, Theiler R, Wong JB, Egli A, Kiel $D P$, Henschkowski J. Fall prevention with supplemental and active forms of vitamin $d$ : A meta-analysis of randomised controlled trials. BMJ 2009;339:b3692. 
53. Lehouck A, Mathieu C, Carremans C, Baeke F, Verhaegen J, Van Eldere J, Decallonne B, Bouillon R, Decramer $M$, Janssens $W$. High doses of vitamin d to reduce exacerbations in chronic obstructive pulmonary disease: A randomized trial. Ann Intern Med 2012;156:105-114.

54. Hornikx M, Van Remoortel H, Lehouck A, Mathieu C, Maes K, Gayan-Ramirez G, Decramer M, Troosters $\mathrm{T}$, Janssens $\mathrm{W}$. Vitamin d supplementation during rehabilitation in copd: A secondary analysis of a randomized trial. Respir Res 2012;13:84.

55. Durup D, Jorgensen HL, Christensen J, Tjonneland A, Olsen A, Halkjaer J, Lind B, Heegaard AM, Schwarz P. A reverse j-shaped association between serum 25-hydroxyvitamin $d$ and cardiovascular disease mortality: The copd study. J Clin Endocrinol Metab 2015;100:2339-2346.

56. Durup D, Jorgensen HL, Christensen J, Schwarz P, Heegaard AM, Lind B. A reverse j-shaped association of all-cause mortality with serum 25-hydroxyvitamin d in general practice: The copd study. J Clin Endocrinol Metab 2012;97:2644-2652.

57. Ross AC, Manson JE, Abrams SA, Aloia JF, Brannon PM, Clinton SK, Durazo-Arvizu RA, Gallagher JC, Gallo RL, Jones G, Kovacs CS, Mayne ST, Rosen CJ, Shapses SA. The 2011 report on dietary reference intakes for calcium and vitamin $d$ from the institute of medicine: What clinicians need to know. J Clin Endocrinol Metab 2011;96:53-58.

58. Heulens N, Korf H, De Smidt E, Cielen N, Maes K, Gysemans C, Verbeken E, Gayan-Ramirez G, Mathieu C, Janssens W. High vitamin d levels contribute to the development of copd-like characteristics in a mouse model of cigarette smoke exposure. Doctoral dissertation: KU Leuven; 2016.

59. Casey DP, Madery BD, Curry TB, Eisenach JH, Wilkins BW, Joyner MJ. Nitric oxide contributes to the augmented vasodilatation during hypoxic exercise. J Physiol 2010;588:373-385.

60. Vanhatalo A, Fulford J, Bailey SJ, Blackwell JR, Winyard PG, Jones AM. Dietary nitrate reduces muscle metabolic perturbation and improves exercise tolerance in hypoxia. J Physiol 2011;589:5517-5528.

61. Kelly J, Fulford J, Vanhatalo A, Blackwell JR, French O, Bailey SJ, Gilchrist M, Winyard PG, Jones AM. Effects of short-term dietary nitrate supplementation on blood pressure, 02 uptake kinetics, and muscle and cognitive function in older adults. Am J Physiol Regul Integr Comp Physiol 2013;304:R73-83.

62. Berry MJ, Justus NW, Hauser JI, Case AH, Helms CC, Basu S, Rogers Z, Lewis MT, Miller GD. Dietary nitrate supplementation improves exercise performance and decreases blood pressure in copd patients. Nitric Oxide 2015;48:22-30.

63. Kerley CP, Cahill K, Bolger K, McGowan A, Burke C, Faul J, Cormican L. Dietary nitrate supplementation in copd: An acute, double-blind, randomized, placebo-controlled, crossover trial. Nitric Oxide 2015;44:105111.

64. Leong P, Basham JE, Yong T, Chazan A, Finlay P, Barnes S, Bardin PG, Campbell D. A double blind randomized placebo control crossover trial on the effect of dietary nitrate supplementation on exercise tolerance in stable moderate chronic obstructive pulmonary disease. BMC Pulm Med 2015;15:52.

65. Shepherd Al, Wilkerson DP, Dobson L, Kelly J, Winyard PG, Jones AM, Benjamin N, Shore AC, Gilchrist M. The effect of dietary nitrate supplementation on the oxygen cost of cycling, walking performance and resting blood pressure in individuals with chronic obstructive pulmonary disease: A double blind placebo controlled, randomised control trial. Nitric Oxide 2015;48:31-37.

66. Baarends EM, Schols AM, Akkermans MA, Wouters EF. Decreased mechanical efficiency in clinically stable patients with copd. Thorax 1997;52:981-986.

67. van de Bool C, Gosker HR, van den Borst B, Op den Kamp CM, Slot IG, Schols AM. Muscle quality is more impaired in sarcopenic patients with chronic obstructive pulmonary disease. J Am Med Dir Assoc 2016;17:415-420.

68. Lam YY, Peterson CM, Ravussin E. Resveratrol vs. Calorie restriction: Data from rodents to humans. Exp Gerontol 2013;48:1018-1024.

69. Ventura-Clapier R. Potentiating exercise training with resveratrol. J Physiol 2012;590:3215-3216.

70. Timmers S, Konings E, Bilet L, Houtkooper RH, van de Weijer T, Goossens GH, Hoeks J, van der Krieken S, Ryu D, Kersten S, Moonen-Kornips E, Hesselink MK, Kunz I, Schrauwen-Hinderling VB, Blaak EE, Auwerx J, Schrauwen P. Calorie restriction-like effects of 30 days of resveratrol supplementation on energy metabolism and metabolic profile in obese humans. Cell Metab 2011;14:612-622. 
71. Ries AL, Kaplan RM, Limberg TM, Prewitt LM. Effects of pulmonary rehabilitation on physiologic and psychosocial outcomes in patients with chronic obstructive pulmonary disease. Ann Intern Med 1995;122:823-832.

72. Kalmijn S, van Boxtel MP, Ocke M, Verschuren WM, Kromhout D, Launer LJ. Dietary intake of fatty acids and fish in relation to cognitive performance at middle age. Neurology 2004;62:275-280.

73. Rifkind JM, Nagababu E, Barbiro-Michaely E, Ramasamy S, Pluta RM, Mayevsky A. Nitrite infusion increases cerebral blood flow and decreases mean arterial blood pressure in rats: A role for red cell no. Nitric Oxide 2007;16:448-456.

74. Presley TD, Morgan AR, Bechtold E, Clodfelter W, Dove RW, Jennings JM, Kraft RA, King SB, Laurienti PJ, Rejeski WJ, Burdette JH, Kim-Shapiro DB, Miller GD. Acute effect of a high nitrate diet on brain perfusion in older adults. Nitric Oxide 2011;24:34-42.

75. Weekes CE, Emery PW, Elia M. Dietary counselling and food fortification in stable copd: A randomised trial. Thorax 2009;64:326-331. 

Samenvatting 
COPD is een veelvoorkomende chronische ziekte die vaak niet alleen de longen aantast maar het hele lichaam. Dit komt niet alleen door ziekte-gerelateerde factoren zoals hypoxie (weefsels in het lichaam worden niet voorzien van voldoende zuurstof), systemische inflammatie (ontsteking in het hele lichaam), oxidatieve stress (schadelijke chemische reacties in het lichaam) en bepaald medicijngebruik, maar ook leefstijlfactoren zoals roken, lage lichamelijke activiteit en ontoereikende voeding. Verlies van massa en functie van de skeletspieren is een veel voorkomende manifestatie die, deels onafhankelijk van de ernst van de longfunctiestoornis, bijdraagt aan een verminderde inspanningstolerantie door symptomen zoals kortademigheid en vermoeidheid en daarmee een vicieuze cirkel van afnemende lichamelijke activiteit. De hoeveelheid spiermassa bepaalt in belangrijke mate de spierfunctie van een patiënt. Deze spiermassa kan niet afgeleid worden uit het lichaamsgewicht omdat het lichaamsgewicht niets zegt over de verhoudingen tussen de verschillende soorten weefsels in het lichaam. Zo kan iemand met een normaal gewicht bijvoorbeeld een "verborgen" lage hoeveelheid spiermassa hebben vanwege een hoge hoeveelheid vetmassa. Daarom is meting van de lichaamssamenstelling belangrijk, waarbij niet alleen onderscheid gemaakt wordt in de hoeveelheid van de verschillende weefsels (spieren, vet, bot) maar ook de verdeling van spiermassa en vetmassa in het menselijk lichaam.

De spiermassa kan gemeten worden met een DEXA scan, die gebruik maakt van röntgenstralen. Maar wanneer is sprake van een te lage spiermassa?

Traditioneel ging men uit van de spiermassa in het totale lichaam, maar er zijn aanwijzingen dat meting van de spiermassa in de armen en de benen een betere indruk geeft van de inspanningscapaciteit van een patiënt. Daarnaast kan een lage spiermassa in de huidige samenleving vaak samengaan met een te hoge vetmassa en een veranderde vetverdeling die leidt tot ophoping van vetmassa in de buikregio (abdominale obesitas).

In Hoofdstuk 2 bestudeerden we hoe vaak deze lichaamssamenstellingsprofielen voorkwam in een groep Nederlandse COPD-patiënten die in aanmerking kwamen voor een longrevalidatieprogramma. Er werd aangetoond dat zowel een lage skeletspiermassa (spiermassa in de armen en benen) vaak voorkwam in patiënten van alle gewichtscategorieën (onder-, normaal, overgewicht en obesitas) en dat dit resulteerde in een lagere spierkracht en bij mannen ook in een lager uithoudingsvermogen. De patiënten die naast een lage skeletspiermassa gelijktijdig te veel vetmassa in de buikregio hadden, leken lichamelijk beter te functioneren. Tevens bleek de skeletspiermassa een betere voorspeller voor lichamelijk functioneren ten opzichte van de spiermassa in het totale lichaam.

Naast een lage spiermassa treden er ook veranderingen op in de skeletspieren van COPD patiënten. De spier bestaat uit spiervezels die kunnen verschillen in snelheid van de spiersamentrekking en het ontwikkelen van de hoeveelheid kracht. Kenmerkend in COPD patiënten is dat er een verschuiving heeft plaatsgevonden in de typen spiervezels. 
De langzame type I vezels, die geschikt zijn voor inspanning op lage intensiteit maar lange duur (oxidatieve vezels), zijn verschoven naar snelle type II vezels, die veel kracht kunnen leveren, maar snel weer uitgeput zijn (glycolytische vezels). Deze verschuiving draagt, naast de longfunctiebeperking bij aan een verlaagd uithoudingsvermogen. Daarnaast zijn de type II vezels gevoeliger voor verschrompeling door ziektegerelateerde prikkels zoals hypoxie en longontsteking.

Het lagere uithoudingsvermogen in mannelijke COPD patiënten met een lage skeletspiermassa (aangetoond in Hoofdstuk 2) impliceert dat hierbij mogelijk afwijkingen in spiervezel type samenstelling betrokken zijn. Daarom hebben we in Hoofdstuk 3 verschillen in spiervezels onderzocht tussen COPD patiënten met en zonder een te lage skeletspiermassa, en gezonde controle personen. COPD patiënten hadden in verhouding minder type I vezels en kleinere type IIx vezels dan de gezonde controle personen. Daarnaast had de groep COPD patiënten met een lage skeletspiermassa een verdere afname in zowel het percentage als de grootte van de type I vezels. Deze bevinding toont dat COPD patiënten met een lage spiermassa extra kwetsbaar zijn; verder onderzoek moet aantonen of er een oorzaak-gevolg relatie is tussen afname van spierkwaliteit en verlies van spiermassa.

Naast roken en te weinig lichamelijke activiteit kan ook het dagelijkse voedingspatroon invloed hebben op de afwijkingen in de lichaamssamenstelling en spiervezels bij patiënten met COPD. Zo kan een te lage eiwitinname een remmende werking hebben op het behoud van spiermassa of kan overmatige vetinname bij een verminderde zuurstofopnamecapaciteit van de spieren bijdragen aan behoud en ophoping van vet in de buikregio. Aangezien dit nog niet uitvoerig is onderzocht hebben we in Hoofdstuk 4 de inname van de belangrijkste voedingsstoffen vergeleken tussen COPD patiënten met verschillende lichaamssamenstellingen. De voedingsinname van de totale onderzochte groep patiënten weerspiegelde een Westers dieet, dat wil zeggen een voedingsinname rijk in verzadigde vetten en laag in vers fruit, groenten en vezels. De inname van vitamines, en vooral vitamine D, was lager dan de aanbevolen hoeveelheid door de Gezondheidsraad bij het merendeel van de patiënten. Verder hadden de patiënten met een lage spiermassa vaak een verhoudingsgewijs lage inname van eiwitten. Patiënten met ophoping van buikvet hadden een lage inname van eiwitten en van veel vitamines. Patiënten die zowel een lage spiermassa als ophoping van buikvet hadden, bleken het vaakst een niet optimale voedingsinname te hebben.

Hoe kan door aanpak van de verminderde spierfunctie de vicieuze cirkel van een verminderde inspanningstolerantie en fysieke activiteit doorbroken worden?

COPD patiënten kunnen door hun arts doorverwezen worden voor een longrevalidatieprogramma, om te leren beter met hun ziekte om te gaan en de conditie te verbeteren. Een longrevalidatieprogramma bestaat uit verschillende, goed op elkaar afgestemde onderdelen, waaronder voorlichting over de aandoening, instructie over goede medi- 
cijninname, voedingsadvies en inspanningstraining. Uit onderzoek is gebleken dat inspanningstraining de spierkracht en het inspanningsvermogen kan verbeteren bij de meeste COPD patiënten. Maar intensieve lichamelijke training verhoogt ook het energiegebruik. Als deze toegenomen energiebehoefte niet gecompenseerd kan worden door de dagelijkse voeding, kan dit bij kwetsbare patiënten leiden tot ongewenst gewichtsverlies.

Uit onderzoek is gebleken dat voedingssupplementen (aanvullingen op de normale voeding) effectief zijn bij COPD patiënten met gewichtsverlies of een verhoogd risico erop. De huidige literatuur suggereert echter dat niet alleen de patiënten met acuut spiermassaverlies en vergevorderd COPD baat hebben bij voedingssupplementen, maar dat ook minder ernstige patiënten hier baat bij zouden kunnen hebben. Momenteel is nog niet goed onderzocht of voedingssupplementen de effecten van inspanningstraining verder kunnen verbeteren, analoog aan het gebruik van voedingssupplementen in de topsport. Voor een optimale opzet van de klinische studie waarin we deze vraag wilden onderzoeken, hebben we in Hoofdstuk 5 een literatuuronderzoek uitgevoerd. In hoofdstuk 6 wordt de NUTRAIN-trial beschreven, waarin de effectiviteit van een specifiek voedingssupplement werd onderzocht tijdens de poliklinische revalidatie van COPD patiënten met een mild tot matige luchtwegobstructie maar een lage spiermassa. Alle patiënten ondergingen een intensief trainingsprogramma bestaande uit 40 sessies in 7 ziekenhuizen. De helft van de deelnemers nam dagelijks 2-3 porties van de drinkbare test-voeding in en de andere helft 2-3 porties van een vergelijkbare verpakking met een lage voedingswaarde (placebo). De testvoeding bevatte naast calorieën en eiwitten voor behoud of versnelde opbouw van spieren ook een specifieke vetzuursamenstelling, waarvan in eerder onderzoek was aangetoond dat deze in staat is om het inspanningsvermogen te verbeteren via gunstige beïnvloeding van de stofwisseling in de spieren. Het voedingssupplement was tevens rijk aan vitamine D, om de vaak voorkomende vitamine $D$ deficiëntie in COPD tegen te gaan welke geassocieerd is met spierzwakte en botontkalking. De resultaten van het onderzoek toonden dat inspanningstraining zeer effectief was in het verbeteren van spierkracht in de benen en het inspanningsvermogen bij goed trainbare COPD patiënten met lage spiermassa. Het voedingssupplement had daarnaast nog gunstige effecten op de voedingsstatus, de spierkracht van de ademhalingspieren en de dagelijkse lichamelijke activiteit, vergeleken met het placeboproduct.

Toekomstig onderzoek zal uitwijzen of deze niet eerder aangetoonde voedingseffecten verklaard worden door verbetering van de kwaliteit van de spieren en/of door effecten op andere orgaansystemen waaronder bijvoorbeeld het hart-vaatstelsel, het immuunsysteem of het brein. Tevens zal er meer accent komen te liggen op de invloed van optimale voedingsinname voor behoud van de korte termijnseffecten van longrevalidatie en een verdere personalisering van de voedingsadviezen op geleide van de verschillende in dit proefschrift beschreven lichaamssamenstellingsprofielen. 


\section{Valorisation}


Valorisation is "the process of creating value from knowledge, by making this knowledge available and suitable for economic and social exploitation and to translate this knowledge into products, services, processes and new business."

This chapter will discuss the current findings in the light of the impact as well as innovative concepts for future health care.

\section{RELEVANCE}

COPD is a highly prevalent chronic disease, which is projected to further increase in the coming decades. Worldwide COPD is a leading cause of morbidity and mortality, resulting in a substantial and increasing economic and social burden. While COPD is characterized by airflow limitation, the degree of airflow limitation poorly correlates with actual disease burden. In fact, the COPD patient's health status is largely determined by extrapulmonary manifestations and comorbidities including skeletal muscle dysfunction, osteoporosis, cardiovascular disease, metabolic syndrome, and psychological disorders. These comorbidities contribute to common symptoms (breathlessness, fatigue), but also to reduced physical activity, disease exacerbations, hospital admissions and mortality.

This thesis highlights the importance of skeletal muscle dysfunction and in particular, low muscle mass as screening and therapeutic target for COPD:

Sarcopenia is defined as low appendicular muscle mass together with low muscle function (strength or performance) by the European Working Group on Sarcopenia. RecentIy, sarcopenia has been recognized as a disease entity with an ICD-10-CM (M62.84) code. Our findings indicate that assessment of 3-compartimental body composition (appendicular muscle mass, abdominal obesity and bone mineral content) might be favourable over 2-compartimental distinction between fat and fat-free mass, indicated by 1) the high persisting prevalence's of sarcopenia and abdominal obesity in all BMI categories; 2) it's discrimination for impaired muscle strength and endurance; 3) the higher predictive value of the 3-compartment prediction model compared to the 1 (BMI) or 2-compartment models. Dual Energy X-ray absorptiometry (DEXA) scans were originally designed for measurement of bone mineral density. This assessment is very relevant In COPD because of the high prevalence of osteoporosis in these patients (Chapter 2). Nowadays most hospitals are also able to use a DEXA scan for measurement of body composition according to the 3-compartmentmodel.

Next to low muscle mass, COPD patients often show structural alterations in muscle fiber type composition. Previous studies have already demonstrated a muscle fiber type [? II shift, and selective atrophy of the type IIx fibers in patients with COPD resulting in a loss of muscle oxidative phenotype. In an outpatient COPD population we revealed an even more pronounced decrease in type I muscle fibers in patients with sarcopenia, 
compared with non-sarcopenic patients and healthy controls. Moreover, sarcopenic patients were characterized by selective atrophy of the type I fibers, independent of the more generalized type II atrophy in COPD as a whole. These findings could reflect a cross-talk between muscle mass and oxidative phenotype regulation, which might accelerate the muscle wasting process in COPD. Future research in this presumed crosstalk may provide new leads for targeted intervention. This study also indicates that sarcopenic patients with COPD seem extra vulnerable as not only their muscle mass but also muscle metabolism is affected.

The cause of abnormalities in body composition and structural changes within muscle in COPD not only involve disease specific factors (e.g. hypoxia, systemic inflammation, oxidative stress and use of corticosteroids) but also lifestyle factors. Lifestyle factors mainly concern smoking and physical activity, but also dietary behaviour. A poor dietary quality may accelerate disturbances in body composition in COPD, but only limited studies have investigated dietary intake from this perspective. We demonstrated differences in the quality of dietary intake between COPD patients with different body composition profiles. Patients with a low muscle mass had a low dietary quality reflected by low intake of micronutrients, especially vitamin D, and a lower intake of protein. Patients with both low muscle mass and abdominal obesity appeared most susceptible for a poor dietary quality. Therefore more attention and guidance is required for COPD patients in order to respect recommendations regarding healthy nutrition. This is presently undervalued relative to modifying sedentary behaviour and smoking cessation.

Exercise training is known to be effective in improving muscle function as well as exercise tolerance in patients with advanced COPD and is considered to be the cornerstone of pulmonary rehabilitation. The COPD guidelines recommend nutritional supplementation to prevent weight loss and promote weight gain in undernourished patients with COPD. However, the potential of nutritional strategies to enhance the efficacy of exercise training in COPD is not yet well established. The randomised placebo-controlled NUTRAIN-trial that we performed, investigated the additional effects of nutritional supplementation on top of exercise training in patients with low muscle mass, as integral part of an out-patient pulmonary rehabilitation program. The nutritional intervention was therefore easily implementable.

The results confirmed a good response to exercise training in COPD patients characterized by moderate airflow imitation and low muscle mass. New insights provided by this thesis include that, while targeted nutritional supplementation did not enhance muscle regain and improvements in lower limb muscle performance in these patients, beneficial effects were observed on nutritional status and inspiratory muscle strength. An unexpected finding was the decline in daily physical activity after exercise training in the control group, which was prevented by nutritional supplementation. These results of the NUTRAIN-trial provide new leads for optimisation of medical nutrition. Furthermore 
the trial highlights the necessity in nutritional therapy to distinguish between supplementation of calories and protein and supplementation of specific nutrients. Moreover, the observed dissociation between physical performance and daily physical activity provides new leads for improvement of daily physical activity.

\section{HEALTH CARE PROVIDERS}

The present thesis gives important insights for health care providers. In order to develop and evaluate effective treatment strategies, individual assessment is required. Body composition needs to be assessed to distinguish not only muscle mass, but also to take body compositional shifts into account. These shifts include both the mass and distribution of muscle, fat and bone mineral density, which are able to serve as a stronger predictor of physical impairment. DEXA is the most appropriate tool for measurement of body composition, as it simultaneously allows for screening of highly prevalent osteoporosis in COPD. Assessment of dietary intake by dieticians is required not only to estimate total intake of calories, but also to identify possible nutrient deficiencies by comparing these with daily recommended intakes by the national Health Council. Daily intake of macro- and micronutrients is often below recommendations in COPD patients. An inadequate dietary intake might accelerate body compositional shifts, as reflected by differences in quality of dietary intake between patients with different body composition profiles.

This thesis therefore underlines the need to further tailor and accentuate nutritional guidelines for specific metabolic phenotypes. Moreover, nutritional and pharmaceutical industries are challenged to develop and optimize medical nutrition and supplements for patients with COPD distinguishing in providing high energy and/or protein or specific nutrients (e.g. vitamin D, poly-unsaturated fatty acids, resveratrol, and nitrate).

\section{SCIENCE: FUTURE RESEARCH QUESTIONS}

The findings in the current thesis might be important for researchers in the field. Meanwhile several new questions were revealed, which are presented in the discussion chapter. Nonetheless the presented findings create new opportunities. Future studies are needed to investigate the efficacy of tailored nutritional interventions for carefully selected COPD patient subgroups defined according to distinct clinical phenotypes. Furthermore, the challenge for future studies is to disentangle the mechanism behind the observed dissociation between physical performance and daily physical activity resulting from nutritional supplementation. Identification and measurement of outcome measures beyond muscle are required to unravel a broader potential of nutritional modulation in COPD. 
Dankwoord 
Eindelijk is het dan zover, mijn proefschrift is af. Via deze weg wil ik iedereen bedanken die heeft bijgedragen aan de totstandkoming van dit proefschrift.

Graag wil ik beginnen met het bedanken van alle patiënten en controle personen die hebben deelgenomen aan de onderzoeken die staan beschreven in dit proefschrift. Zonder hen was het allemaal niet gelukt. Ik heb vooral veel bewondering voor de patienten die tijdens een veeleisend revalidatieprogramma gemotiveerd waren om mee te werken aan de NUTRAIN-trial, een interventieonderzoek waarvoor zij 4 maanden dagelijks voedingssupplementen moesten innemen en veel extra metingen moesten ondergaan. De gesprekken gedurende het onderzoek gingen vaak samen met een lach, maar ook soms met een traan. Hopelijk heb ik voor jullie een bijdrage kunnen leveren.

Mijn promotor prof. Annemie Schols, ik heb enorm veel bewondering voor je grote kennis, ervaring, gedrevenheid en (vaak noodzakelijke) kritische blik. Als ik tijdens het schrijven van manuscripten even niet verder kwam, keek ik uit naar je feedback. Deze zorgde voor een nieuwe kijk op de gevonden resultaten, waardoor ik weer enthousiast aan de slag kon gaan. Dank voor je begeleiding (en soms het delen van frustraties) in de afgelopen jaren. Ook ben ik je zeer dankbaar voor de kans om de ervaring die ik tijdens mijn promotieonderzoek heb opgedaan in mijn huidige baan als postdoc toe te mogen passen en verder te ontwikkelen in een groot Europees onderzoek.

Mijn tweede promotor Prof. Emiel Wouters, graag wil ik u bedanken voor de mogelijkheid om binnen de vakgroep Longziekten te promoveren. Ook wil ik u en Ingrid Augustin bedanken voor de mogelijkheid om mijn promotieonderzoek uit voeren in samenwerking met CIRO Expertisecentrum voor Chronisch Orgaanfalen in Horn. Het was heel prettig samenwerken met de CIRO-medewerkers. Ik waardeer het ook enorm dat ik altijd heb mogen deelnemen aan de teambuildingactiviteiten en personeelsfeestjes.

Erica, toen ik net begon met mijn promotieonderzoek was je met zwangerschapsverlof, en tijdens de afronding ervan was je zelf begonnen met een nieuwe uitdaging. Bij sommige onderdelen van mijn promotieonderzoek was je daarom wat minder betrokken. Desalniettemin hebben we fijn samengewerkt aan een aantal analyses. Hiervoor wil ik je bedanken!

Frits, als arts betrokken bij het de NUTRAIN-trial en coauteur bij het merendeel van mijn publicaties. Ik wil je bedanken voor je betrokkenheid bij mijn promotieonderzoek, waarbij je altijd veel oog had voor de klinische impact van de gevonden resultaten.

Martijn, je was niet direct betrokken bij mijn project, maar je stond toch altijd open voor het geven van (wetenschappelijk) advies en ik hoorde volgens jou gewoon bij de groep. Dank hiervoor! Ik wens je veel succes als toekomstig professor!

Annie en Riny, dank voor het verzorgen van de leefstijlcounselling tijdens de onderhoudsfase van de NUTRAIN-trial. Jullie zijn schatten. Ik wens jullie veel geluk. 
Sarah, ik ben heel dankbaar dat we elkaar hebben leren kennen tijdens onze spannende promotietijd. Wat hebben we samen veel gelachen, soms een beetje gehuild, en kleine en grote geheimpjes met elkaar kunnen delen! Inmiddels zijn we allebei drukke, maar o zo trotse mama's. Laten we elkaar nooit uit het oog verliezen.

Ook wil ik de rest van mijn lieve CIRO collega-onderzoekers: Carmen, Nienke, Jeannet, Dionne, Dionne, Anouk, Fiona, Wai-Yan en Rafael, bedanken voor de geweldige tijd die we met $z$ 'n allen hebben gehad. ledereen was er voor elkaar en ook buiten werktijd konden wij ons prima vermaken, vooral onder het genot van een hapje en drankje! Ik wens jullie allemaal veel succes met jullie carrières en hoop dat we contact blijven houden!

Ook wil ik graag nog andere CIRO-medewerkers bedanken: Gerrie voor het herhaaldelijk aanreiken van de sleutel van de kelder waarin de voedingssupplementen opgeslagen stonden; Frits, Lowie, Daisy en Eefje voor de inclusieadviezen; Paula, Christel, Inge en Marjanka voor de voedingsanamneses; Marco, Jeannet, Jos, Koen, Tim, Martijn, Trineke, Kitty en Marian voor uitvoering van metingen; Annelies, Mariëtte, Peggy, Gonny, Petra en Els voor de bloedverwerkingen. Maurice, dank voor je klinische adviezen. Miriam, dank voor de wetenschappelijke adviezen. Irma, dank voor het mogen oefenen met het inbrengen van een infuus en Daisy, het is nooit nodig geweest, maar ik wil je toch bedanken voor je bereidheid om me hierbij te ondersteunen. Bedankt iedereen die me ooit heeft geholpen bij het verplaatsen van de vele en zware dozen met voedingssupplementen! Alle overige CIRO medewerkers wil ik bedanken voor de leuke sociale contacten, maar vooral de medewerking en begrip voor wetenschappelijk onderzoek.

Bedankt alle collega's van de afdeling Pulmonologie: Harry, Ramon, Chiel, Marco, Rosanne, Stephanie, Martijn, Karin, Anita, Sarah, Pieter, Judith, Wessel, Jules, Casper, Cheryl, Mieke, Juanita en Niki. Ook de voormalige, inmiddels gepromoveerde collega's die mij tijdens de uitvoering van mijn klinisch onderzoek op CIRO niet zo veel hebben gezien, maar altijd vriendelijk en behulpzaam waren. Valéry, zonder jou was het mij niet gelukt om de NUTRAIN-trial op te starten. Jij hebt me wegwijs gemaakt in het opzetten van een klinische trial en alles wat daar bij komt kijken.

Een bijzonder plekje verdienen mijn dierbare collega's van het SPRINTT-team, met wie ik met veel plezier samenwerk. Nick, Clarie en Jos, dank voor jullie steun tijdens de afgelopen hectische periode!

Het invoeren van de verzamelde data was een hele klus. Thecla, ik wil je bedanken voor al je hulp hierbij. Nu wens ik jou heel veel succes met jouw eigen promotieonderzoek!

Ook wil ik de stagiaires bedanken die hun steentje hebben bijgedragen: Kelly, Sharon, Bo en Cengiz.

Mijn dank gaat uit naar het Longfonds voor de toekenning van de subsidie die het mogelijk maakte om dit promotieonderzoek uit te kunnen voeren. 
Nutricia Research wil ik bedanken voor de samenwerking en het produceren en leveren van de voedingssupplementen voor de NUTRAIN-trial. In het bijzonder wil ik bedanken: Ardy van Helvoort, Paul Vos, Barbara Mourmans, Mirjam Slagter en Elleny Balder, met wie ik contact heb gehad tijdens de uitvoering van de trial of daarna.

Beste coauteurs, bedankt voor de inhoudelijke feedback voorafgaand op indiening van de artikelen opgenomen in dit proefschrift.

Hartelijk dank aan de leden van de beoordelingscommissie van dit proefschrift, bestaande uit Prof. Ronald Mensink, Prof. Yvonne Heijdra, Prof. Lisette de Groot, Prof. Aalst Bast en Prof. Jeroen Kooman, voor hun beoordeling en goedkeuring van dit proefschrift.

Marie-José, dank voor het ontwerpen van de mooie cover van mijn proefschrift!

Annet en Jenet, wat bijzonder dat jullie straks naast mij staan als mijn paranimfen. Mijn lieve zusje Annet. Vroeger maakten we in stressvolle periodes, zoals tijdens proefwerkweken, vooral lolletjes samen om even de spanning te vergeten. Nu kunnen we nog altijd goed voor wat afleiding zorgen wanneer de ander dit nodig heeft, maar kunnen we ook hele serieuze gesprekken hebben. Lieve Jenet, jij bent mijn beste vriendin al zo lang als ik me kan herinneren. Allebei hebben we een drukke, veeleisende baan, maar wat hebben we het altijd gezellig als we, ook samen met onze mannen en kids, afspreken. Dat doen we eigenlijk veel te weinig.

Ook de rest van mijn vriendengroep: Stijn, Michelle, Helga, Jacques, Laura, Mark, Imke, Remco, Ruud, Petra, Nikki, Renske, Kevin, Britt, Mathijs, Michelle, Ruud, Steffie, Joost, Crissy, Ben, Ivana, Stefan, Lana, Pim, Sandy, Patrick, Maikel, Roel, Wouter, Maarten en Suzanne, bedankt voor alle steun en gezelligheid!

Ook een extra blijk van waardering voor de klussers, in het bijzonder Jo, Tjeu, pap, Loy en Jorg. Al maandenlang gaat al jullie vrije tijd naar de verbouwing van ons eigen droomhuis, waar we straks met z'n viertjes gaan genieten!

Bedankt Loy, Mieke, Gwenn en Jasper voor jullie steun en interesse. Jo en Marian, bedankt dat jullie altijd voor ons klaarstaan en natuurlijk ook voor het vaak mogen aanschuiven bij het avondeten wanneer wij het zelf even te druk hebben.

Lieve pap en mam, dank voor het vormen van de basis die dit alles mogelijk maakte. Jullie hebben me altijd vrij gelaten om mijn eigen keuzes te maken en te worden wie ik vandaag ben. Dank voor jullie onvoorwaardelijke steun en hulp.

Lieve Jorg, het was een hele tocht, maar je ziet het: mijn promotieonderzoek is nu echt klaar. We hebben tijdens deze periode samen heel wat te verwerken gehad, maar we zijn een goed team samen (en dat hebben we vaker naar elkaar uitgesproken). Weet dat ik enorm veel van je hou en ik hoop dat er nu een rustigere periode aanbreekt, na het 'druk zijn met promoveren'. Ik wil je bedanken voor het geven van moed wanneer ik dit nodig had, maar ook voor laten zien wat echt belangrijk is in het leven. Twee jaar geleden zijn we een gezin- 
netje geworden en in de zomer verwachten we ons tweede kindje én ons eigen droomhuis te betrekken. Ik ben ontzettend trots op jou aan mijn zij, trots op jou als geweldige papa en zelfs als ontpopte klusser! Lieve Ries, jij kunt me al mijn zorgen spontaan laten vergeten met je ondeugende oogjes en aanstekelijke lach. Lieve kleine meid in mijn buik, nu al een druktemakertje. Wat kijk ik uit naar je komst! 

Curriculum vitae 
Coby van de Bool werd geboren op 29 april 1987 in Neer. In 2006 behaalde ze haar Voorbereidend Wetenschappelijk Onderwijs diploma aan Scholengemeenschap Sint Ursula in Horn. Ze startte met haar studie Gezondheidswetenschappen aan de Universiteit Maastricht en specialiseerde zich in het vakgebied Bewegingswetenschappen. Tijdens haar Bacheloropleiding liep ze stage bij de vakgroep Bewegingswetenschappen, waar ze onderzoek deed naar het looppatroon bij COPD patiënten, die waren doorgestuurd voor een Longrevalidatie programma bij CIRO Expertisecentrum voor Chronisch Orgaanfalen in Horn. Ook haar stage tijdens de Master Biology of Human Performance vond plaats bij de vakgroep Bewegingswetenschappen. Deze was gericht op het testen van spieruithoudingsvermogen via elektrostimulatie van de spier bij COPD patiënten. In 2010 behaalde ze cum laude haar Master diploma. In hetzelfde jaar is Coby gestart met haar promotieonderzoek bij de afdeling Longziekten aan de Universiteit Maastricht, onder supervisie van Prof. Dr. Annemie Schols en Prof. Dr. Emiel Wouters. Dit promotieonderzoek was gericht op de effecten van specifieke voedingsuppletie bovenop inspanningstraining in COPD patiënten met een lage spiermassa en vond plaats in samenwerking met het Longfonds, Nutricia Research en CIRO Expertisecentrum voor Chronisch Orgaanfalen in Horn. Het hiervoor uitgevoerde werk staat beschreven in dit proefschrift. Ook werden deze bevindingen op verschillende nationale en internationale congressen gepresenteerd, wat in 2016 resulteerde in de European Respiratory Society (ERS) Grant for Best Abstracts in Pulmonary Rehabiliation \& Chronic Care. Sinds 2016 is Coby vanuit de Universiteit Maastricht als dagelijkse coördinator betrokken bij de Europese SPRINTT-trial. Dit onderzoek is gericht op het aanpakken van verlies van spiermassa in kwetsbare ouderen middels voeding en beweging. 


\section{List of publications}


van de Bool C, van Helvoort A, Rutten EP, Franssen FM, Wouters EF, Schols AM. A randomised clinical trial investigating the efficacy of targeted nutrition as adjunct to exercise training in COPD. Provisionally accepted in Journal of Cachexia, Sarcopenia and Muscle. 2017

Beijers RJ, van de Bool C, van den Borst B, Franssen FM, Wouters EF, Schols AM. Normal Weight but Low Muscle Mass and Abdominally Obese: Implications for the Cardiometabolic Risk Profile in Chronic Obstructive Pulmonary Disease. Journal of the American Medical Directors Association. 2017.

van de Bool C, Gosker HR, van den Borst B, Op den Kamp CM, Slot IGM, Schols AMWJ. Muscle Quality is More Impaired in Sarcopenic Patients With Chronic Obstructive Pulmonary Disease. Journal of the American Medical Directors Association. 2016.

van de Bool C, Rutten EP, Franssen FM, Wouters EF, Schols AM. Antagonistic implications of sarcopenia and abdominal obesity on physical performance in COPD. European journal of clinical nutrition. 2015 Aug;46(2):336-45.

Sanders KJC, Kneppers AEM, van de Bool C, Langen RCJ, Schols AMWJ. Cachexia in chronic obstructive pulmonary disease: new insights and therapeutic perspective. Journal of Cachexia, Sarcopenia and Muscle. 2015:n/a-n/a.

Stewart KF, Meis JJ, van de Bool C, Janssen DJ, Kremers SP, Schols AM. Maintenance of a Physically Active Lifestyle After Pulmonary Rehabilitation in Patients With COPD: A Qualitative Study Toward Motivational Factors. Journal of the American Medical Directors Association. 2014 Jun 16.

van de Bool C, Mattijssen-Verdonschot C, van Melick PP, Spruit MA, Franssen FM, Wouters EF, et al. Quality of dietary intake in relation to body composition in patients with chronic obstructive pulmonary disease eligible for pulmonary rehabilitation. European journal of clinical nutrition. 2013 Dec 11.

van de Bool C, Steiner MC, Schols AM. Nutritional targets to enhance exercise performance in chronic obstructive pulmonary disease. Current Opinion in Clinical Nutrition and Metabolic Care. 2012 Nov;15(6):553-60.

Annegarn J, Spruit MA, Savelberg HH, Willems PJ, van de Bool C, Schols AM, et al. Differences in Walking Pattern during 6-Min Walk Test between Patients with COPD and Healthy Subjects. PLoS One. 2012;7(5):e37329. 
